\title{
A Multidisciplinary Airplane Research Integrated Library With Applications To Partial Turboelectric Propulsion
}

\author{
T. Druot* \\ Ecole Nationale de l'Aviation Civile, Toulouse, France \\ Airbus Operations SAS, Toulouse, France \\ M. Belleville ${ }^{\dagger}$ \\ Airbus Operations SAS, Toulouse, France \\ P. Roches \\ Ecole Nationale de l'Aviation Civile, Toulouse, France \\ F. Gallard ${ }^{\S}$ \\ Institute of Technology IRT Saint Exupéry, Toulouse, France \\ N. Peteilh ${ }^{\mathbb{I}}$ \\ Ecole Nationale de l'Aviation Civile, Toulouse, France \\ A. Gazaix" \\ Institute of Technology IRT Saint Exupéry, Toulouse, France
}

\begin{abstract}
The aim of this paper is to present a new model library developped as a new test case to benchmark optimization algorithms and Multidisciplinary Design Optimization (MDO) formulations. It introduces the MARILib software (Multidisciplinary Airplane Research Integrated Library). MARILib's first objective is to provide models for research on a wide range of aircraft concepts, from business jets to super jumbos, and also some unconventional configurations, through an Overall Aircraft Design (OAD) approach. The second objective is to share a new benchmark test case for MDO strategies, which does not raise intellectual property issues. The third objective is to describe a case study for educational and training purposes. MARILib will be available as Open Source.
\end{abstract}

\section{Nomenclature}

Without special notice, all units are international standard units.

$(.)_{\text {fan }} \quad=$ quantity related to the fan

$(.)_{\text {Free Stream }}=$ quantity related to free stream

(.) hybrid $=$ quantity related to the hybrid architecture

(.) Inlet $\quad=$ quantity related to the inlet

$(.)_{j e t}=$ quantity related to the jet

$(.)_{0} \quad=$ quantity related to reference turbofan without hybridation

$\delta_{0} \quad=$ theoretical boundary layer thickness around a cylindrical fuselage of length $L$

$\delta_{1} \quad=$ assessed boundary layer thickness around the e-fan hub

$\delta \quad=$ boundary layer thickness

$\eta_{e F} \quad=$ "propeller like" e-fan efficiency

$\eta_{C} \quad=$ wire conductivity efficiency

*Associate Professor, Air Transport department, thierry.druot-ext@enac.fr

${ }^{\dagger}$ Expert Engineer, Future Project Office, mathieu.belleville@ airbus.com

† Associate Professor, Air Transport department, pascal.roches@enac.fr

${ }^{\S}$ Research Engineer, System Engineering and Modeling department, francois.gallard@irt-saintexupery.com

"IIssociate Professor, Air Transport department, nicolas.peteilh@enac.fr

"MDO team leader, Systems Engineering and Modeling Department, on leave from Airbus Operations SAS, Toulouse, France 


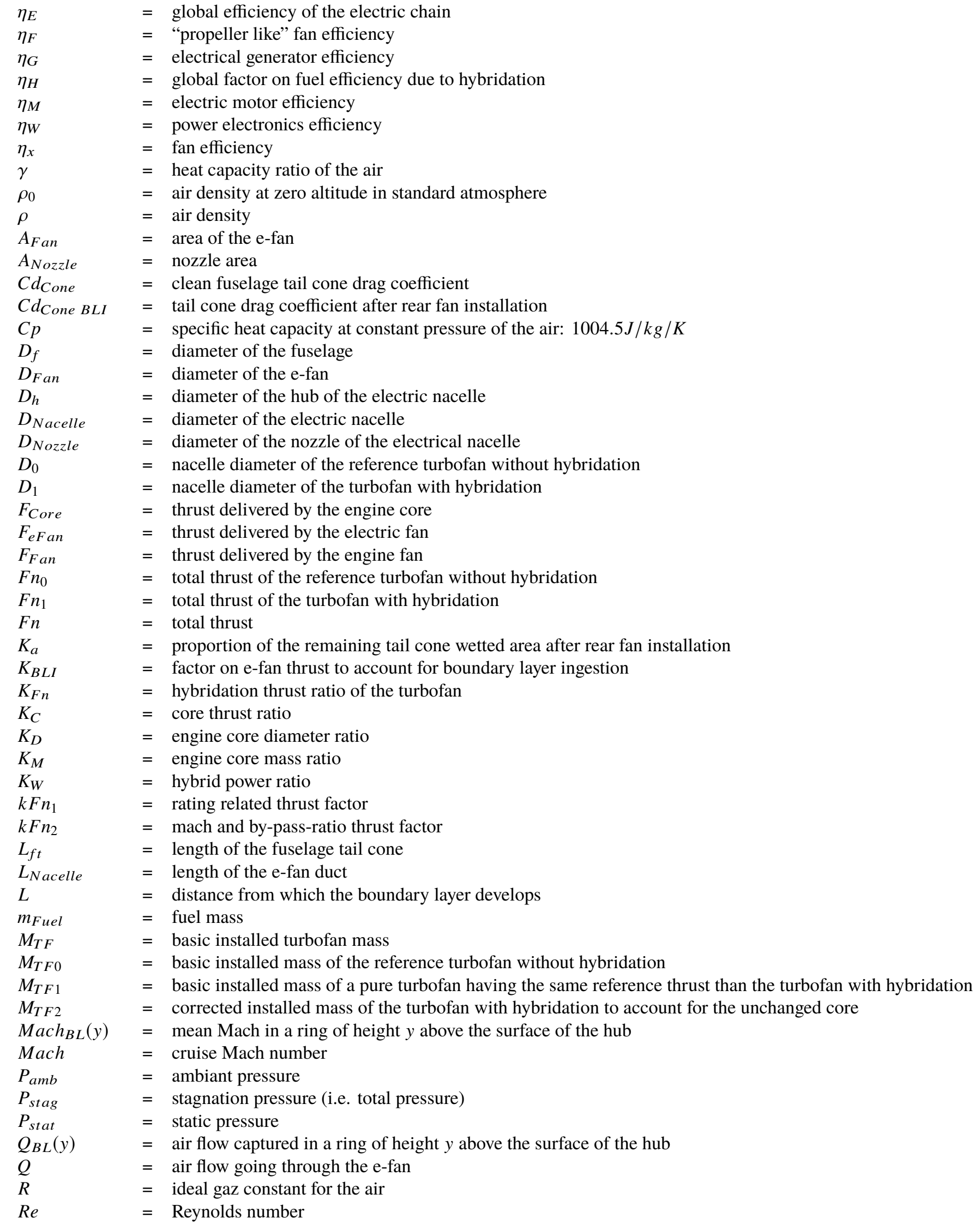




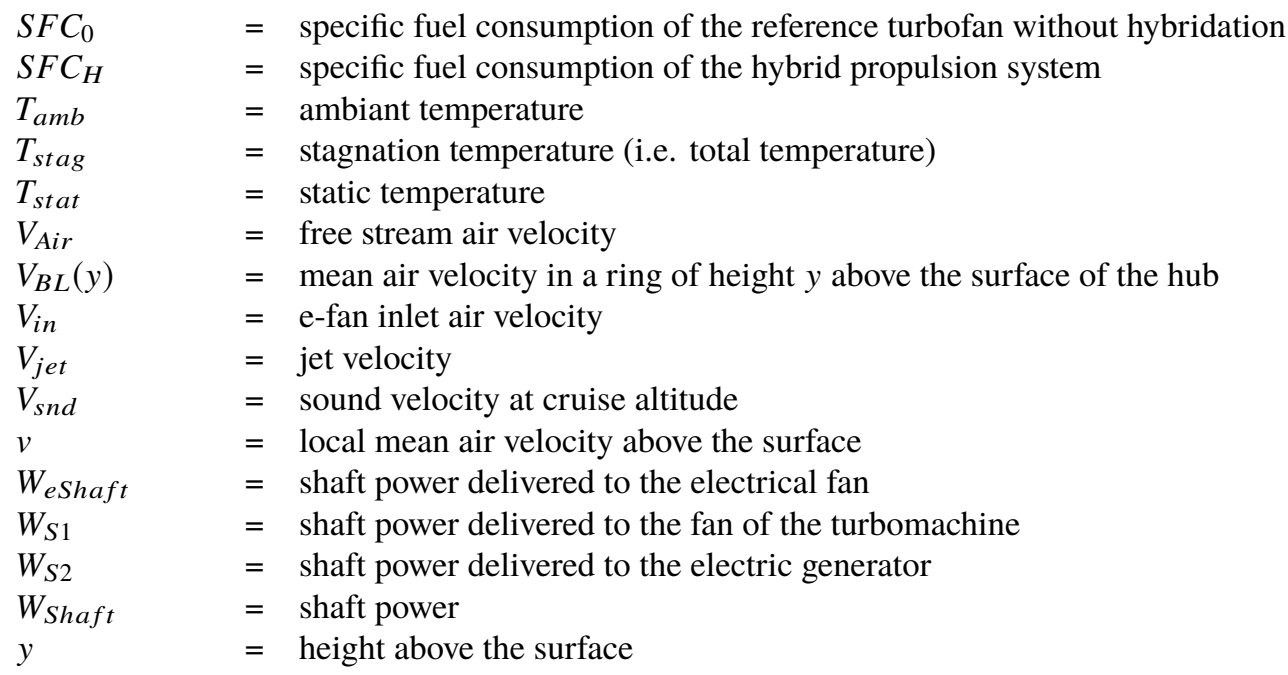

\section{Introduction}

Researchers developing optimization algorithms use benchmark analytic optimization problems such as the Rosenbrock function, or the CUTEr [1] and CUTEst [2] test suites to assess the relative performance of algorithms. These hundreds of benchmark problems are recognized by the research community, as these papers were cited more than 700 times.

MDO brings new challenges for benchmarking algorithms compared to standard optimization, because of the deeply structured nature of MDO problems. In MDO, a complex system is decomposed into multiple disciplines, each discipline depends on variables that may be shared with other disciplines, or that may be computed by one of them (so called the coupling variables). The MDO algorithms must take that structure into account to appropriately and efficiently solve the MDO problems. The resolution processes are then organized according to different strategies, and there exist multiple ways of creating optimization problems from such processes. The combination of the two defines the MDO architecture, or MDO formulations [3]. There currently exists a set of benchmark problems in MDO, among which the Sellar, Propane combustion, Sobjeski's SSBJ [4] problems. Those problems are used by the MDO community, but they are either unrelated to aircraft design, or, for the SSBJ test case, do not rely on physical equations, since the discipline's outputs are mostly based on arbitrary interpolation coefficients. This is an issue because the mathematical properties of the models (continuity, differentiability, monotony, multi-modality) have a large effect on the relative performance of the algorithms. On the other hand, there exists open source conceptual design libraries such as SUAVE [5], but the problem is not decomposed into disciplines directly interfaced with MDO frameworks, although it was partially interfaced for the mission time integration [6].

Therefore, we identified six main issues that must be addressed towards building an equivalent to CUTEst for the MDO community:

- Issue 1: The purpose of MDO algorithms (or MDO formulations) is to exploit the problem structure, so these problems must be structured

- Issue 2: The problem structure of benchmarks must be representative of real MDO problems, such as aircraft design

- Issue 3: the problem's equations must be based on physical equations with known assumptions, or reproducible statistical regressions on known data or models.

- Issue 4: the problems must be fast to execute, to enable benchmarks

- Issue 5: the problems' definition must be shared

- Issue 6: the benchmarks must be numerous to avoid over tuning of algorithms on a problem dependent feature

MARILib aims to contribute to address the five first issues, and partially the last one, by providing a set of MDO problems along with MARILib. 
MARILib contains models that not only address a single airplane concept, but a range of concepts from business jets to super jumbos, and also some unconventional configurations. Indeed, in many research studies initiated in cooperation between Industries and Research Laboratories, it appeared to be difficult to find as starting point a reference airplane description which would be globally consistent, which would correspond to a given set of Top Level Requirements, and which does not raise intellectual property issues. As of today, the development status of MARILib enables to:

1) Generate test cases for MDO experimentation: about 100 functions representing about one thousand lines of codes covering all disciplines: Geometry, Mass and Center of Gravity CG, Propulsion, Aerodynamics, Mission, Low speed and High speed performances, Handling Quality (tail sizing), Costs, Environment and basic design processes.

2) Build a consistent description of a twin turbofan engine airplane designed from only 3 requirements:

- Passenger capacity (from about 8 to 600 passengers)

- Nominal range (from about 2000NM to 8000NM)

- Cruise Mach number (from about 0.5 to 0.85 )

3) Integrate a simple modelling of hybrid propulsive architecture (Starc ABL like) and deliver consistent results when comparing hybrid to classical arrangement.

The paper is divided into four parts. A first section presents the overall characteristics of the physical description of the airplane in MARILib, the physical principles applied to implement the design capability and a kind of design process classically used in conceptual design. The second section presents how the model can take into account a hybrid architecture similar to the NASA Starc ABL. The third section presents some results that were obtained when applying a design process to this hybrid configuration. Finally, the fourth section presents how to integrate MARILib into the Generic Engine for MDO Scenarios (GEMS).

\section{Model characteristics}

\section{A. Library overview}

Presently, the model is only capable to model tube and wing airplanes with two or four turbofan engines. It is split into 12 components, including the aircraft itself, each of them described by specific variables, as shown on Table 1 .

As a result of this, 160 variables describe the whole aircraft, 120 additional variables, not mentioned in the above table, quantify most important operational performances of the aircraft, which brings to 280 the total number of variables of the whole model for a twin turbofan tube and wing. The list of variables and their signification is given in appendix.

MARILib has been initially programmed in Scilab and then have been migrated to Python. All formulas in the code takes and delivers values in international standard units $(\mathrm{m}, \mathrm{kg}, \mathrm{s}, \mathrm{J}, \mathrm{N}, \mathrm{W}, \ldots)$. No formula presented in this paper will be associated with specific units, standards units are assumed everywhere (ranges are in meter, specific fuel consumptions are in $\mathrm{kg} / \mathrm{N} / \mathrm{s}, \ldots$ ).

At this stage of the migration to Python language, initial Scilab functions have not yet been distributed into object methods, more experience on the library is required to define the best contour of the future objects.

The top level folder architecture is presented in Fig. 1 .

The organization of the present implementation of the airplane model is based on a split between attributes related to the aircraft taken as a whole (aircraft level) and attributes related to airplane components. Three main folders are packaging the aircraft model, the two first ones (aircraft_data and aircraft model) defines aircraft level attributes, the third one (airplane) defines component level attributes:

- aircraft_data: defines the Aircraft class which stores all the characteristics of a given airplane design along the progression of the design process. In addition, there are two Python files defining respectively:

- Physical performances at airplane level (Aerodynamics, Propulsion, Weights and CGs)

- Operational performances (Low speeds, High Speeds, Missions, Economics and Environment)

- aircraft model: defines functions that applies at aircraft level. These functions are split into the following two sub-folders:

- airplane contains four files with functions related to: aerodynamics, airplane design, regulation, and visualization. 
Table 1 Number of descriptive variables of the airplane model in MARILib

\begin{tabular}{|c|c|c|c|}
\hline Component & Geometry & Mass \& CG & Other \\
\hline Cabin & 7 & 4 & \\
\hline Payload & & 10 & \\
\hline Tank & 9 & 2 & \\
\hline Landing gear & & 2 & \\
\hline Fuselage & 5 & 2 & \\
\hline Wing & 29 & 2 & \\
\hline Horizontal tail & 19 & 2 & 4 \\
\hline Vertical tail & 18 & 2 & 5 \\
\hline Pylon & 14 & 2 & \\
\hline Nacelle & 3 & & 10 \\
\hline Engine & & 46 \\
\hline Aircraft & 104 & & \\
\hline Total & & & \\
\hline
\end{tabular}

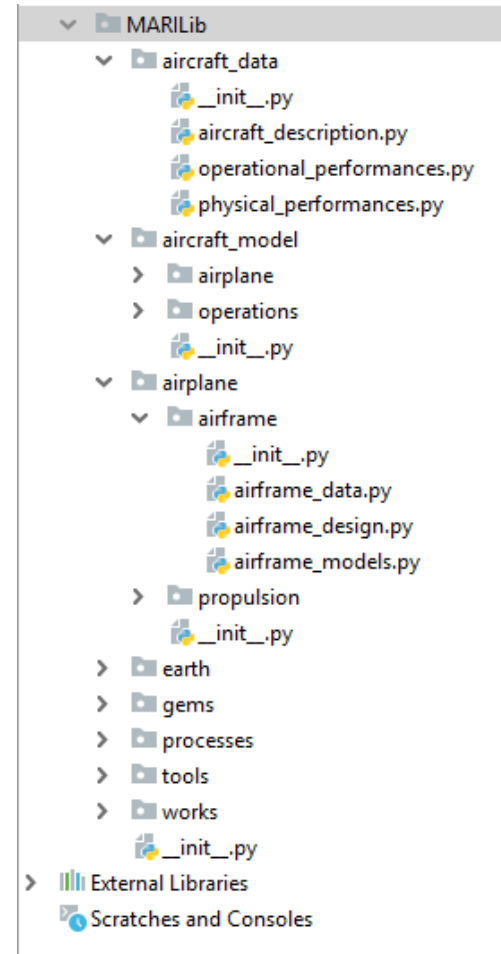

Fig. 1 MARILib top level folder architecture

- operations contains five files with functions related to: environmental impact, flight mechanics, handling qualities, mission, princing and costing.

- airplane: is dedicated to component classes and functions. It is split into two sub-folders, one dedicated to airframe components and the other to propulsion components.

The airframe sub-folder contains three Python files:

- airframe_data defines the component classes (cabin, fuselage, wing, ... ) 
- airframe_design defines the functions which are used to predesign components attributes before any process has been applied or during design processes. The variables that will be defined by running the design process must be instantiated with initial values to run these functions.

- airframe_models defines the component related functions which are necessary to simulate aircraft operations. These functions are mainly related to local aerodynamic coefficients.

The propulsion sub-folder reproduces this three-file architecture for propulsion system and contains presentely only two different systems : turbofan and hybrid partial turboelectric nl. Each of these systems is described using three files as explained above ( $x y z$ stands for the type of propulsion system) :

- $x y z \_d a t a$ for classes definition,

- $x y z \_$design for predesign functions, and

- xyz_models for simulations.

Two additional small libraries are completing the aircraft model:

- earth contains a model of standard atmosphere as well as some complementary data about earth environment and fuel characteristics

- tools provides some math functions and a small unit conversion library.

Finally, the folder processes contains process bricks for design. One of the most important file is initialization which contains all functions providing default values for design. These default values are parameterized by only five parameters:

- design_range: the nominal range used to size the aircraft,

- cruise_mach: the nominal Mach number of the aircraft during cruise,

- n_pax_ref: the nominal number of passengers used to size the cabin, generally, it is a two-class layout,

- propu_config: the propulsive architecture (1: for turbofan, 2 : for partial turboelectric),

- n_engine: the number of engines which is basically 2 (4 is accepted but not fully tested at that time).

More details are given in the next section about initialization.

A typical design sequence can be assemble using functions provided in the library processes. Here below, is presented a sequence composed with highly integrated blocks:

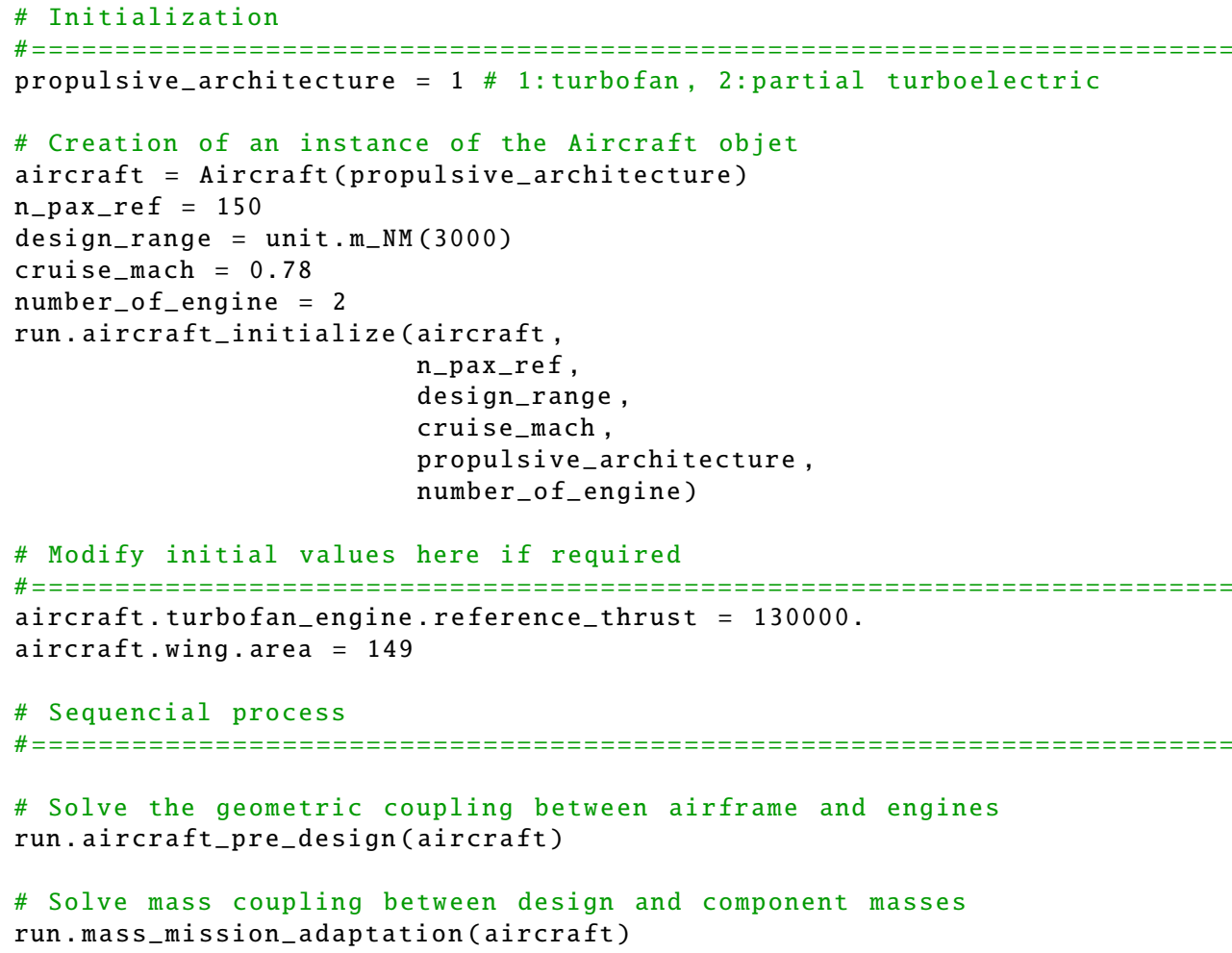




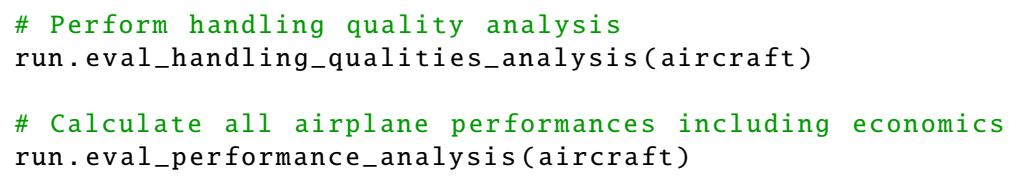

At the end of this process, all required quantities are available to be able to loop the sequence within an optimization process. Next section will present the underlying methodology which is classical.

\section{B. Design principles}

The design process is posed as an inverse problem: the main performance features of the aircraft are known and the computational procedure aims at finding its detailed definition to match these performances. In the context of airplane design this question is treated as an optimization problem which aims to define the top level parameters of an airplane which would minimize (or maximize) a given criterion whilst ensuring a given set of constraints.

The cost function and constraints must have design parameters (WingArea, EngineSize, ...) as input, which requires the existence of a parametric model of the airplane.

$$
\begin{aligned}
\min _{X=(\text { WingArea,EngineSize, } M T O M)} & \text { Criterion }(X)(\text { e.g.Cost }) \\
\text { s.t. } & g_{i}(X) \leq g_{i}^{\text {constr }} \quad \forall i \in[1, n]
\end{aligned}
$$

The target performances are expressed in term of:

1) Mission Requirements (range, speed, seat capacity, ... )

2) Operational constraints (take off field length, approach speed, time to climb, ceilings, ...)

3) Customer-Oriented performance criteria (fuel, weight, cost, present value, ...)

The physical parameters defining the aircraft are split into:

1) Design variables (wing area, span, engine max thrust, empennage areas, ... )

2) Technological assumptions (materials, engine type, actuator type, regulation, ....)

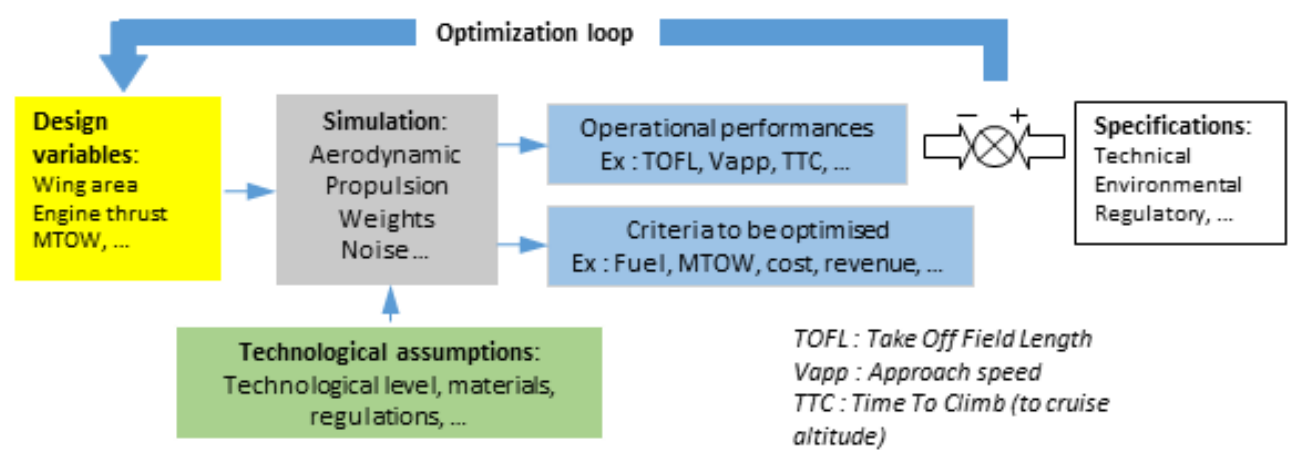

Fig. 2 Optimization loop

The core process of the aircraft conceptual design follows the steps:

1) Expression of Top Level Requirements (TLRs), most important ones are Nominal number of passengers, design range and cruise Mach number.

2) Expression of design assumptions, ex: overall topology, number of front seats, number of aisles, number of engines, empennage type (classical or T-tail), .. These design assumptions may evolve in the future but a starting values are needed to be able to run the models.

3) Initialization of design variables. This can be done by taking values from an existing aircraft close to the targetted one in term of TLRs or by considering the top level categories which are determined by nominal number of 
passengers, design range and cruise Mach number. This last approach is used in the initialization functions. At this stage, we suppose that a model chain exists that can produce all required quantities of interest.

4) Application of a design process (e.g. Multi Discipline Feasible (MDF)) to converge the aircraft definition towards a solution.

5) Processing of sensitivity studies to understand the rational of the exhibited solution.

Steps 4 and 5 may trigger several loops restarting at any previous steps of the process as long as a consistent set of TLRs and design assumptions is not reached according to engineering judgment and client wishes. An overall representation of the core process is shown in Fig. 2

The proposed library can manage automatically the process from step 1 to step 4, of course by taking some strong assumptions about TLRs. Step 5 is handled by the MDO library GEMS [7],[8], which usage along with MARILib is briefly introduced in the present paper.

A minimal amount of information is required to initialize the process :

- propu_config : the propulsive architecture (1: for turbofan, 2 : for partial turboelectric),

- n_engine : the number of engines which is basically 2 (4 is accepted but not fully tested at that time).

- design_range : the nominal range used to size the overall aircraft,

- cruise_mach : the nominal Mach number of the aircraft during cruise,

- n_pax_ref : the nominal number of passengers used to size the aircraft, generally, it is a 2 class layout, sometimes 3 class for long range.

Initialization functions will provide all complementary data to initiate the first run of the model chain. For instance, the choice between under wing engine mounting or rear fuselage mounting will be done according to the required number of passengers. Of course, one can overwrite initialization values with his own ones.

All initializations are implemented in the function aircraft_initialize (...) in the processes.design library. This function must be called before any design activity, but it is possible to overwrite any initialized variable afterward. Among all initialization, most important ones are probably those related to the Top Level Requirements (TLRs) listed below :

- n_pax_front: number of seats in a row (economic class),

- n_aisle: number of aisle (economic class),

- m_pax_nominal: nominal mass allowance for one passenger (passenger + luggage),

- m_pax_max: maximum mass allowance for one passenger (passenger + luggage),

- ref_cruise_altp: reference cruise altitude (most often used altitude for cruise),

- top_of_climb_altp: required top of climb (may be lower than reference cruise altitude),

- req_oei_altp: required one engine ceiling altitude,

- nacelle_attachment: 0: under wing, 1: rear fuselage,

- reference_thrust: generally sea level static thrust (the driving parameter of engine size, weight, consumption and thrust),

- bpr: by pass ratio of installed turbofans,

- wing_area: wing reference area,

- wing_aspect_ratio: wing aspect ratio,

- hld_type: type of high lift devices (0 to 10: from clean wing to various combinations of slats and flaps),

- htp_attachment: type of empennages, 0: classical, 1: T-tail,

- range_cost_mission: range of the cost evaluation mission,

- utilization: number of airplane rotation per year,

- req_tofl: maximum take-off field length at Maximum Take Off Weight (MTOW) and given conditions,

- req_app_speed: maximum approach speed at Maximum Landing Weight (MLW) and given conditions,

- req_ttc: maximum Time To Climb to top_of_climb_altp,

- req_oei_slope: minimum air path for one engine ceiling estimation,

- req_vz_climb: minimum climb speed at 97\%MTOW, nominal initial cruise altitude and Max CLimb (MCL) rating,

- req_vz_cruise: minimum climb speed at 97\%MTOW, nominal initial cruise altitude and Max CRuise (MCR) 
rating,

Once initialization is completed, the design activity can start. The sizing of airplanes components are ensured by a set of functions called eval_component_name_design (...) and eval_component_name_mass(...). These functions are based on very simple formulas. The formula's complexity is a trade between accuracy and computational time. Most of them are linear regressions. Public data were used when available or simplifications of known formulas coming from [9-16] were made. The underlying idea is not to be accurate in value prediction but to give robust orders of magnitude through the full design domain going from business jets to super jumbos. Moreover, when some quantities do not vary a lot across the domain, they have been taken as constants. If one knows better formulas in a specific context, it is easy to replace provided ones and take benefit of the overall model integration of MARILib.

Examples of formula for geometrical predesign:

$$
\begin{gathered}
\text { cabin_width }=0.15+0.38 n \_p a x \_f r o n t+1.05 n \_a i s l e \\
\text { fuselage_width }=\text { cabin_width }+0.40 \\
v t p \_a s p e c t \text { ratio }=1.7 \\
\text { htp_aspect_ratio }=5
\end{gathered}
$$

Concerning mass estimation functions, the rationale is that matter is roughly distributed on surfaces, so, all structural mass estimation functions are based on a given weight per square meter (except for pylon and landing gears). The Fig. 3 illustrates this for the fuselage

Examples of formula for mass estimation:

$$
\begin{gathered}
v t p \_m a s s=25 v t p \_a r e a \\
h t p \_m a s s=22 h t p \_a r e a \\
\text { fuselage_mass }=5.47[\pi \text { fuselage_length } \sqrt{\text { fuselage_width fuselage_height }}]^{1.2}
\end{gathered}
$$

Concerning this last formula, the expression below the square root is the equivalent diameter of the fuselage. The expression between brackets is the fuselage skin area considered without any tapering, but is also proportional to the cabin floor area. In this case, the constant 5.47 cannot be interpreted as a mass per square meter for the whole structure because of the power 1.2. These values (factor 5.47 and exponent 1.2) has been found by regression using data and formulas coming from [9-16].

System mass and landing gear mass are driven by characteristic weights:

$$
\begin{gathered}
\text { system_mass }=0.545 \mathrm{MTOW}^{0.8} \\
l d g \_ \text {mass }=0.02 \mathrm{MTOW}^{1.03}+0.012 \mathrm{MLW}
\end{gathered}
$$

Pylon, nacelle and engine masses are driven by engine Sea Level Static Thrust (SLST):

$$
\begin{gathered}
\text { pylon_mass }=0.0031 S L S T \text { n_engine } \\
\text { nacelle_mass }=(1250+0.021 S L S T) n \_ \text {_engine }
\end{gathered}
$$

Wing mass is taken from Shevel [14].

The core model chain contains the following 7 steps: 


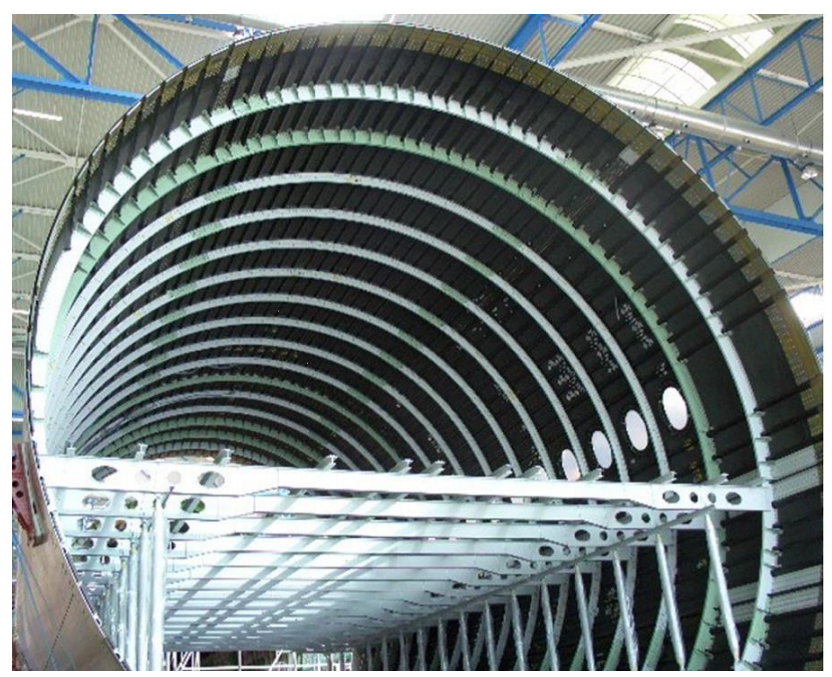

Fig. 3 Matter is distributed on surfaces, example of the fuselage

1) Initialization

2) Airframe predesign

3) Propulsion predesign

4) Mass and CG estimation

5) Nominal mission simulation

6) Operational performance estimation

7) Costs estimation

These steps are presented in the N2 diagram of Fig. 4 . Not all the variables have been mentioned but only those responsible of the couplings that have to be solved during the design process. In order to improve lisibility, some packaging of the functions has been done:

- Individual component design functions have been gathered into two blocks: Airframe_predesign and Propulsion_predesign.

- All mass and center of gravity assessments have been packaged into the Mass and CG estimation block.

- All performance estimations are in the block called Performances.

- All criteria evaluations, especialy, economics and environmental are in the block Criteria.

- Finally, the box called Weight balance produces a new value of MTOW from Operating Weight Empty (OWE), payload and total mission fuel.

It should be noted that the coupling between airframe and propulsion predesigns must be solved to obtain a consistent geometrical description. In fact, this coupling is a little bit artificial because a pure sequential treatment could be implemented by merging airframe and propulsion predesign functions, but this possibility is only due to the simplicity of used internal formulas. In real life, different engineering teams are operating separately. It was decided to let this separation as an opportunity to experiment MDO processes.

The expression in italic about drag, thrust and Specific Fuel Consumption (SFC) stands for model functions that allow to compute these quantities in the various flight conditions required to simulate mission and evaluate operational performances.

This core model chain also shows some couplings between modules Mass, Nominal mission and Weight balance through MTOW, Maximum Zero Fuel Weight (MZFW) and MLW. The resolution of these couplings correspond to the so called Mass-Mission adaptation which consists in having exactly the right structural mass to carry the required payload and fuel for the nominal mission. An example of treatment is presented in the N2 diagram of Fig. 5 .

An adequate solving process applied to this core model chain is able to produce consistent values of characteristic weights (MTOW, MLW, MZFW, OWE, and Manufacturer Weight Empty (MWE)) as well as operational performances (Take Off Field Length, Approach speed, Ceilings, Time to climb, ...) and cost criteria (Cash Operating Cost, Direct Operating Cost). All tool ingredients are gathered to be able to optimize the initial airplane. Most common topmost 


\begin{tabular}{|c|c|c|c|c|c|c|c|c|}
\hline TLRs & $\begin{array}{l}\text { propu_config } \\
\text { n_engine }\end{array}$ & $\begin{array}{c}\text { cruise_mach } \\
\text { n_pax_ref }\end{array}$ & cruise_mach & & $\begin{array}{l}\text { design_range } \\
\text { cruise_mach }\end{array}$ & & & \\
\hline & Initialization & $\begin{array}{c}\text { wing_area } \\
\text { hld_type } \\
\text { htp_attachment } \\
\text {... }\end{array}$ & $\begin{array}{c}\text { ref_cruise_altp } \\
\text { n_engine SLST BPR } \\
\text { engine_attachment } \\
\ldots\end{array}$ & $\begin{array}{l}\text { MTOW } \\
\text { MZFW } \\
\text { MLW }\end{array}$ & & Payload & $\begin{array}{c}\text { Operational } \\
\text { requirements }\end{array}$ & $\begin{array}{c}\text { Economic } \\
\text { assumptions }\end{array}$ \\
\hline & & $\begin{array}{c}\text { Airframe } \\
\text { preDesign }\end{array}$ & $\begin{array}{l}\text { fuselage_width } \\
\text { fuselage_height } \\
\text { fuselage_length } \\
\text { nacelle_x_axe }\end{array}$ & $\begin{array}{l}\text { Airframe } \\
\text { geometry }\end{array}$ & Airframe drag & & $\begin{array}{l}\text { Airframe drag } \\
\text { Airframe lift }\end{array}$ & $\begin{array}{l}\text { Airframe drag } \\
\text { Airframe lift }\end{array}$ \\
\hline & & $\begin{array}{l}\text { nacelle_y_axe } \\
\text { nacelle_length }\end{array}$ & $\begin{array}{l}\text { Propulsion } \\
\text { preDesign }\end{array}$ & $\begin{array}{c}\text { nacelle_mass } \\
\text { pylon_mass }\end{array}$ & $\begin{array}{l}\text { Engine drag } \\
\text { Engine thrust } \\
\text { Engine SFC }\end{array}$ & & $\begin{array}{l}\text { Engine drag } \\
\text { Engine thrust }\end{array}$ & $\begin{array}{c}\text { Engine drag } \\
\text { Engine thrust } \\
\text { Engine SFC }\end{array}$ \\
\hline & & & & $\begin{array}{l}\text { Mass \& Cg } \\
\text { estimation }\end{array}$ & & $\begin{array}{c}\text { OWE } \\
\text { MZFW } \\
\text { MLW }\end{array}$ & $\begin{array}{l}\text { MLW } \\
\text { OWE }\end{array}$ & $\begin{array}{l}\text { OWE } \\
\text { MWE }\end{array}$ \\
\hline & & & & & $\begin{array}{c}\text { Nominal } \\
\text { mission }\end{array}$ & fuel_total & & \\
\hline & & MTOW & & $\begin{array}{l}\text { MTOW } \\
\text { MZFW } \\
\text { MLW }\end{array}$ & MTOW & $\begin{array}{l}\text { Weight } \\
\text { balance }\end{array}$ & MTOW & MTOW \\
\hline & & & & & & & \begin{tabular}{|c} 
Operational \\
Performances
\end{tabular} & \\
\hline & & & & & & & & $\begin{array}{c}\text { Cost } \\
\text { functions }\end{array}$ \\
\hline
\end{tabular}

Fig. 4 N2 diagram of the core model chain

design parameters are Wing area and Sea Level Static Thrust (reference_thrust which drives the engine size, thrust, consumption and weight through the parametric engine model).

To run this optimization process, it is just needed to input values to the topmost 3 TLRs (Design range, Cruise speed and passenger capacity), the two design options (propulsive architecture, number of engine) and to the following operational requirements:

1) Maximum take-off field length, sea level, ISA+15, MTOW

2) Maximum approach speed, sea level, ISA+15, MLW

3) Maximum time to climb to Top of Climb altitude, ISA, $97 \%$ MTOW

4) Minimum climb speed at Top of Climb altitude, ISA, cruise Mach, $97 \%$ MTOW, MCL rating

5) Minimum climb speed at Top of Climb altitude, ISA, cruise Mach, $97 \%$ MTOW, MCR rating

6) Minimum air path at required One Engine Inoperative ceiling, ISA, best speed, $95 \%$ MTOW, MCN rating

If the user does not know this requirements, initializing functions are available to propose acceptable values. The N2 diagram of Fig. 6includes the performance optimization loop.

In addition to this core process, a very simple Handling Quality (HQ) library has been implemented which is focused on tail area sizing together with longitudinal positioning of the wing versus the fuselage. This operation is classically performed, for tube and wing arrangements, outside of the core process because it has normally limited impact on the overall design (wing positioning is a question of number of frame before and after the wing attachment and tail areas is normally a question of a few square meters from pre-design values). This HQ process evaluate only one single CG forward limit (trim at landing) and one single CG backward limit (static stability: margin versus neutral point) and tries to match these limits with max forward and max backward CG requirements produced by the CG function. The N2 diagram of the HQ process is presented on Fig. 7

In real life, this last process is rather an optimization because there are many HQ constraints to satisfy and one never knows which ones will be active. Moreover, forward or backward CG active constraints may be different depending 


\begin{tabular}{|c|c|c|c|c|c|c|c|c|c|}
\hline $\begin{array}{l}\text { propu_config } \\
\text { n_engine n_pax } \\
\text { design_range } \\
\text { cruise_mach }\end{array}$ & & $\begin{array}{l}\text { cruise_mach } \\
\text { n_pax_ref }\end{array}$ & cruise_mach & & $\begin{array}{c}\text { design_range } \\
\text { cruise_mach } \\
\text { n_pax }\end{array}$ & $\begin{array}{l}\text { design_range } \\
\text { cruise_mach }\end{array}$ & & & \\
\hline \multirow[t]{10}{*}{ Initialization } & $\begin{array}{l}\text { wing_area } \\
\text { SLST }\end{array}$ & $\begin{array}{c}\text { wing_aspect_ratio } \\
\text { hld_type } \\
\text { htp_attachment } \\
\ldots\end{array}$ & $\begin{array}{c}\text { ref_cruise_altp } \\
\text { n_engine SLST BPR } \\
\text { engine_attachment } \\
\ldots\end{array}$ & $\begin{array}{l}\text { MTOW } \\
\text { MZFW } \\
\text { MLW }\end{array}$ & & & Payload & $\begin{array}{l}\text { Operational } \\
\text { requirements }\end{array}$ & \begin{tabular}{|} 
Economic \\
assumptions
\end{tabular} \\
\hline & $\begin{array}{l}\text { PreDesign } \\
\text { loop }\end{array}$ & $\begin{array}{l}\text { nacelle_y_axe } \\
\text { nacelle_length }\end{array}$ & & & & & & & \\
\hline & & $\begin{array}{l}\text { Airframe } \\
\text { preDesign }\end{array}$ & $\begin{array}{l}\text { fuselage_width } \\
\text { fuselage_height } \\
\text { fuselage_length } \\
\text { nacelle_x_axe }\end{array}$ & & $\begin{array}{l}\text { Airframe } \\
\text { geometry }\end{array}$ & Airframe drag & & $\begin{array}{l}\text { Airframe drag } \\
\text { Airframe lift }\end{array}$ & $\begin{array}{l}\text { Airframe drag } \\
\text { Airframe lift }\end{array}$ \\
\hline & $\begin{array}{l}\text { nacelle_y_axe } \\
\text { nacelle_length }\end{array}$ & & $\begin{array}{l}\text { Propulsion } \\
\text { preDesign }\end{array}$ & & $\begin{array}{l}\text { nacelle_mass } \\
\text { pylon_mass }\end{array}$ & $\begin{array}{l}\text { Engine drag } \\
\text { Engine thrust } \\
\text { Engine SFC }\end{array}$ & & $\begin{array}{l}\text { Engine drag } \\
\text { Engine thrust }\end{array}$ & $\begin{array}{c}\text { Engine drag } \\
\text { Engine thrust } \\
\text { Engine SFC }\end{array}$ \\
\hline & & & & $\begin{array}{c}\text { Mass-Mission } \\
\text { loop }\end{array}$ & $\begin{array}{l}\text { MTOW } \\
\text { MZFW } \\
\text { MLW }\end{array}$ & MTOW & & MTOW & MTOW \\
\hline & & & & $\begin{array}{l}\text { MZFW } \\
\text { MLW }\end{array}$ & $\begin{array}{l}\text { Mass \& } \mathrm{Cg} \\
\text { estimation }\end{array}$ & & OWE & $\begin{array}{l}\text { MLW } \\
\text { OWE }\end{array}$ & $\begin{array}{l}\text { OWE } \\
\text { MWE }\end{array}$ \\
\hline & & & & & & $\begin{array}{l}\text { Nominal } \\
\text { mission }\end{array}$ & FuelTotal & & \\
\hline & & MTOW & & MTOW & & & $\begin{array}{l}\text { Weight } \\
\text { balance }\end{array}$ & & \\
\hline & & & & & & & & Performances & \\
\hline & & & & & & & & & $\begin{array}{c}\text { Cost } \\
\text { functions }\end{array}$ \\
\hline
\end{tabular}

Fig. 5 N2 diagram of the core process

on the mass of the aircraft which makes this process very tricky. Nevertheless, the great simplification that has been adopted reveals to be clever enough to improve tail sizing in comparison to volume based pre-sizing performed in Airframe predesign functions. The coupling of the HQ process to the core process can be done as shown on Fig. 8 .

The overall process described above is a chain of a MDF process (performance optimization) with constraint satisfaction process (Tail re-sizing) into a fixed point overall loop. Experience shows that this scheme converges most of the time if we divide by 2 the changes in Vertical Tail Plane (VTP) area, Horizontal Tail Plane (HTP) area and wing position that are requested by the tail sizing step. Convergence is generally quite rapid ( 2 to 3 loops) but in some cases, it appears to be longer (more than 12 loops). The use of a fixed point scheme at this stage seems not very efficient, this way of doing has been selected just because it reflects some common practices. More efficient MDO strategies can surely be applied.

It is interesting to notice that the attempt to merge all constraint satisfaction sub-processes into a single one seems not to improve convergence in the difficult situations. At this stage, it is not possible to formally exclude the possibility of a bug, further investigations will be done to understand the causes of the problem. Nevertheless, it is to be noticed that tail sizing and wing positioning impact all disciplines through many causal loops. These multiple interactions may lead to difficulties to reach the optimum, especially when the domain around is very flat, which is the case here. It would be very interesting to test others MDO processes on this problem.

At the end of the process, it is possible to draw a simple 3 view drawing mainly for sanity check. The sketch shown on Fig. 9 is drawn into a $100 \mathrm{~m}$ x $100 \mathrm{~m}$ square to give an absolute perception of the size.

\section{Examples of design}

A few examples of design are presented in Table 2 and Fig. 10 These designs have been directly computed from top 3 inputs (range, speed, number of passengers) and the initialization functions. For all trials, design variables were Wing area and engine size and optimization criterion was MTOW. The yellow colored cells in the bottom of Table 2 indicate which constraints have been activated. 


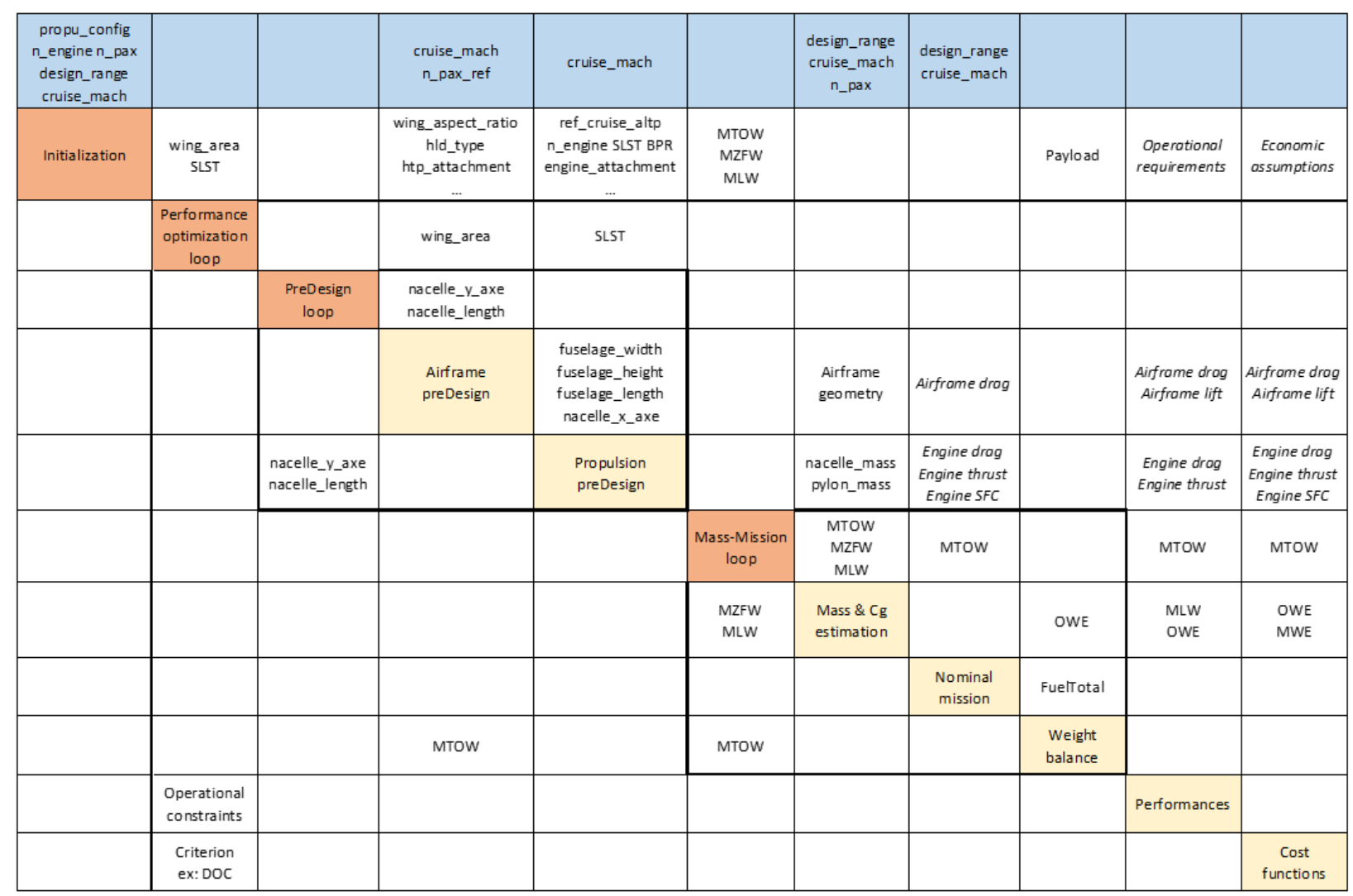

Fig. 6 N2 diagram of the performance optimisation

\begin{tabular}{|c|c|c|c|c|}
\hline Pre-sizing & $\begin{array}{c}\text { wing_x_root } \\
\text { htp_area } \\
\text { vtp_area }\end{array}$ & $\begin{array}{c}\text { wing_area } \\
\text { wing_aspect_ratio } \\
\text { hld_type htp_type } \\
\text { MTOW }\end{array}$ & $\begin{array}{c}\text { MTOW } \\
\text { MZFW } \\
\text { MLW }\end{array}$ & $\begin{array}{c}\text { Airframe drag } \\
\text { Airframe lift } \\
\text { Engine drag } \\
\text { Engine thrust }\end{array}$ \\
\hline $\begin{array}{c}\text { wing_x_root } \\
\text { htp_area } \\
\text { vtp_area }\end{array}$ & Tail sizing & $\begin{array}{c}\text { d_x_wing } \\
\text { d_htp_area }\end{array}$ & Airframe \\
\hline & geometry & \\
\hline & $\begin{array}{c}\text { c_g_max_fwd_req } \\
\text { preDesign }\end{array}$ & $\begin{array}{c}\text { Mass \& Cg } \\
\text { estimation }\end{array}$ & OWE \\
\hline & $\begin{array}{c}\text { max_fwd_cg_trim } \\
\text { max_bwd_cg_stall }\end{array}$ & d_vtp_area & & Handling \\
& & & Qualities \\
\hline
\end{tabular}

Fig. 7 N2 diagram of the HQ process

Note that initializing functions are making big decisions about airplane TLRs. Even if top 3 inputs correspond to existing design, other characteristics may be quite different because they do not match with other TLRs.

Finally, several gradient based optimizers from Scipy.minimize toolbox have been tried with various success (COBYLA, SLSQP, Trust-constr). Trust-constr has been finally selected with adapted pre-scaling of constraints and criteria. This setting seems to converge reasonably fast on most of the designs that have been proposed to it. A possible source of problem is probably the necessity to rely on finite differences to build the gradient of the functions, indeed, the module functions are using a lot of internal zero finding using Scipy.minimize.f_solve and basic settings which may introduce some numerical noise. If so, going to automatic differentiation may improve the situation. In any case, further 
Table 2 Some automatic designs from MARILib

\begin{tabular}{|c|c|c|c|c|c|c|}
\hline & unit & Airplane 1 & Airplane 2 & Airplane 3 & Airplane 4 & Airplane 5 \\
\hline Capacity & & 8 & 110 & 150 & 280 & 300 \\
\hline Range & $\mathrm{NM}$ & 3300 & 3100 & 3000 & 6100 & 8000 \\
\hline Cruise Mach & & 0.79 & 0.78 & 0.78 & 0,82 & 0.85 \\
\hline SLST & daN & 3200 & 9435 & 11795 & 31780 & 39485 \\
\hline BPR & & 5 & 9 & 9 & 9 & 9 \\
\hline Wingarea & $\mathrm{m}$ & 41,2 & 110,9 & 146,3 & 356,7 & 444,7 \\
\hline Span & $\mathrm{m}$ & 19,3 & 31,6 & 36,3 & 56,7 & 63,3 \\
\hline Fuselage length & $\mathrm{m}$ & 18.5 & 32,5 & 37.2 & 59,3 & 51,8 \\
\hline Fuselage width & $\mathrm{m}$ & 2.4 & 3.5 & 3.9 & 5.7 & 5,7 \\
\hline MTOW & $\mathrm{kg}$ & 17900 & 59380 & 76330 & 231290 & 298170 \\
\hline MLW & $\mathrm{kg}$ & 17900 & 51260 & 67130 & 175680 & 209080 \\
\hline OWE & $\mathrm{kg}$ & 11900 & 34710 & 44740 & 122180 & 150400 \\
\hline MWE & $\mathrm{kg}$ & 11470 & 30930 & 39770 & 104260 & 125760 \\
\hline TOFL & $\mathrm{m}$ & 1520 & 2000 & 2000 & 2795 & 3000 \\
\hline App Speed & $\mathrm{kt}$ & 135 & 135,7 & 135,1 & 140 & 136,8 \\
\hline OEl path & $\%$ & 1,8 & 1,8 & 1,9 & 1,3 & 1,2 \\
\hline Vz Climb MCL & $\mathrm{ft} / \mathrm{min}$ & 480 & 440 & 470 & 535 & 525 \\
\hline Vz Climb MCR & $\mathrm{ft} / \mathrm{min}$ & 0 & 60 & 90 & 180 & 170 \\
\hline TTC & $\mathrm{min}$ & 22,4 & 25 & 25 & 25 & 25 \\
\hline
\end{tabular}

investigations will be required to make automatic optimization more robust.

MARILib reveals to be quite robust exploring the design space from business jets to super jumbo, however, it remains possible to put the design process in a situation where it cannot start. This may happen when initializing functions are unable to propose a data configuration which can be evaluable by all sub models. In most of the case, it is possible to unlock the process by increasing the SLST proposed by the corresponding initialization function (as it is well known that "with big engines, you can fly anything. ..").

Even if the set of TLRs matches perfectly an existing airplane, MARILib will, of course, not be able to retrieve the whole set of characteristics of the aircraft with high precision, this would reveal some sort of magic. But programmers may introduce shifts on the output of sub models to recover a known value. If enough reference data are available, the library can be tuned to reproduce the design of a reference aircraft and be used to assess some technological effects as the one which is proposed in the following of this paper.

If MARILib is not very precise to predict an existing design it can nevertheless be quite good as long as only differences between two designs are looked for. 


\begin{tabular}{|c|c|c|c|c|c|c|c|c|c|c|c|c|c|c|c|}
\hline & & & & & & & & & & & & & & & 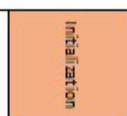 \\
\hline & & & & & & & & & & & & & & $\overline{8} \frac{2}{8}$ & 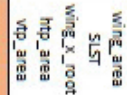 \\
\hline & & & & 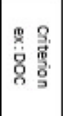 & 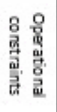 & & & & & & & & 量 & 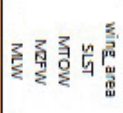 & \\
\hline & & & & & & & & & & 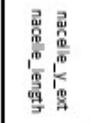 & & 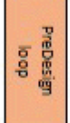 & & & \\
\hline & & 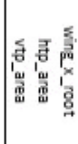 & & & & 总 & & & & & 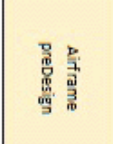 & 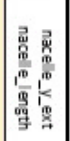 & 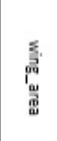 & & 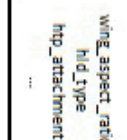 \\
\hline & & 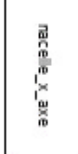 & & & & & & & & 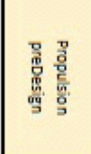 & 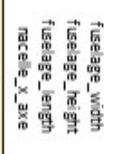 & & 贵 & & 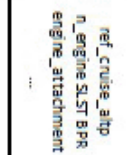 \\
\hline & & & & & & 产 & & 翌䨔 & 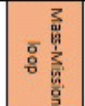 & & & & & 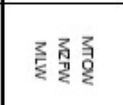 & 翋䨔寻 \\
\hline & & 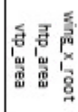 & & & & & & 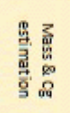 & 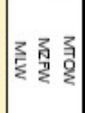 & 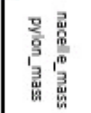 & 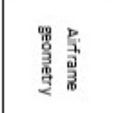 & & & & \\
\hline & & & & & & & 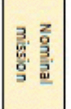 & & है & 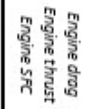 & 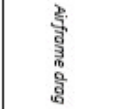 & & & & \\
\hline & & & & & & 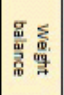 & 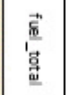 & 鬲 & & & & & & & $\begin{array}{l}\text { 总 } \\
\text { 商 }\end{array}$ \\
\hline & & & & & 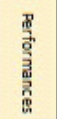 & & & 虽京 & 产 & 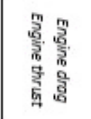 & 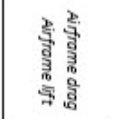 & & & & 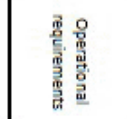 \\
\hline & & & & 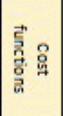 & & & & 릴 & 竓 & 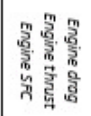 & 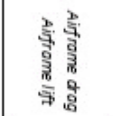 & & & & 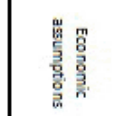 \\
\hline 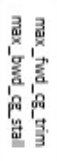 & 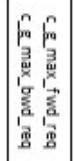 & & 志 & & & & & & & & & & & & 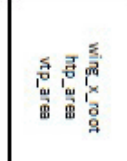 \\
\hline 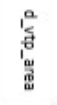 & & 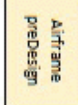 & 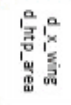 & & & & & & है & & & & & & \\
\hline & 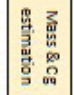 & 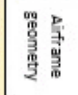 & & & & & & & है & & & & & & \\
\hline 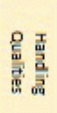 & 总 & & & & & & & & है & 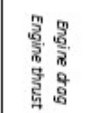 & 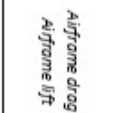 & & & & \\
\hline
\end{tabular}

Fig. 8 N2 diagram of the overall process 


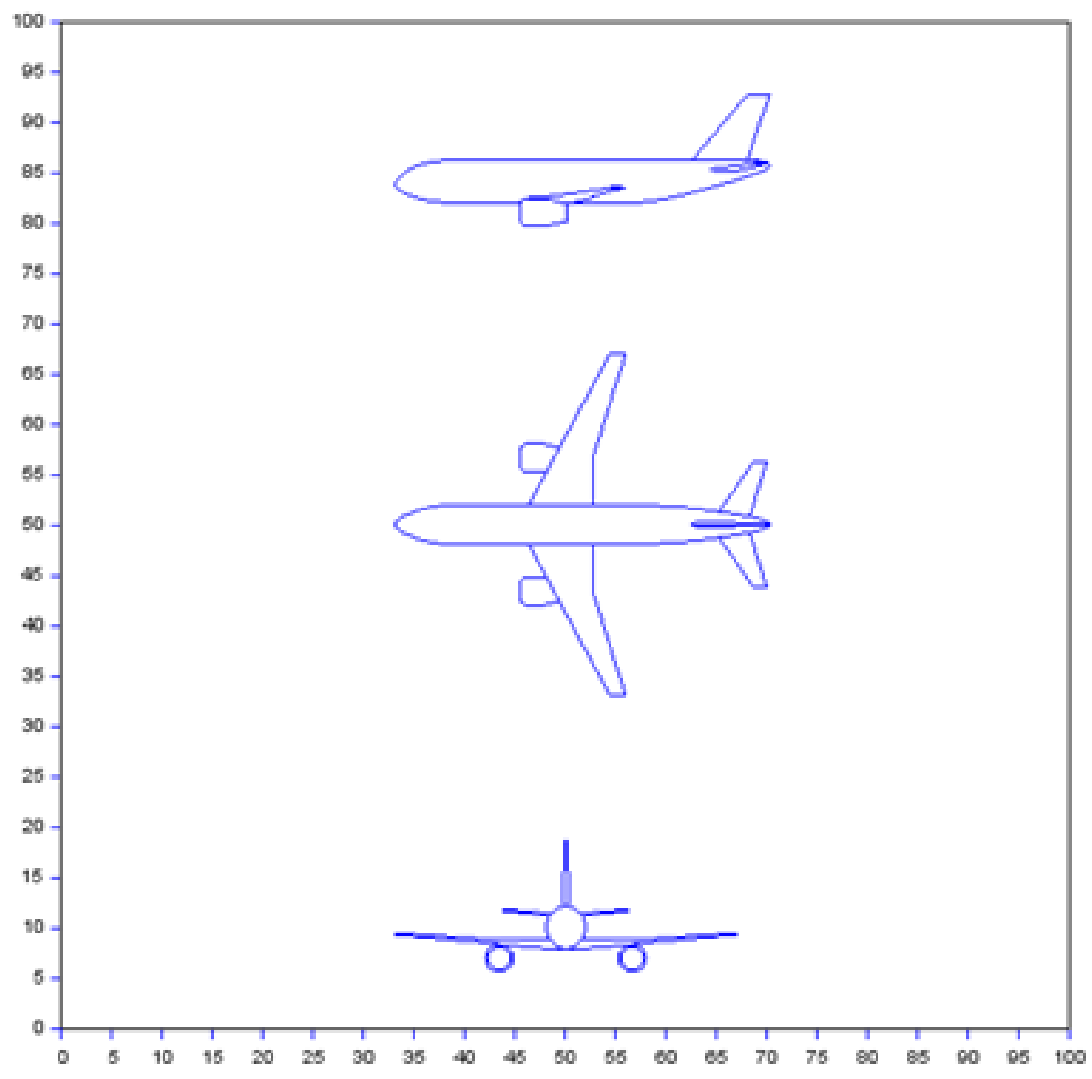

Fig. 9 Sanity check with 3 view drawing

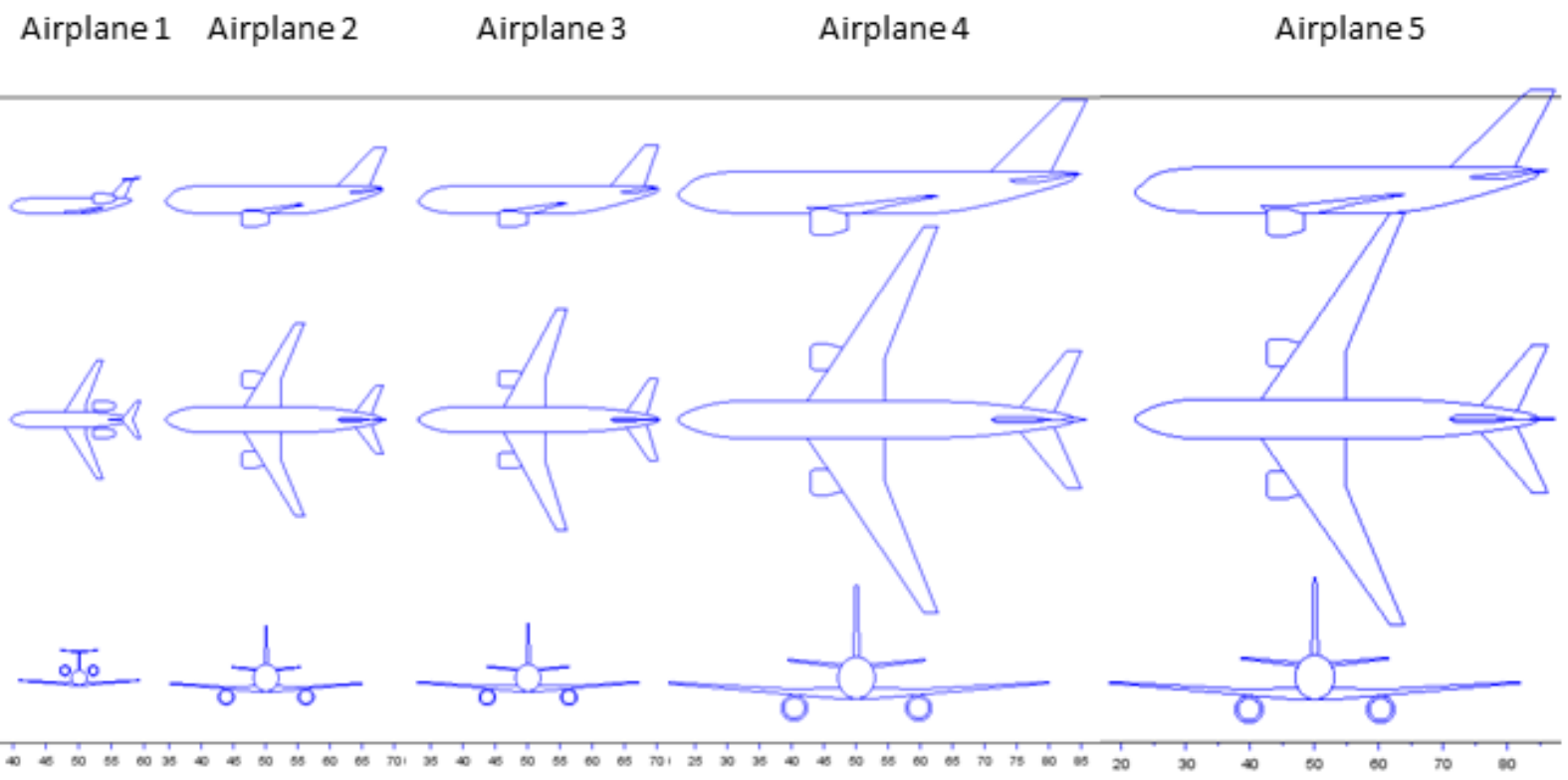

Fig. 10 3view drawing of the 5 airplanes 


\section{Hybrid architecture}

It is proposed to use MARILib to experiment the possibility to model a hybrid architecture and to compare the performances of 2 configurations, one classical and one hybrid, optimized according to the same set of TLRs. The selected architecture, a partial turbo-electric, is described in Fig. 11.

\section{A. Architecture definition}

The reference aircraft is Airplane $\mathrm{n}^{\circ} 3$ presented above. When components of an electric chain are added to a classical configuration, all new components are adding their weight and power loss and some of them are also adding drag. At the end of the chain, some thrust is produced that will not in itself compensate the additional weight, power loss and drag. As a result of this, the initial step of hybridization always reveals a loss in overall performance. To have a chance to decrease this loss or even to turn it into some benefit, the designer must take advantage of some specificities of electric devices. In the proposed arrangement, most important benefit is expected to come from the location of the electric fan at the rear end of the fuselage where it can ingest part (or totality) of the boundary layer. The boundary layer which is surrounding rear fuselage tail cone contains energy that have been dissipated on fuselage skin as drag and part of this energy can be recaptured for propulsion purpose.

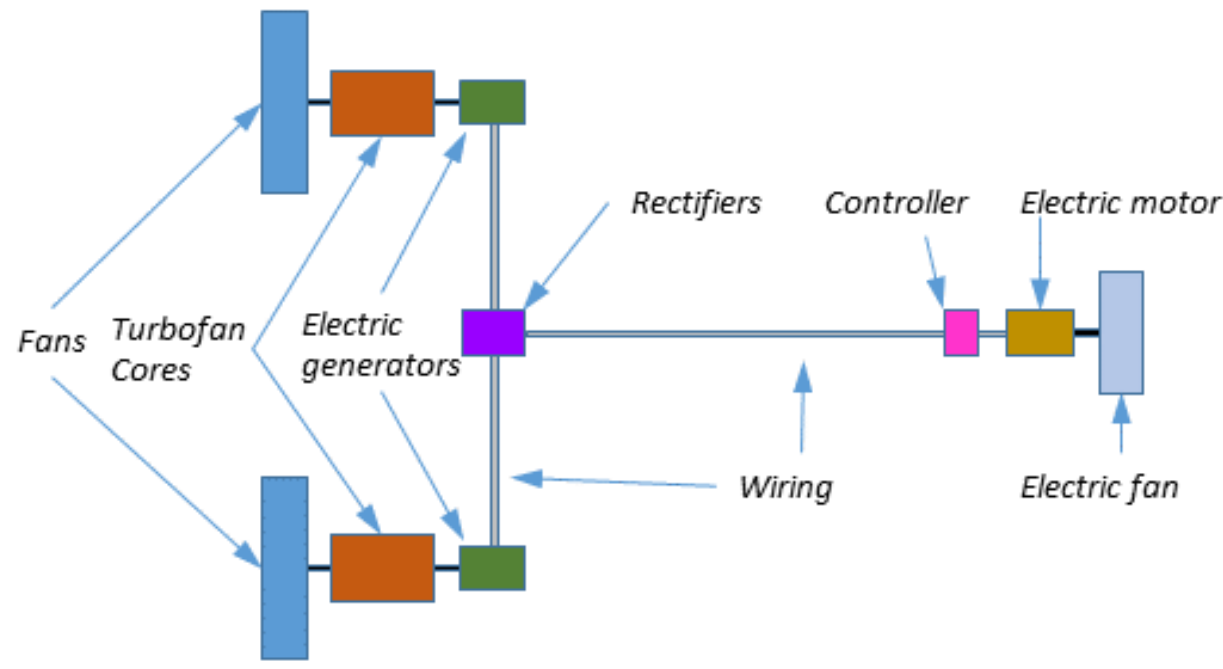

Fig. 11 Hybrid architecture

The weight of the components of the electric chain depend on the amount of power they have to manage. As a starting point, following assumptions have been taken for the power density of each type of component:

- Generator: $10 \mathrm{~kW} / \mathrm{kg}$,

- Rectifier: $20 \mathrm{~kW} / \mathrm{kg}$,

- Wiring: $20 \mathrm{~kW} / \mathrm{kg}$,

- Cooling: $15 \mathrm{~kW} / \mathrm{kg}$,

- Controller: $20 \mathrm{~kW} / \mathrm{kg}$,

- Motor: $10 \mathrm{~kW} / \mathrm{kg}$,

- Fan and mounting: $5 \mathrm{~kW} / \mathrm{kg}$.

The airplane which integrates this propulsive architecture could look like the NASA STARC ABL [17] presented in Fig. 12

To model this kind of hybrid architecture, it is necessary to take into account all the main aspects of the electric chain and their impact on airplane performance. It is also necessary to quantify the benefit of the boundary layer ingestion. These models must be parametric so that they can play their role in the design process of the whole airplane. To make this possible, some strong assumptions have been taken. This has been done by considering some quantities as constants.

Before defining the model, it is interesting to recall what is at stake with the selected architecture: Ingesting the fuselage boundary layer is supposed to bring some benefit by recovering part of the energy dissipated as drag on the 

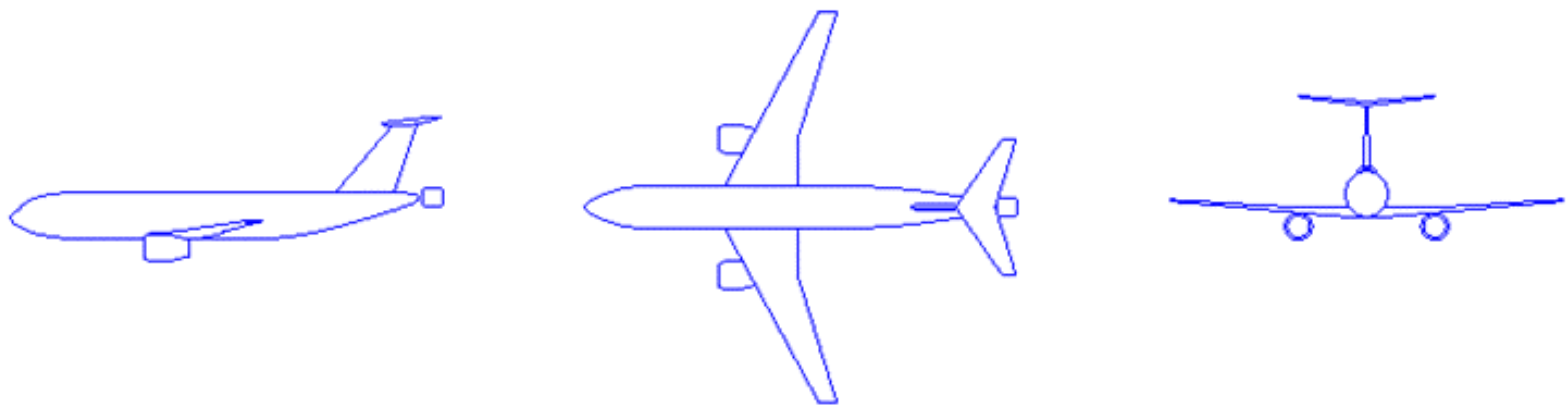

Fig. 12 Rear end fuselage mounted e-fan

fuselage skin. This energy is delivered around the fuselage as an air mass flow which has been dragged in the direction of the movement, the model must of course integrate this aspect. The main difficulty of Boundary Layer Ingestion (BLI) modelling is that drag and thrust interact tightly to produce an overall benefit which is hard to quantify without some complicated mathematics that are out of the scope of MARILib. Fortunately, the particular arrangement with an engine at the rear end of the fuselage can help to simplify the approach.

As the electric engine is plugged at most downstream position on the fuselage, the fuselage drag will be considered as unchanged except about tail cone drag (drag due to fuselage tapering) which may be reduced. As a consequence, only 2 phenomena can contribute to the benefit of the selected arrangement:

1) The reduction of fuselage tail cone drag

2) The kinetic energy captured by the inlet flow of the e-fan

The reduction of the fuselage tail cone drag is treated considering that the presence of the e-fan reduces the proportion of the cone wetted area which is generating this specific drag. This is really a rough model but we will take it at this stage. The principle and the notations are illustrated in Fig. 13 .

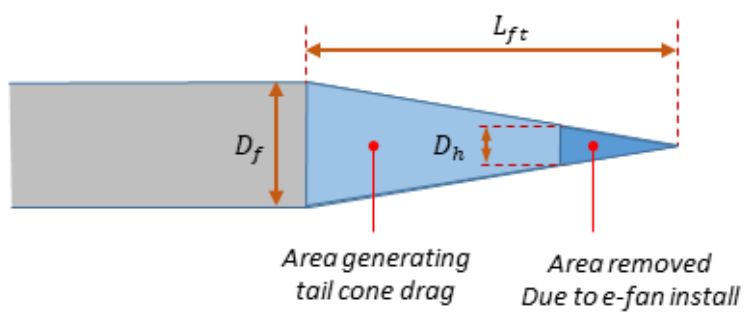

Fig. 13 Tail cone drag generating area

With a bit of geometry, the proportion $K_{a}$ of remaining wetted area over total initial wetted area can be expressed as following:

$$
K_{a}=1-\left(\frac{D_{h}}{D_{f}}\right)^{2}
$$

Consequently, remaining tail cone drag coefficient $C d_{\text {Cone } B L I}$ can be estimated from clean fuselage coefficient $C d_{\text {Cone }}$ as following:

$$
C d_{\text {Cone BLI }}=C d_{\text {Cone }}\left(1-\left(\frac{D_{h}}{D_{f}}\right)^{2}\right)
$$

The resulting benefit, with the geometry of the test case, is in the order of magnitude of 0.3 drag count which is very tiny, and perhaps pessimistic. 
Basically, the e-fan that swallows part or totality of a boundary layer will take benefit of the global reduction of the inlet speed and jet speeds. To produce the same thrust as an e-fan working in free stream, it will use less power, or, with the same shaft power, it will produce more thrust. The reduction of the inlet speed depends on the inlet mass flow itself. If the mass flow is small, only the lower part of the boundary layer will be swallowed and the average speed reduction will be high. The resulting benefit will be high but the thrust produced will remain small. If the mass flow is important, the inlet will swallow a large part of the air outside of the boundary layer and the average speed reduction will be low. Then the benefit will be reduced but the thrust produced will be high. As we can see, best conditions cannot be found without optimizing the design of the e-fan. The model described below integrates these antagonist effects and allows looking for an optimal design.

\section{B. Defining a hybrid SFC}

The first objective is to find an expression of the $S F C$ of a hybrid propulsive system from the characteristics of its components. The principle that has been applied is to start from a pure turbofan of a given size, weight, thrust and consumption (characterized by its SLST, By Pass Ratio (BPR) and its cruise $S F C$ ) and to derive from it a hybrid architecture introducing all necessary parameters to control the new components. The pure thermodynamic model is presented in the next chapter.

At big grain level, as shown in Fig. 14, a turbofan can be seen as 2 main components: a core and a fan coupled by a shaft. The whole system converts fuel flow into propulsive power with a given efficiency.

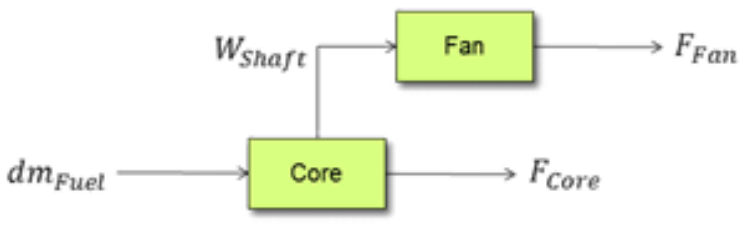

Fig. 14 Simplified architecture of a turbofan

The first big assumption will be to consider that the ratio $K_{C}=F_{\text {Core }} /\left(F_{\text {Core }}+F_{\text {Fan }}\right)$ is constant and equal to about $13 \%$. Actually, this ratio seems not to vary a lot in the whole flight domain (except in idle) for BPR higher or equal to about 5 . With this assumption, it can be written:

$$
\begin{gathered}
F_{\text {Core }}=K_{C}\left(F_{\text {Core }}+F_{\text {Fan }}\right) \\
F_{\text {Fan }}=\left(1-K_{C}\right)\left(F_{\text {Core }}+F_{\text {Fan }}\right)
\end{gathered}
$$

What is classically called fan efficiency is the capability of the fan to convert shaft power into kinetic energy. This efficiency is here taken as a constant with a value corresponding to high efficiency fans:

$$
\eta_{x}=\frac{\frac{1}{2} Q\left(V_{\text {jet }}^{2}-V_{\text {in }}^{2}\right)}{W_{\text {Shaft }}} \approx 0.95
$$

For the purpose, a "propeller like" efficiency of the fan has been introduced with a value corresponding to highly efficient devices:

$$
\eta_{F}=\frac{V_{\text {Air }} F_{F a n}}{W_{\text {Shaft }}} \approx 0.82
$$

These two efficiencies will be used in the following formulas to connect thrust, power and speed.

By definition:

$$
\frac{d m_{\text {Fuel }}}{d t}=S F C_{0}\left(F_{\text {Fan }}+F_{\text {Core }}\right)
$$

Combining Eqs. (15, , 16, , 18) and (19) gives: 


$$
\begin{gathered}
W_{\text {Shaft }}=\frac{V_{\text {Air }}\left(1-K_{C}\right)}{\eta_{F} S F C_{0}} \frac{d m_{\text {Fuel }}}{d t} \\
F_{\text {Core }}=\frac{K_{C}}{S F C_{0}} \frac{d m_{\text {Fuel }}}{d t}
\end{gathered}
$$

All the elements are now in place to go to the next step which consists in deriving some power from the fan shaft to an electric generator. In normal operation (all engine operative) a simplification of the proposed partial turbo-electric architecture is shown on Fig. 15

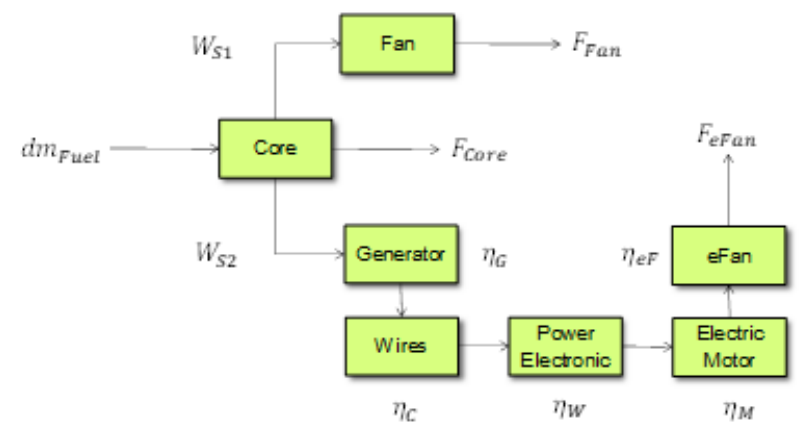

Fig. 15 Simplified partial turbo-electric architecture

Each component of the electric chain from the generator to the electric motor have its own efficiency. All these efficiencies can be merged into a single one. A value of $90 \%$ for this overall efficiency corresponds to a mean individual efficiency of each component of about $98 \%$ which is challenging:

$$
\eta_{E}=\eta_{G} \eta_{C} \eta_{W} \eta_{M} \approx 0.90
$$

The factor $K_{W}$ is now introduced: the ratio of the total power available on the fan shaft which is routed to the electric generator, this ratio will be a design parameter for the hybrid architecture:

$$
\begin{gathered}
W_{S 2}=K_{W}\left(W_{S 1}+W_{S 2}\right) \\
W_{S 1}=\left(1-K_{W}\right)\left(W_{S 1}+W_{S 2}\right)
\end{gathered}
$$

Combining Eqs. (18), 22, 23) and (24), gives:

$$
\begin{gathered}
F_{F a n}=\frac{\eta_{F}}{V_{A i r}} W_{S 1}=\frac{\eta_{F}\left(1-K_{W}\right)\left(W_{S 1}+W_{S 2}\right)}{V_{A i r}} \\
F_{\text {eF an }}=\frac{\eta_{e F} \eta_{E}}{V_{A i r}} W_{S 2}=\frac{\eta_{e F} \eta_{E} K_{W}\left(W_{S 1}+W_{S 2}\right)}{V_{A i r}}
\end{gathered}
$$

Combining Eqs. 20, 21, 25 and 26, produces:

$$
\begin{gathered}
F_{F a n}=\frac{\left(1-K_{W}\right)\left(1-K_{C}\right)}{S F C_{0}} \frac{d m_{F u e l}}{d t} \\
F_{\text {eFan }}=\frac{\eta_{e F} \eta_{E} K_{W}\left(1-K_{C}\right)}{\eta_{F} S F C_{0}} \frac{d m_{F u e l}}{d t} \\
F_{\text {Core }}=\frac{K_{C}}{S F C_{0}} \frac{d m_{F u e l}}{d t}
\end{gathered}
$$

Summing all the forces leads to: 


$$
F_{\text {Core }}+F_{F a n}+F_{e F a n}=\frac{K_{C} \eta_{F}+\left(1-K_{C}\right)\left(\eta_{e F} \eta_{E} K_{W}+\eta_{F}\left(1-K_{W}\right)\right)}{\eta_{F} S F C_{0}} \frac{d m_{F u e l}}{d t}
$$

Finally:

$$
F_{\text {Core }}+F_{F a n}+F_{\text {eFan }}=\frac{\eta_{H}}{S F C_{0}} \frac{d m_{F u e l}}{d t}
$$

With:

$$
\eta_{H}=K_{C}+\left(1-K_{C}\right)\left(\frac{\eta_{e F}}{\eta_{F}} \eta_{E} K_{W}+\left(1-K_{W}\right)\right)
$$

We obtain an expression of the SFC of the hybrid architecture based on the SFC of a pure turbofan:

$$
S F C_{H}=\frac{S F C_{0}}{K_{C}+\left(1-K_{C}\right)\left(\frac{\eta_{e F}}{\eta_{F}} \eta_{E} K_{W}+\left(1-K_{W}\right)\right)}
$$

In fact, the turbofan which will be modified to drive a generator on its fan shaft will have approximately the same core but a reduced fan diameter, it will not be the same engine as the initial one, so that the term $S F C_{0}$ has no longer a clear signification.

A possible interpretation is that $S F C_{0}$ is a sort of technological level. From the point of view of the modified turbofan, it is the theoretical $S F C$ of an engine without power offtake, which would have the same core, and which would have the adequate fan to absorb efficiently all the shaft power delivered by its core.

This expression of $S F C_{H}$ allows to continue using Breguet equation for the hybrid airplane.

Additionally, it is possible to derive from Eqs. (16), (27), (28) and (29) a relation to compute the available power on the electric fan shaft from the total thrust $F_{0}$ of a classical turbofan without power offtake:

$$
W_{\text {eShaft }}=V_{\text {Air }} \frac{\eta_{E} K_{W}+\left(1-K_{W}\right)}{\eta_{F}\left(K_{c}+\left(1-K_{C}\right)\left(1-K_{W}\right)\right)}\left(F_{\text {Core }}+F_{F a n}\right)_{0}
$$

Here again, the term $\left(F_{F a n}+F_{C o r e}\right)_{0}$ is the theoretical thrust of an engine without power offtake, which would have the same core, and which would have the adequate fan to absorb efficiently all the shaft power delivered by its core.

It is to be noted that Eqs. (33) and (34) can be used on top of a model of pure turbofan, which is great regarding our objective of simplicity.

\section{Definition of the initial turbofan engine}

Pure turbofan engine model has been selected as simple as possible and is classical in the context of conceptual design. Thrust is globally scaled by the reference Sea Level Static Thrust (SLST) which is modulated by 3 factors:

$$
F n=S L S T k F n_{1}(\text { rating }) k F n_{2}(B P R, M a c h)\left(\frac{\rho}{\rho_{0}}\right)^{0.75}
$$

1) $\mathrm{kFn} 1$ is a constant depending on engine rating

$$
\begin{array}{ll}
\text { if rating }=\text { MTO (Max Take Off }) & k F n_{1}=0.800, \\
\text { if rating }=\text { MCN (Maxi Continuous) } & k F n_{1}=0.688, \\
\text { if rating }=\text { MCL (Max CLimb) } & k F n_{1}=0.624, \\
\text { if rating }=\text { MCR (Max Cruise) } & k F n_{1}=0.560, \\
\text { if rating }=\text { FID (Flight Idle) } & k F n_{1}=0.100
\end{array}
$$

2) $k F n_{2}$ is a factor that drives the thrust decrease versus Mach number and By Pass Ratio (BPR) according to a polynomial surrogate presented on Fig. 16. This surrogate has been established by running a simple thermo-mechanical engine model and varying BPR and Mach number.

$$
k F n_{2}=0.475 M a c h^{2}+0.091\left(\frac{B P R}{10}\right)^{2}-0.283\left(\frac{B P R}{10}\right)-0.663 M a c h-0.081 B P R+1.192
$$




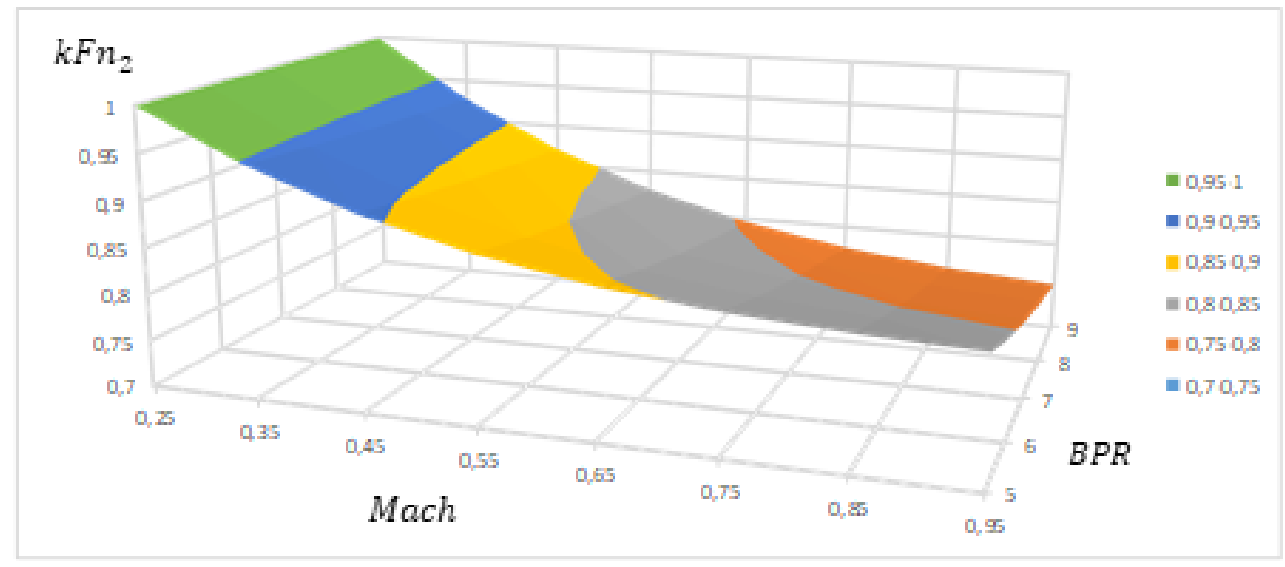

Fig. 16 Thrust dependence versus Mach and BPR

3) Finally, the term $\left(\frac{\rho}{\rho_{0}}\right)^{0.75}$ is driving the dependence of the thrust versus altitude

Fuel consumption is defined in cruise condition only by its Specific Fuel Consumption $(S F C)$ as a regression versus BPR shown on Fig. 17

$$
S F C_{0}=\left(0.4+\frac{1}{B P R^{0.895}}\right)\left(\frac{1}{36000}\right)
$$

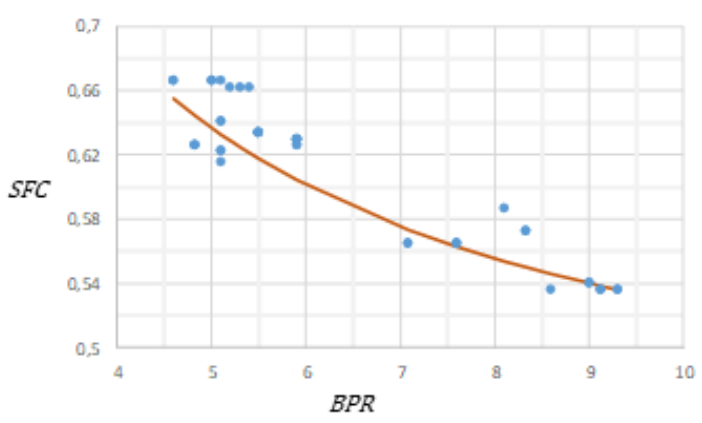

Fig. 17 SFC regression versus BPR

\section{Derivation of a turbofan model}

The engine with power offtake will have the same core but a reduced fan diameter. Considering that the air vein will be optimized for the new level of power, we consider that the fan efficiencies will remain unchanged. The new total thrust of the adapted engine is linked to the original thrust by:

$$
K_{F n}=\frac{F n_{1}}{F n_{0}}=K_{C}+\left(1-K_{C}\right)\left(1-K_{W}\right)
$$

The diameter of the adapted fan can be calculated simply by applying the classical relation for engine scaling modified to take account of the diameter of the core which remain unchanged. To do so, we introduced $K_{D}$, the proportion of the total engine diameter which is taken by the core. In practice, this ratio depends on the BPR of the engine, we proposed the following formula extracted from measurements on several engine drawings:

$$
K_{D}=0.7-0.05(B P R-5)
$$

The classical formula for engine diameter is: 


$$
\frac{D_{1}}{D_{0}}=\sqrt{\frac{F n_{1}}{F n_{0}}}=\sqrt{K_{F n}}
$$

Adapted formula is:

$$
\frac{D_{1}}{D_{0}}=\sqrt{K_{F n}}+K_{D}\left(1-\sqrt{K_{F n}}\right)
$$

The last aspect to be derived is the weight of the adapted engine with power offtake. Here again, a constant has been introduced to quantify the ratio of the core weight upon the total engine weight: $K_{\mathbf{M}}$. Due to a lack of available data, we retain the same expression as for $K_{D}$ :

$$
K_{M}=0.7-0.05(B P R-5)
$$

The same approach as for the diameter has been adopted: start from the weight variation due to thrust decrease by using the weight estimation function of a pure turbofan and introduce on top the effect of an unchanged core:

Pure turbofan weight estimation:

$$
M_{T F}=1250+0.021 S L S T
$$

Basic weight ratio:

$$
\frac{M_{T F 1}}{M_{T F 0}}=\frac{1250+0.021 S L S T K_{F n}}{1250+0.021 S L S T}
$$

Adapted weight ratio:

$$
\frac{M_{T F 2}}{M_{T F 0}}=\frac{M_{T F 1}}{M_{T F 0}}+K_{M}\left(1-\frac{M_{T F 1}}{M_{T F 0}}\right)
$$

The constant coefficients that have been introduced to build this model of coupled turbofan and generator are assigned with the following values:

- $\eta_{x} \approx 0.95$,

$\cdot \eta_{F} \approx 0.82$

- $\eta_{e F} \approx \eta_{F}$,

- $K_{C} \approx 0.13$,

- $K_{D} \approx 0.7-0.05(B P R-5)$,

- $K_{M} \approx 0.7-0.05(B P R-5)$.

The variables that have been defined to drive the turbofan adapted with power offtake and reduced fan are:

- $K_{W}$,

- $S L S T$,

- $B P R$.

These shifts of physical interpretation are not really a problem as overall effective $S L S T$ and $B P R$ can still be computed afterwards. Initial $S L S T$ and $B P R$ are just pure design variables of the hybrid configuration.

The effective $S L S T_{\text {hybrid }}$ of the hybrid propulsion can be computed from the input variable $S L S T$ as following:

$$
S L S T_{\text {hybrid }}=(\underbrace{K_{C}+\left(1-K_{C}\right)\left(1-K_{W}\right)}_{\text {Contribution of the turbofan }}+\underbrace{\frac{\eta_{e F} \eta_{E} K_{W}+\left(1-K_{W}\right)}{\eta_{F}\left(K_{C}+\left(1-K_{C}\right)\left(1-K_{W}\right)\right)}}_{\text {Contribution of the electric fan }}) S L S T_{0}
$$

The effective $B P R_{\text {hybrid }}$ of the hybrid propulsion must now be computed including the air flow going through the e-fan in the total cold flow. 


\section{E. Definition of the electric fan}

The electric part of the architecture have now to be treated and more specially the design of the electric nacelle. The design principles are presented considering that the nacelle is in free air (without BLI). These design principles can be applied with or without BLI just by adapting air velocities and mass flows according to the boundary model presented in the next section.

Following quantities are looked for:

- $D_{F a n}$,

- D Nacelle,

- L Lacelle,

- $D_{\text {Nozzle }}$.

Known data are:

- Mach,

- $V_{\text {Air }}$,

- $V_{\text {snd }}$,

- $D_{h}$,

- Weshaft,

- $\eta_{x} \approx 0.95$,

- $\eta_{e F} \approx 0.82$,

- $C p$.

The definitions of $\eta_{x}$ and $\eta_{e F}$ give:

$$
\eta_{e F}=\frac{V_{\text {Air }} F_{\text {eFan }}}{W_{\text {eShaft }}}=\eta_{x} \frac{V_{\text {Air }} Q\left(V_{\text {jet }}-V_{\text {in }}\right)}{\frac{1}{2} Q\left(V_{j e t}^{2}-V_{\text {in }}^{2}\right)}=\eta_{x} \frac{2 V_{\text {Air }}}{V_{j e t}+V_{\text {in }}}
$$

Noting $V_{j e t}-V_{i n}=\Delta V$ and making the assumption that $V_{i n}=V_{A i r}$ bring:

$$
\frac{\eta_{e F}}{\eta_{x}}=\frac{2 V_{\text {Air }}}{V_{j e t}+V_{i n}}=\frac{2 V_{\text {Air }}}{2 V_{\text {Air }}+\Delta V}=\frac{1}{1+\frac{\Delta V}{2 V_{\text {Air }}}}
$$

From which $\Delta V$ can be obtained (about $75 \mathrm{~m} / \mathrm{s}$ with proposed values of $\eta_{x}$ and $\eta_{e F}$ ):

$$
\Delta V=2 V_{A i r}\left(\frac{\eta_{x}}{\eta_{e F}}-1\right)
$$

The shaft power is converted into kinetic energy according to Eq. 51].

$$
W_{\text {eShaft }} \eta_{x}=\frac{1}{2} Q\left(V_{j e t}^{2}-V_{i n}^{2}\right)
$$

Using Eqs. (50) and (51) gives:

$$
Q=\frac{W_{\text {eShaft }} \eta_{x}}{2 V_{\text {Air }}^{2} \frac{\eta_{x}}{\eta_{e F}}\left(\frac{\eta_{x}}{\eta_{e F}}-1\right)}
$$

Stagnation pressure and temperature at air inlet are given by:

$$
\begin{gathered}
P_{\text {stag }}=P_{a m b}\left(1+\frac{\gamma-1}{2} M a c h^{2}\right)^{\frac{\gamma}{\gamma-1}} \\
T_{\text {stag }}=T_{\text {amb }}\left(1+\frac{\gamma-1}{2} M a c h^{2}\right)
\end{gathered}
$$

The Mach number at fan input, $M a c h_{f a n}$, is taken equal to 0.5 which is a classical design rule for air inlet. The corrected air flow per area gives a relation between mass flow and section: 


$$
\frac{Q}{A_{\text {Fan }}}=\frac{P_{\text {stag }}}{\sqrt{T_{\text {stag }}}} \sqrt{\frac{\gamma}{R}} \frac{\text { Mach }_{\text {fan }}}{\left(1+\frac{\gamma-1}{2} M_{a c h_{\text {fan }}^{2}}^{2}\right)^{\frac{\gamma+1}{2(\gamma-1)}}}
$$

From which the area of the e-fan vein section can be obtained:

$$
A_{\text {Fan }}=Q \frac{\sqrt{T_{\text {stag }}}}{P_{\text {stag }}} \sqrt{\frac{R}{\gamma}} \frac{\left(1+\frac{\gamma-1}{2} M_{\text {ach }}^{2}\right)_{\text {fan }}^{\frac{\gamma+1}{2(\gamma-1)}}}{\text { Mach }_{\text {fan }}}
$$

Considering the diameter of the hub, the diameter of the fan is:

$$
D_{\text {Fan }}=\sqrt{D_{h}^{2}+\frac{4}{\pi} A_{F a n}}
$$

The nacelle diameter $D_{\text {Nacelle }}$ is deduced from $D_{\text {Fan }}$ taking into account a necessary structural thickness around the fan:

$$
D_{\text {Nacelle }}=1.20 D_{\text {Fan }}
$$

The nacelle length $L_{N a c e l l e}$ is deduced from $D_{\text {Nacelle }}$ as follows:

$$
L_{\text {Nacelle }}=1.5 D_{\text {Nacelle }}
$$

Nozzle diameter is computed the same way as fan diameter but considering the exhaust velocity.

$$
V_{j e t}=V_{\text {air }}+\Delta V
$$

Stagnation temperature after the fan can be calculated as following:

$$
T_{\text {stag }_{\text {jet }}}=T_{\text {stag }}+\frac{W_{\text {eShaft }}}{Q C p}
$$

Static temperature is now:

$$
T_{\text {stat }}=T_{\text {stag }_{j e t}}-\frac{V_{j e t}^{2}}{2 C p}
$$

From which sound velocity can be obtained by:

$$
V_{\text {sndjet }}=\sqrt{\gamma R T_{\text {stat }}}
$$

Which leads to:

$$
\text { Mach }_{\text {jet }}=\frac{V_{\text {jet }}}{V_{\text {sndjet }}}
$$

Finally, stagnation pressure can be computed at nozzle exhaust considering that gas expansion is continued until ambient pressure:

$$
P_{\text {stag }_{j e t}}=P_{a m b}\left(1+\frac{\gamma-1}{2} M_{a c h} h_{j e t}\right)^{\frac{\gamma}{\gamma-1}}
$$

All quantities are now available to compute the nozzle area:

$$
A_{\text {Nozzle }}=Q \frac{\sqrt{T_{\text {stag }_{\text {jet }}}}}{P_{\text {stag }_{\text {jet }}}} \sqrt{\frac{R}{\gamma}} \frac{\left(1+\frac{\gamma-1}{2} \text { Mach }_{\text {jet }}^{2}\right)^{\frac{\gamma+1}{2(\gamma-1)}}}{\text { Mach }_{\text {jet }}}
$$

And finally: 


$$
D_{\text {Nozzle }}=\sqrt{\frac{4}{\pi} A_{\text {Nozzle }}}
$$

All required elements are now available to be able to compute off design working point of the electric fan. Before this, the model of boundary layer is presented as it is used for of design e-fan computations.

\section{F. Model of the boundary layer}

Many things have been written about Boundary layer ingestion and its benefit for air transport efficiency. Here, we do not pretend to propose precise approach to model BLI but just a simple one, only based on most important aspects of the phenomenon.

The thickness of a turbulent boundary layer which develops over a flat surface is classically given by Eq. 68.

$$
\delta=\frac{0.385 L}{(\operatorname{Re} L)^{\frac{1}{5}}}
$$

Where $R e$ is the Reynold's number per length unit and $L$ is the distance from which the boundary layer develops, $\delta$ is the height above the surface at which air longitudinal velocity has reached $99 \%$ of free stream velocity.

The longitudinal velocity, in airplane frame, at $y$ height above the surface is given by Eq. 696) and illustrated on Fig. 18 and Fig. 19 .

$$
v=V_{\text {Air }}\left(\frac{y}{\delta}\right)^{\frac{1}{7}}
$$

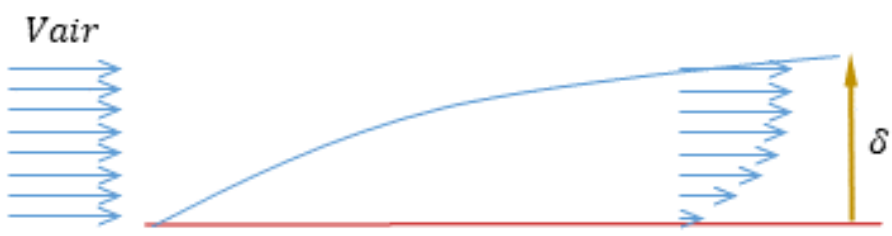

Fig. 18 Boundary layer velocity profile in airplane frame

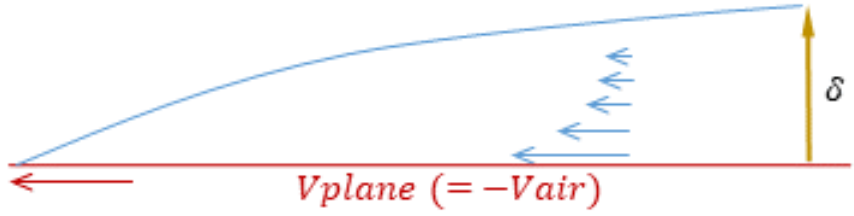

Fig. 19 Boundary layer velocity profile in ground frame

The problem is to model the shape of the boundary layer in front of the e-fan. The geometry of the fuselage rear end is a bit complicated, with a non-symmetrical necking immersed into the downwash of the wing, a complicated air flow structure can be expected at this place. At least, no full 3D description of the flow is required but a mean axisymmetric model. The model presented below has been built using mass flow considerations.

The drawing number 1 of Fig. 20 presents the target arrangement to model. Assessing the thickness and velocity profile of the resulting boundary layer at e-fan input, has been done in two steps as illustrated on Fig. 20 .

1) Using Eq. 68), compute the boundary layer thickness $\delta_{0}$ of the theoretical fuselage of drawing $\mathrm{n}^{\circ} 2$ at the same longitudinal position of the e-fan inlet of drawing $n^{\circ} 1$. In ground frame, according to Eq. (69), this boundary layer contains a certain mass flow $Q_{B L}$, e.g. all the air mass which is dragged by the moving fuselage (presented in blue). 
2) Compute the thickness $\delta_{1}$ of the boundary layer, of the same velocity profile (Eq. 699), which will pass the same mass flow $Q_{B L}$ around the hub of the e-fan, as illustrated on drawing number 3 of Fig. 20 The resulting boundary layer thickness is of course greater, i.e. $\delta_{0}<\delta_{1}$.

The resulting air velocity profile is used to compute the mass flow averaged velocity $V_{B L}$ which is swallowed by the e-fan according to its dimensions, power and flying conditions.

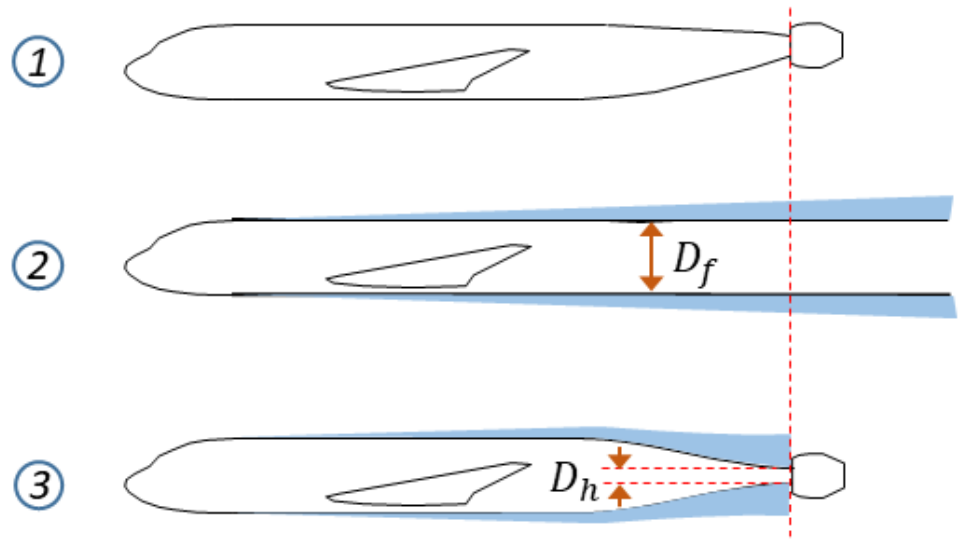

Fig. 20 Boundary layer thickness at e-fan inlet

Fuselage diameter $D_{f}$ and hub diameter $D_{h}$ being given, it is possible to compute $\delta_{1}$ as a function of $\delta_{0}$ independently from any other data. The resulting curve is presented on Fig. 21].

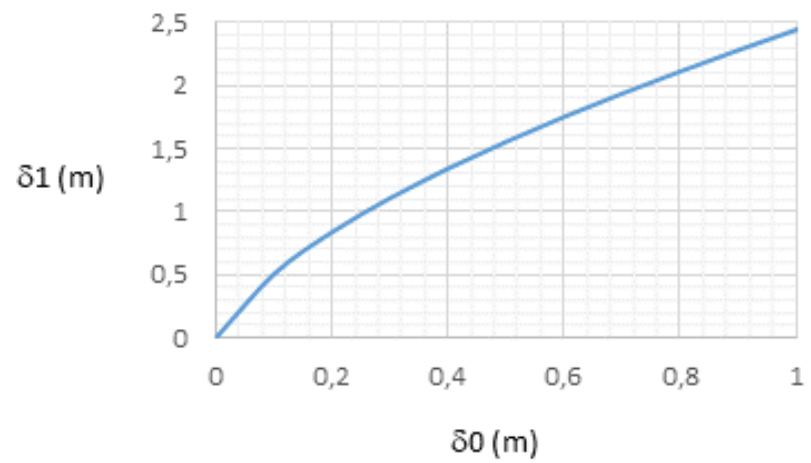

Fig. 21 Boundary layer thickness at e-fan inlet versus theoretical thickness on fuselage wall

The difference between mass flow averaged air velocity and the free stream air velocity $V_{A i r}-V_{B L}(y)$ can be computed versus the captured air flow around the hub $Q_{B L}(y)$ as shown in Eq. (70) where $y$ is the thickness of the air ring around the hub which is swallowed by the e-fan. Figure 22 illustrates this situation. This theoretical curve has been compared versus a curve obtained by post-treatment of a RANS computation on a similar geometry. The comparison is presented on Fig. 23 which shows no significant differences at the targeted level of precision.

$$
\frac{V_{\text {Air }}}{V_{B L}(y)}=\frac{Q_{\text {Free } \operatorname{Stream}}(y)}{Q_{B L}(y)}
$$

\section{G. Off design behavior of the electric fan}

Supposing the e-fan has been designed according to the process presented above, another process to simulate its behavior inside the rear fuselage wake in all the flight domain must be put in place. 


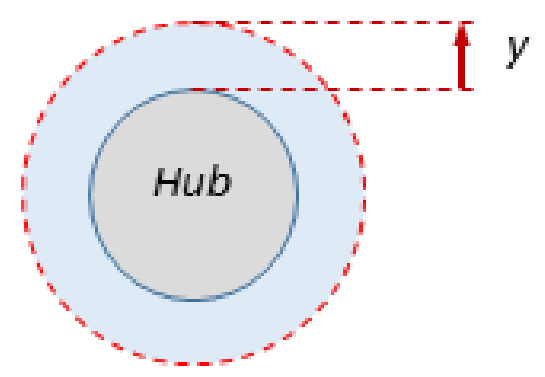

Fig. 22 Air ring swallowed by the e-fan

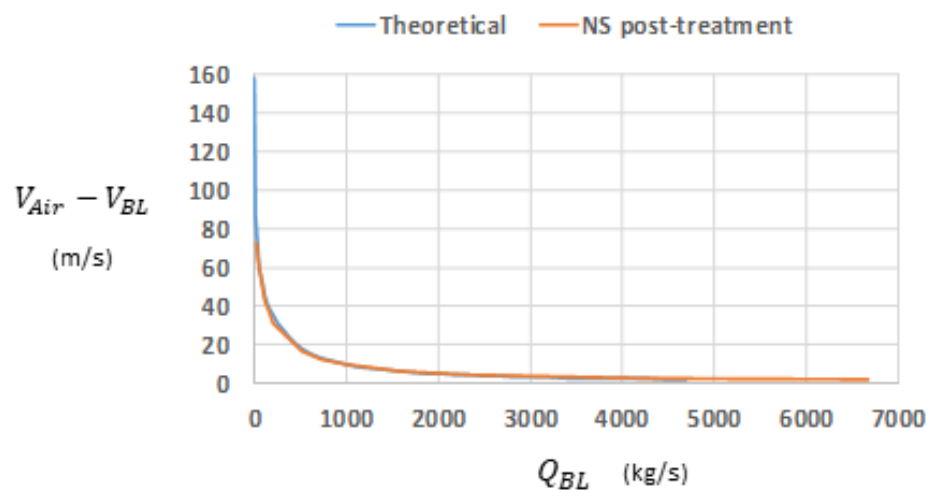

Fig. 23 Comparison Theory - RANS

We want to compute $F n_{e F a n}$.

Known data are:

- $\eta_{x} \approx 0.95$,

- $\eta_{F} \approx 0.82$

- $\eta_{e F} \approx \eta_{F}$,

- $\eta_{E} \approx 0.90$

- $K_{C} \approx 0.13$,

- $K_{W}$,

- $D_{f}$,

- $D_{h}$,

- DNozzle,

- Whaft

- Mach,

- $V_{\text {Air }}$

- $V_{\text {snd }}$.

A 3 steps approach has been selected:

1) Calculate the theoretical boundary layer thickness $\delta_{0}$ of a virtual fuselage of constant diameter and interpolate $\delta_{1}$ in the precomputed curve (see Fig. 21].

2) Calculate the thickness of the air ring swallowed by the e-fan according to the available power on the e-fan shaft and deduce the mass flow $Q_{e F a n}$ across the e-fan and air speeds at inlet $\left(V_{B L}\right)$ and jet $\left(V_{j e t}\right)$. This is done according to the process presented below.

3) Calculate the resulting e-fan thrust with:

$$
F n_{e F a n}=Q_{e F a n}\left(V_{j e t}-V_{B L}\right)
$$


The process to compute air flow characteristics across the e-fan is looking for the thickness $y$ of the air ring that enters the e-fan inlet. To find this thickness, a function is built to get $y$ as input and produce a residual which must be driven to zero. This solving is managed by a math library function, here, only the skeleton of the function is presented.

1) From $D_{f}, D_{h}, \delta 1$ and $y$, calculate the captured air flow $Q_{B L}(y)$ and the mass flow averaged air flow speed loss $d V_{B L}$ using Eqs. (69) and (70).

2) Calculate inlet air speed $V_{B L}(y)$ :

$$
V_{B L}(y)=V_{A i r}-d V_{B L}(y)
$$

3) From $W_{\text {eShaft }}$ calculate $M a c h_{j e t}$ the same way that have been used for e-fan design:

$$
\begin{gathered}
V_{\text {jet }}(y)=\sqrt{\frac{2 W_{\text {eShaft }}}{Q_{B L}(y)}+\left(V_{\text {Air }}-d V_{B L}(y)\right)^{2}} \\
T_{\text {stag }_{\text {jet }}}=T_{\text {stag }}+\frac{W_{\text {eShaft }}}{Q_{B L}(y) C p} \\
T_{\text {stat jet }}=T_{\text {stag jet }}-\frac{V_{\text {jet }}(y)^{2}}{2 C p} \\
V_{\text {sndjet }}=\sqrt{\gamma R T_{\text {stat jet }}} \\
\text { Mach }_{\text {jet }}(y)=\frac{V_{\text {jet }}(y)}{V_{\text {snd jet }}}
\end{gathered}
$$

4) From $D_{\text {Nozzle }}$ calculate the air mass flow across the nozzle

$$
\begin{gathered}
P_{\text {stag }}=P_{\text {amb }}\left(1+\frac{\gamma-1}{2} \operatorname{Mach}_{\text {jet }}^{2}\right)^{\frac{\gamma}{\gamma-1}} \\
Q_{B L}^{\prime}(y)=D_{\text {Nozzle }} \frac{P_{\text {stag }}}{\sqrt{T_{\text {stag }}}} \sqrt{\frac{\gamma}{R}} \frac{\operatorname{Mach}_{\text {jet }}(y)}{\left(1+\frac{\gamma-1}{2} \operatorname{Mach}_{\text {jet }}(y)^{2}\right)^{\frac{\gamma+1}{2(\gamma-1)}}}
\end{gathered}
$$

The solver must then find $y$ so that $Q_{B L}^{\prime}(y)$ equal to $Q_{B L}(y)$.

\section{H. Effect of BLI on fuel consumption}

Thanks to previous development, it is possible to calculate total thrust of the propulsive hybrid architecture but to be able to compute used fuel during missions, we must also determine the impact of BLI on fuel consumption. This can be done by modifying Eq. (18) and more particularly, by changing the signification of $\eta_{e F}$.

$$
\eta_{e F}=\frac{V_{\text {Air }} F_{\text {eFan }}}{W_{\text {eShaft }}}
$$

Originally, $\eta_{e F}$ is an efficiency but it also quantifies the thrust that can be obtained by the $e F a n$ from a given mechanical power $W_{e S h a f t}$ at a given speed $V$. Just sticking to this definition, the factor $K_{B L I}$ is introduced to give the relative $e F$ an thrust increase due to BLI. $K_{B L I}$ can be obtained by virtually running the e-fan with and without boundary layer ingestion, in cruise condition, and do the ratio of the obtained thrusts.

Finally:

$$
F_{e F a n}=\frac{\eta_{e F} K_{B L I} W_{e S h a f t}}{V}
$$

In Eq. (33), $\eta_{e F}$ just have to be replaced by the product $\eta_{e F} K_{B L I}$ to introduce the effect of BLI on overall consumption. 
Table 3 e-chain design versus installed electric power

\begin{tabular}{|c|c|c|c|c|c|c|c|c|c|c|}
\hline & unit & $0.05 \mathrm{MW}$ & $0.25 \mathrm{MW}$ & $0.5 \mathrm{MW}$ & $0.75 \mathrm{MW}$ & 1.MW & $1.25 \mathrm{MW}$ & $1.5 \mathrm{MW}$ & $1.75 \mathrm{MW}$ & 2.MW \\
\hline$L_{\text {Fan }}$ & $m$ & 1,05 & 1,43 & 1,76 & 2,02 & 2,25 & 2,44 & 2,62 & 2,79 & 2,94 \\
\hline$D_{F a n}$ & $m$ & 0.58 & 0.80 & 0.98 & 1.12 & 1.25 & 1.36 & 1.46 & 1.55 & 1.63 \\
\hline$D_{\text {Nozzle }}$ & $m$ & 0.26 & 0.50 & 0.68 & 0.80 & 0.91 & 1,0 & 1.08 & 1.16 & 1.23 \\
\hline$d V_{B L I} / V_{A i r}$ & - & 0.45 & 0.34 & 0.29 & 0.27 & 0.25 & 0.23 & 0.22 & 0.20 & 0.196 \\
\hline$K_{B L I}$ & - & 1.50 & 1.33 & 1.27 & 1.23 & 1.21 & 1.19 & 1.18 & 1.17 & 1.16 \\
\hline$K_{S F C}$ & - & 0.9985 & 0.996 & 0.994 & 0.993 & 0.992 & 0.992 & 0.992 & 0.992 & 0.993 \\
\hline $\begin{array}{c}e \text {-chain } \\
\text { mass }\end{array}$ & $k g$ & 31 & 154 & 308 & 463 & 617 & 771 & 925 & 1079 & 1233 \\
\hline
\end{tabular}

$$
S F C_{H}=\frac{S F C_{0}}{K_{C}+\left(1-K_{C}\right)\left(\frac{\eta_{e F} K_{B L I}}{\eta_{F}} \eta_{E} K_{W}+\left(1-K_{W}\right)\right)}
$$

It is to be noted that the product $\eta_{e F} K_{B L I}$ is no longer an efficiency, it can be higher than 1 because the limit of the studied system has been changed (the speed "seen" by the fan is different from $V_{A i r}$ ).

Table 3 summarizes the evolution of some important parameters when varying the mechanical power of the electric motor.

When shaft power varies from $50 \mathrm{~kW}$ to $2 \mathrm{MW}$, one can observe that:

1) Inlet velocity loss varies from about $45 \%$ to $20 \%$ of the free stream velocity.

2) The e-fan thrust is from about $50 \%$ to $15 \%$ higher than in free stream.

3) The SFC improves from about $0.15 \%$ to $0.8 \%$ with a plateau of maximum effect between $1 \mathrm{MW}$ and $1.75 \mathrm{MW}$.

Considering these first results, it seems that we may expect no more than about $1 \%$ benefit in SFC with this type of architecture but we must integrate all the other aspects and more especially weight. Thanks to the modelling principles described below, we have all bricks in hand to solve a complete design problem.

\section{Some results from design process}

The reference airplane is the Airplane 3 of Table 2 Presented values of fuel consumption and Cash Operating Cost have been computed on a 800NM mission. A first optimization has been done according to the same set of TLRs as Airplane 3 and the comparison with Airplane 3 is presented below. Additionally, some sensitivity studies have been done to experiment the behavior of the implementation of partial turbo-electric model into MARILib. The process presented in Fig. 6has been played for all the following trials. It is to be noticed that in order to accelerate the convergence of the optimization, handling quality modules have not been used for empennage sizing. Empennage sizes have been determined through constant volume coefficients.

\section{A. Optimization of a partial turboelectric}

As fuel consumption reduction is an objective when dealing with hybrid architecture, the block fuel on 800NM mission has been used as an optimization criterion for all following computations. The e-fan power has been set to 1 MW for a first attempt and the wing area and engine size have been optimized to minimize block fuel for both classical and hybrid configurations. The main results are presented in Table 4

At $1 \mathrm{MW}$ e-fan power, we can see that the overall benefit in term of block fuel is very marginal $(-0.16 \%)$. The next set of trials will try to look for the optimal e-fan power.

The present result can nevertheless be explained by the fact that the downsizing of the fan of the turbofans produces a benefit of $270 \mathrm{~kg}$, which does not compensate the additional $620 \mathrm{~kg}$ of the overall electric chain. Furthermore, the new 
Table 4 Comparison between classical and 1 MW hybrid aircraft

\begin{tabular}{|c|c|c|c|c|}
\hline & unit & Airplane 3 & Hybrid & $\begin{array}{l}\text { Relative } \\
\text { difference }\end{array}$ \\
\hline Capacity & seat & 150 & 150 & - \\
\hline Range & NM & 3000 & 3000 & - \\
\hline Cruise Mach & - & 0.78 & 0.78 & - \\
\hline Overall SLST & daN & 11460 & 11300 & $-1,4 \%$ \\
\hline Turbofan mass & $\mathrm{kg}$ & 7500 & 7230 & $-3,6 \%$ \\
\hline e-fan power & kW & - & $1 \mathrm{MW}$ & \\
\hline Electric chain mass & $\mathrm{kg}$ & - & 620 & \\
\hline Wing area & $\mathrm{m}^{2}$ & 151,9 & 152,9 & $+0,66 \%$ \\
\hline Span & $\mathrm{m}$ & 37 & 37,1 & $+0,27 \%$ \\
\hline Fuselage length & $\mathrm{m}$ & 37.2 & 37,2 & \\
\hline Fuselage width & $\mathrm{m}$ & 3.9 & 3,9 & \\
\hline MTOW & $\mathrm{kg}$ & 76840 & 77210 & $+0,48 \%$ \\
\hline MLW & $\mathrm{kg}$ & 67700 & 68130 & $+0,64 \%$ \\
\hline OWE & $\mathrm{kg}$ & 45270 & 45670 & $+0,88 \%$ \\
\hline MWE & $\mathrm{kg}$ & 40300 & 40710 & $+1,02 \%$ \\
\hline Cruise SFC & $\mathrm{Kg} / \mathrm{daN} / \mathrm{h}$ & 0.5399 & 0.5355 & $-0,81 \%$ \\
\hline Cruise L/D & - & 18.32 & 18,31 & $-0,22 \%$ \\
\hline TOFL & $\mathrm{m}$ & 1930 & 1970 & $+2,07 \%$ \\
\hline App Speed & Kt & 133,2 & 133,1 & $-0,08 \%$ \\
\hline OEl path & $\%$ & 2,0 & 1,8 & $-10 \%$ \\
\hline Vz Climb MCL & $\mathrm{ft} / \mathrm{min}$ & 470 & 470 & - \\
\hline Vz Climb MCR & $\mathrm{ft} / \mathrm{min}$ & 90 & 100 & $+11 \%$ \\
\hline TTC & $\min$ & 25 & 25 & - \\
\hline Block Fuel 800NM & $\mathrm{Kg}$ & 3701 & 3695 & $-0,16 \%$ \\
\hline COC 800NM & $\$ /$ trip & 9892 & 9891 & $-0,01 \%$ \\
\hline $\mathrm{CO} 2$ metric & $10^{-7} \mathrm{Kg} / \mathrm{km} / \mathrm{m}^{0.48}$ & 7774 & 7752 & $-0,28 \%$ \\
\hline
\end{tabular}


optimum requires an increase of the wing area by $1 \mathrm{~m}^{2}$, which results in an overall increase of about 400kg of the MWE. Finally, as the L/D in cruise remains roughly stable, the $0.8 \%$ benefit in SFC are vanished by the MWE increase.

This first result is a bit disappointing but up to now, the e-fan power has not been optimized. This is the objective of the next step of this short study.

\section{B. Effect of e-fan power}

The power of the e-fan electric motor has been varied from 50kW to 4MW. Only the graphics are presented on Fig. 24 but more extensive data are in the Table 5 . Table 6, and Table 7 presented in appendix. Graphics have been drawn for three criteria: Block fuel, Cash Operating Cost (COC), $\mathrm{CO}_{2}$ metric and three physical characteristics of the airplane: overall propulsion mass, cruise SFC and L/D. An optimal e-fan power of about $250 \mathrm{~kW}$ is clearly visible on the curves, sadly, the overall benefit in term of block fuel for instance is about $0.6 \%$. The lift to drag ratio experiments a small variation with a curious minimum at about $1.75 \mathrm{MW}$ which is due to the competing evolution of wetted area versus wing area but this variation is not the main ingredient of the global result. The specific fuel consumption shows a clear minimum at about $1.5 \mathrm{MW}$ but the benefit culminates at about $0.85 \%$ which is barely enough to compensate the increase of the propulsion system mass for low values of e-fan power. With the assumptions that have been taken, it seems that the presented hybrid configuration shows a margin benefit in the range of $1 \%$ in term of bloc fuel. Of course, at this stage, one cannot exclude the possibility of an over simplification or even a bug somewhere in the library.
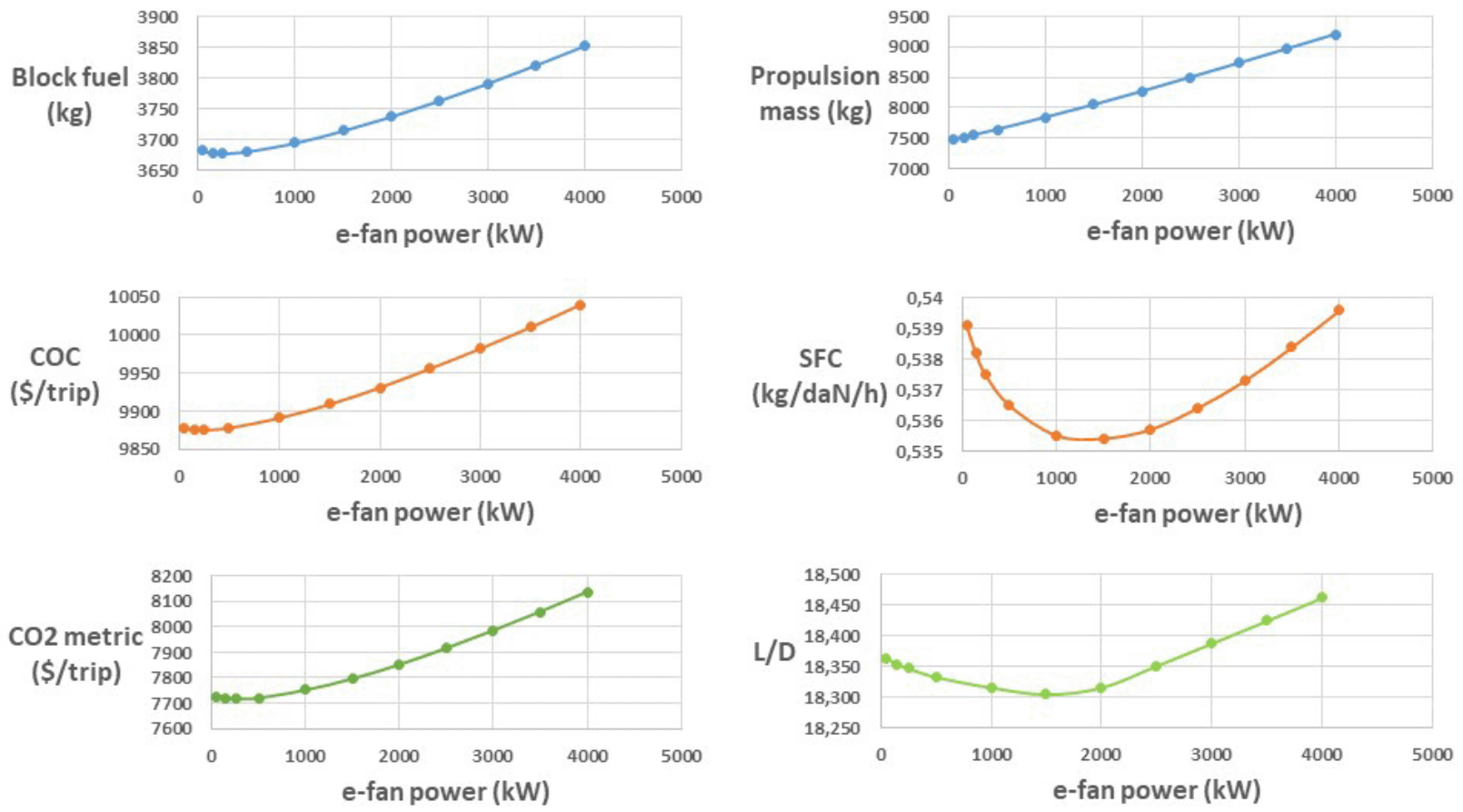

Fig. 24 Effect of e-fan power with basic assumptions

\section{Effect of electric chain efficiency}

For this test, electric chain efficiency has been increased from $90 \%$ to $95 \%$, which corresponds to a mean component efficiency of about $99 \%$ for the components of the electric chain. Installed electric power has been varied in the same range as previously. Results are presented in Fig.25.

The global behavior is similar to what has been obtained in the previous study but here the benefit in term of block fuel is obtained at about $500 \mathrm{~kW}$ and is raising $0.8 \%$. The main difference seems to come from the SFC which shows a benefit of about $1.5 \%$ for an e-fan power of about $3.5 \mathrm{MW}$. 

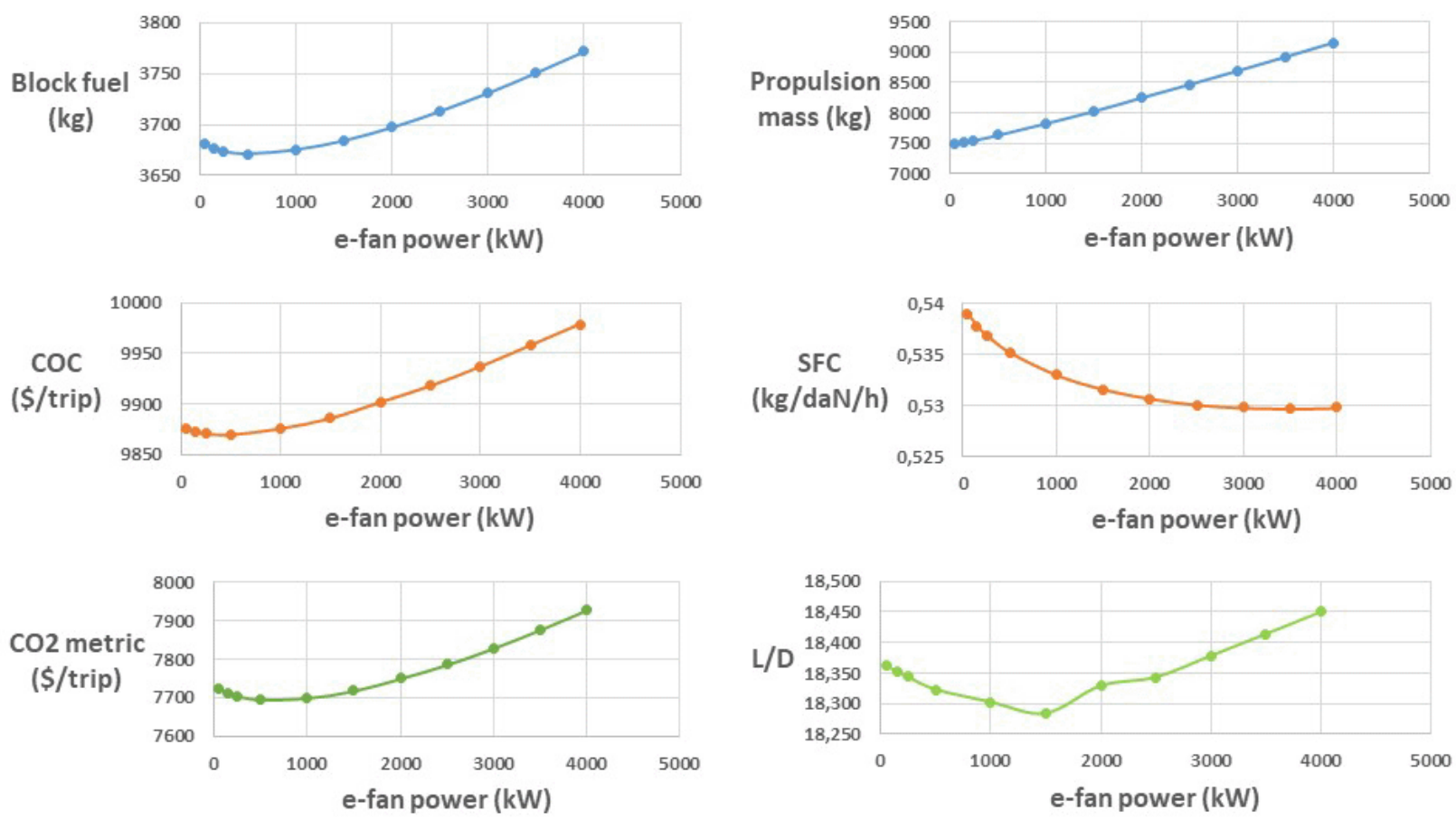

Fig. 25 Effect of e-fan power with electric chain efficiency at $95 \%$

\section{Electric chain power density}

For this last test, power density of all components of the electric chain have been doubled compared to those presented in paragraphs 5.1. 5.2. 5.3, which would be an achievable challenge, even if the e-chain mass for low e-fan power seems a bit optimistic. The results of this last test are presented on Fig. 26

In this case also, benefit of hybridization remains margin and only appears for limited electric power of about 1.5 MW. Maximum SFC benefit appears at 3.5 MW and is about 1.5\%. COC benefit is not significant and maximum fuel reduction is close to $1 \%$. 


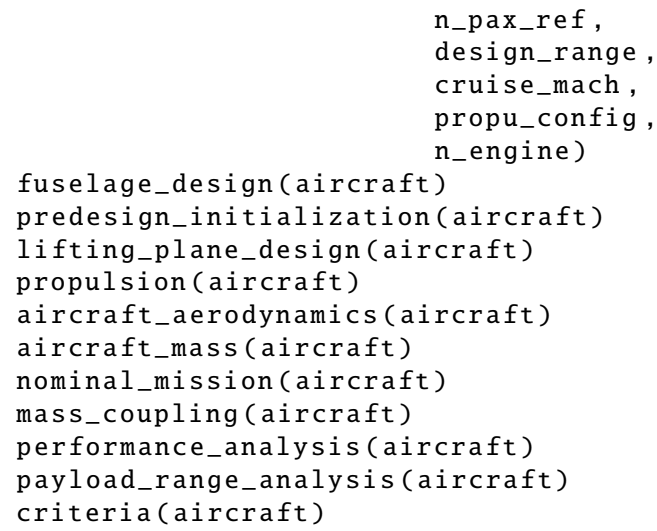

This sequence can be run as is, since all necessary inputs along it are computed by upper steps or initialized by dedicated functions. It is the only input required by to build the suitable GEMS wrapper around each function. Afterwards, an N2 diagram can be drawn in order to check the effective dependencies between the functions. If dependencies are correct, the approach allows to manage any design problem that can be built using the functions of the initial sequence according to a user selected solving process like IDF or MDF as illustrated in Fig. 27. Therefore, the OAD design problems can be addressed through the wide range of MDO formulations, optimization, DOE, surrogate models and coupling algorithms available in GEMS. 


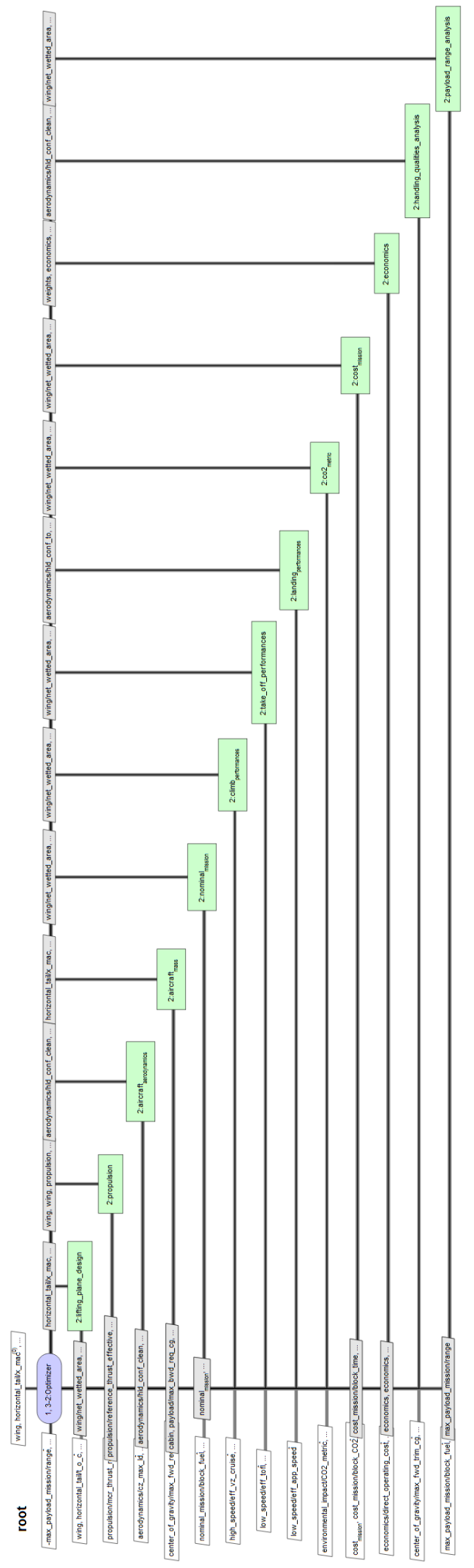

(a) IDF formulation

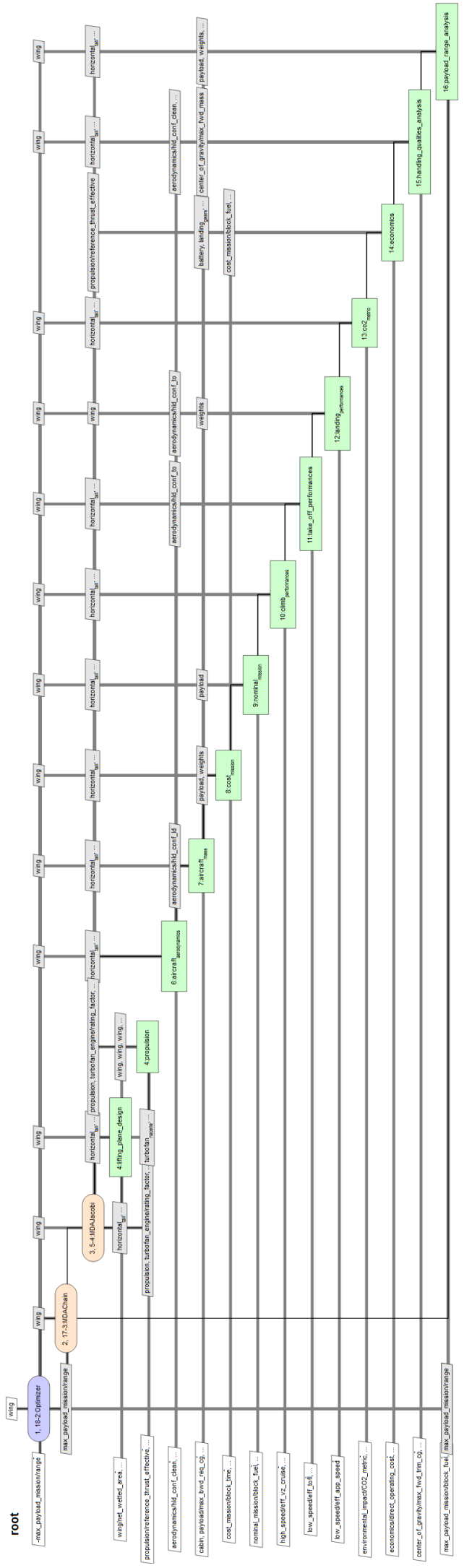

(b) MDF formulation

Fig. 27 Examples of MDF and IDS XDSM diagrams of GEMS processes generated from MARIlib functions 


\section{Conclusion}

This paper has introduced MARILib software (Multidisciplinary Airplane Research Integrated Library). The models in MARILib are globally much simpler than models that can be found in other aircraft conceptual design software but they revealed to be quite robust in finding the relevant order of magnitude of aircraft definition in a wide range of designs. The library can be used to experiment MDO strategies, generate consistent starting point for aircraft design studies and also be an easy to use playground for teaching activities in the field of conceptual aircraft design. For experienced users, MARILib can also be a laboratory to develop and experiment simple models as the partial turbo-electric with boundary layer ingestion which have been presented and couple them with an airplane design process. As a side effect, the propulsion hybridization introduces many new design parameters which makes more complex the overall design problem and give more opportunities to test MDO strategies. Finally, an automatic interfacing of MARILib with the GEMS MDO library has been illustrated. MARILib will be available as Open Source.

\section{Appendix}

More extensive results from effect of e-fan power analysis

Table 5 Effect of e-fan power with electric chain efficiency at $95 \%$ - (a)

\begin{tabular}{|c|c|c|c|c|c|c|c|c|c|c|c|c|c|}
\hline e-fan power & MW & - & 0.05 & 0.15 & 0,25 & 0,5 & 1,0 & 1,5 & 2,0 & 2,5 & 3,0 & 3,5 & 4,0 \\
\hline e-chain mass & $\mathrm{kg}$ & - & 31 & 93 & 154 & 308 & 617 & 925 & 1233 & 1542 & 1850 & 2158 & 2467 \\
\hline $\begin{array}{c}\text { Effective ref } \\
\text { thrust }\end{array}$ & daN & 11460 & 11401 & 11382 & 11367 & 11341 & 11307 & 11286 & 11285 & 11306 & 11330 & 11359 & 11391 \\
\hline $\begin{array}{c}\text { Turbofan } \\
\text { nacelle mass }\end{array}$ & $\mathrm{kg}$ & 7500 & 7459 & 7428 & 7400 & 7339 & 7229 & 7128 & 7038 & 6959 & 6883 & 6810 & 6739 \\
\hline $\begin{array}{l}\text { Propulsion } \\
\text { mass }\end{array}$ & $\mathrm{kg}$ & 7500 & 7490 & 7521 & 7554 & 7647 & 7846 & 8053 & 8271 & 8501 & 8733 & 8968 & 9206 \\
\hline Wing area & $\mathrm{m}^{2}$ & 151,9 & 152 & 152 & 152,1 & 152,3 & 153 & 153,8 & 155,3 & 157,7 & 160,1 & 162,6 & 165,1 \\
\hline MTow & $\mathrm{kg}$ & 76840 & 76669 & 76686 & 76724 & 76858 & 77211 & 77618 & 78121 & 78722 & 79344 & 79981 & 80634 \\
\hline MLW & $\mathrm{kg}$ & 67700 & 67615 & 67647 & 67692 & 67823 & 68133 & 68470 & 68893 & 69410 & 69937 & 70473 & 71017 \\
\hline OWE & $\mathrm{kg}$ & 45270 & 45191 & 45222 & 45264 & 45386 & 45675 & 45991 & 46386 & 46869 & 47362 & 47863 & 48371 \\
\hline MWE & $\mathrm{kg}$ & 40300 & 40227 & 40258 & 40300 & 40422 & 40711 & 41027 & 41422 & 41905 & 42398 & 42899 & 43407 \\
\hline Cruise SFC & $\mathrm{kg} / \mathrm{daN} / \mathrm{h}$ & 0.5399 & 0,5391 & 0,5382 & 0,5375 & 0,5365 & 0,5355 & 0,5354 & 0,5357 & 0,5364 & 0,5373 & 0,5384 & 0,5396 \\
\hline Cruise L/D & - & 18.32 & 18,364 & 18,354 & 18,347 & 18,333 & 18,316 & 18,305 & 18,316 & 18,352 & 18,388 & 18,425 & 18,462 \\
\hline TOFL & m & 1930 & 1934 & 1939 & 1944 & 1954 & 1973 & 1991 & 2000 & 2000 & 2000 & 2000 & 2000 \\
\hline App speed & kt & 133,2 & 133 & 133,1 & 133,1 & 133,1 & 133,1 & 133,1 & 132,9 & 132,3 & 131,8 & 131,3 & 130,8 \\
\hline $\begin{array}{c}\text { Vz TOC } \\
\text { MCL rating }\end{array}$ & $\mathrm{ft} / \mathrm{min}$ & 470 & 469 & 469 & 470 & 471 & 474 & 477 & 479 & 482 & 485 & 487 & 490 \\
\hline Time to climb & $\min$ & 25 & 25 & 25 & 25 & 25 & 25 & 25 & 25 & 25 & 25 & 25 & 25 \\
\hline Block fuel & $\mathrm{kg}$ & 3701 & 3682 & 3679 & 3678 & 3681 & 3695 & 3715 & 3738 & 3764 & 3792 & 3822 & 3853 \\
\hline $\operatorname{coc}$ & $\$ /$ trip & 9892 & 9877 & 9875 & 9875 & 9878 & 9891 & 9909 & 9931 & 9956 & 9982 & 10010 & 10040 \\
\hline $\mathrm{CO}_{2}$ metric & $\begin{array}{c}10 \mathrm{e}-4 \mathrm{~kg} \\
/ \mathrm{km} / \mathrm{m}^{0.48}\end{array}$ & 7774 & 7727 & 7719 & 7717 & 7721 & 7752 & 7796 & 7851 & 7915 & 7984 & 8057 & 8134 \\
\hline
\end{tabular}


Table 6 Effect of e-fan power with electric chain efficiency at 95\% - (b)

\begin{tabular}{|c|c|c|c|c|c|c|c|c|c|c|c|c|c|}
\hline e-fan power & MW & - & 0.05 & 0.15 & 0,25 & 0,5 & 1,0 & 1,5 & 2,0 & 2,5 & 3,0 & 3,5 & 4,0 \\
\hline e-chain mass & kg & - & 31 & 93 & 154 & 308 & 617 & 925 & 1233 & 1542 & 1850 & 2158 & 2467 \\
\hline $\begin{array}{c}\text { Effective ref } \\
\text { thrust }\end{array}$ & daN & 11460 & 11400 & 11377 & 11359 & 11322 & 11273 & 11235 & 11245 & 11238 & 11250 & 11265 & 11284 \\
\hline $\begin{array}{c}\text { Turbofan } \\
\text { nacelle mass }\end{array}$ & kg & 7500 & 7458 & 7425 & 7396 & 7329 & 7212 & 7103 & 7017 & 6925 & 6842 & 6762 & 6685 \\
\hline $\begin{array}{c}\text { Propulsion } \\
\text { mass }\end{array}$ & kg & 7500 & 7489 & 7518 & 7550 & 7637 & 7829 & 8028 & 8250 & 8467 & 8692 & 8920 & 9152 \\
\hline Wing area & $\mathrm{m}^{2}$ & 151,9 & 152 & 151,9 & 151,9 & 151,9 & 152,4 & 152,8 & 155,5 & 157,1 & 159,4 & 161,8 & 164,2 \\
\hline мтоW & $\mathrm{kg}$ & 76840 & 76659 & 76658 & 76677 & 76754 & 77025 & 77337 & 77881 & 78340 & 78886 & 79448 & 80025 \\
\hline MLW & $\mathrm{kg}$ & 67700 & 67609 & 67633 & 67668 & 67765 & 68040 & 68328 & 68852 & 69269 & 69768 & 70277 & 70793 \\
\hline OWE & kg & 45270 & 45186 & 45209 & 45242 & 45332 & 45589 & 45858 & 46348 & 46737 & 47204 & 47679 & 48162 \\
\hline MWE & $\mathrm{kg}$ & 40300 & 40222 & 40245 & 40278 & 40368 & 40625 & 40894 & 41384 & 41773 & 42240 & 42715 & 43198 \\
\hline Cruise SFC & $\mathrm{kg} / \mathrm{daN} / \mathrm{h}$ & 0.5399 & 0,539 & 0,5378 & 0,5369 & 0,5352 & 0,533 & 0,5316 & 0,5307 & 0,5301 & 0,5298 & 0,5297 & 0,5298 \\
\hline Cruise L/D & - & 18.32 & 18,363 & 18,352 & 18,343 & 18,323 & 18,302 & 18,283 & 18,329 & 18,343 & 18,378 & 18,414 & 18,450 \\
\hline TOFL & $m$ & 1930 & 1934 & 1940 & 1945 & 1957 & 1977 & 1997 & 1992 & 2000 & 2000 & 2000 & 2000 \\
\hline App speed & kt & 133,2 & 133 & 133,1 & 133,1 & 133,3 & 133,3 & 133,4 & 132,7 & 132,5 & 132 & 131,5 & 131 \\
\hline $\begin{array}{c}\text { Vz TOC } \\
\text { MCL rating }\end{array}$ & $\mathrm{ft} / \mathrm{min}$ & 470 & 469 & 469 & 470 & 471 & 474 & 476 & 479 & 482 & 484 & 487 & 489 \\
\hline Time to climb & $\min$ & 25 & 25 & 25 & 25 & 25 & 25 & 25 & 25 & 25 & 25 & 25 & 25 \\
\hline Block fuel & $\mathrm{kg}$ & 3701 & 3681 & 3676 & 3673 & 3671 & 3675 & 3684 & 3697 & 3713 & 3731 & 3751 & 3772 \\
\hline $\operatorname{coc}$ & $\$ /$ trip & 9892 & 9877 & 9875 & 9875 & 9878 & 9891 & 9909 & 9931 & 9956 & 9982 & 10010 & 10040 \\
\hline $\mathrm{CO}_{2}$ metric & $\begin{array}{c}10 \mathrm{e}-4 \mathrm{~kg} \\
/ \mathrm{km} / \mathrm{m}^{0.48}\end{array}$ & 7774 & 7727 & 7719 & 7717 & 7721 & 7752 & 7796 & 7851 & 7915 & 7984 & 8057 & 8134 \\
\hline
\end{tabular}

Table 7 Effect of e-fan power with electric chain efficiency at 95\% - (c)

\begin{tabular}{|c|c|c|c|c|c|c|c|c|c|c|c|c|c|}
\hline e-fan power & MW & - & 0.05 & 0.15 & 0,25 & 0,5 & 1,0 & 1,5 & 2,0 & 2,5 & 3,0 & 3,5 & 4,0 \\
\hline e-chain mass & $\mathrm{kg}$ & - & 15 & 46 & 77 & 154 & 308 & 463 & 617 & 771 & 925 & 1079 & 1233 \\
\hline $\begin{array}{c}\text { Effective ref } \\
\text { thrust }\end{array}$ & daN & 11460 & 11397 & 11368 & 11344 & 11293 & 11212 & 11144 & 11083 & 11049 & 11022 & 10998 & 10978 \\
\hline $\begin{array}{c}\text { Turbofan } \\
\text { nacelle mass }\end{array}$ & $\mathrm{kg}$ & 7500 & 7457 & 7421 & 7390 & 7317 & 7185 & 7063 & 6946 & 6842 & 6743 & 6646 & 6551 \\
\hline $\begin{array}{c}\text { Propulsion } \\
\text { mass }\end{array}$ & $\mathrm{kg}$ & 7500 & 7489 & 7518 & 7550 & 7637 & 7829 & 8028 & 8250 & 8467 & 8692 & 8920 & 9152 \\
\hline Wing area & $\mathrm{m}^{2}$ & 151,9 & 152 & 151,8 & 151,7 & 151,6 & 151,7 & 151,8 & 152 & 153,4 & 155 & 156,6 & 158,3 \\
\hline мтоW & $\mathrm{kg}$ & 76840 & 76632 & 76573 & 76536 & 76484 & 76461 & 76493 & 76559 & 76752 & 76975 & 77214 & 77467 \\
\hline MLW & $\mathrm{kg}$ & 67700 & 67586 & 67560 & 67546 & 67534 & 67552 & 67599 & 67664 & 67854 & 68067 & 68288 & 68517 \\
\hline OWE & $\mathrm{kg}$ & 45270 & 45164 & 45141 & 45127 & 45116 & 45132 & 45176 & 45237 & 45415 & 45614 & 45821 & 46034 \\
\hline MWE & $\mathrm{kg}$ & 40300 & 40200 & 40177 & 40163 & 40152 & 40168 & 40212 & 40273 & 40451 & 40650 & 40857 & 41070 \\
\hline Cruise SFC & $\mathrm{kg} / \mathrm{daN} / \mathrm{h}$ & 0.5399 & 0,539 & 0,5378 & 0,5369 & 0,5352 & 0,5329 & 0,5315 & 0,5305 & 0,5299 & 0,5296 & 0,5295 & 0,5295 \\
\hline Cruise L/D & - & 18.32 & 18,362 & 18,350 & 18,339 & 18,318 & 18,285 & 18,259 & 18,237 & 18,249 & 18,266 & 18,285 & 18,305 \\
\hline TOFL & $\mathrm{m}$ & 1930 & 1934 & 1938 & 1943 & 1952 & 1968 & 1984 & 1998 & 2000 & 2000 & 2000 & 2000 \\
\hline App speed & kt & 133,2 & 133 & 133,1 & 133,1 & 133,1 & 133,1 & 133,1 & 133,1 & 132,7 & 132,2 & 131,7 & 131,3 \\
\hline $\begin{array}{c}\text { Vz TOC } \\
\text { MCL rating }\end{array}$ & $\mathrm{ft} / \mathrm{min}$ & 470 & 469 & 469 & 469 & 471 & 473 & 475 & 477 & 479 & 481 & 483 & 485 \\
\hline Time to climb & $\min$ & 25 & 25 & 25 & 25 & 25 & 25 & 25 & 25 & 25 & 25 & 25 & 25 \\
\hline Block fuel & $\mathrm{kg}$ & 3701 & 3679 & 3672 & 3667 & 3659 & 3651 & 3649 & 3650 & 3654 & 3660 & 3668 & 3677 \\
\hline $\operatorname{coc}$ & $\$ /$ trip & 9892 & 9875 & 9869 & 9865 & 9859 & 9853 & 9852 & 9854 & 9859 & 9866 & 9874 & 9884 \\
\hline $\mathrm{CO}_{2}$ metric & $\begin{array}{l}10 \mathrm{e}-4 \mathrm{~kg} \\
/ \mathrm{km} / \mathrm{m}^{0.48}\end{array}$ & 7774 & 7722 & 7705 & 7693 & 7674 & 7656 & 7652 & 7657 & 7672 & 7691 & 7715 & 7743 \\
\hline
\end{tabular}




\section{List of airplane descriptive variables in MARILib}

Longitudinal positions are taken from nose cone.

Orders of magnitude are given as powers of ten.

The units presented are usual units.

\begin{tabular}{|l|l|l|l|}
\hline Name & Unit & $\begin{array}{l}\text { Order of } \\
\text { magni- } \\
\text { tude }\end{array}$ & Description \\
\hline design_driver & NM & 3 & Range of design mission \\
\hline design_range & mach & -1 & Nominal cruise Mach number \\
\hline cruise_mach & $\mathrm{ft}$ & 4 & Reference cruise altitude (generally 35000ft) \\
\hline ref_cruise_altp & $\mathrm{ft}$ & 4 & Top of climb altitude (may be lower or equal to reference cruise altitude) \\
\hline top_of_climb_altp
\end{tabular}

\begin{tabular}{|l|l|l|l|}
\hline Name & Unit & $\begin{array}{l}\text { Order of } \\
\text { magni- } \\
\text { tude }\end{array}$ & Description \\
\hline low_speed & \multicolumn{3}{|l|}{} \\
\hline disa_tofl & degK & 1 & Temperature shift for take off field length computation \\
\hline altp_tofl & ft & 4 & Altitude for take off field length computation \\
\hline kvs1g_tofl & no_dim & 0 & Minimum allowed stall speed margin at take off \\
\hline req_tofl & m & 3 & Maximum take off field length at MTOW and given conditions \\
\hline eff_tofl & m & 3 & Effective take off field length at MTOW and given condition \\
\hline eff_kvs1g & no_dim & 0 & Effective stall speed margin at take off \\
\hline seg2_path & no_dim & 0 & Air path at 35 ft at take off \\
\hline limitation & int & 0 & Active limitation \\
\hline disa_app_speed & degK & 1 & Temperature shift for approach speed computation \\
\hline altp_app_speed & $\mathrm{ft}$ & 3 & Altitude for approach speed computation \\
\hline kvs1g_app_speed & no_dim & 0 & Minimum allowed stall speed margin at landing \\
\hline req_app_speed & $\mathrm{kt}$ & 2 & Maximum approach speed at MLW and given conditions \\
\hline eff_app_speed & $\mathrm{kt}$ & 2 & Effective approach speed at MLW and given condition \\
\hline disa_oei & degK & 1 & Temperature shift for One Engine Inoperative (OEI) \\
\hline req_oei_altp & $\mathrm{ft}$ & 4 & Required One Engine Inoperative (OEI) minimum altitude \\
\hline req_oei_path & $\%$ & 0 & Required minimum slope OEI at 95\%MTOW, required altitude and MCN rating \\
\hline eff_oei_path & $\%$ & 0 & Effective slope OEI at 95\%MTOW, required altitude and MCN rating \\
\hline oei_best_speed & $\mathrm{kt}$ & 2 & Calibrated Air Speed (CAS) at which slope is maximum in given conditions \\
\hline
\end{tabular}




\begin{tabular}{|l|l|l|l|}
\hline Name & Unit & $\begin{array}{l}\text { Order of } \\
\text { magni- } \\
\text { tude }\end{array}$ & Description \\
\hline high_speed & \multicolumn{3}{|l|}{} \\
\hline disa_climb & degK & 1 & Temperature shift for Maximum climb speed computation \\
\hline req_vz_climb & $\mathrm{ft} / \mathrm{min}$ & 2 & $\begin{array}{l}\text { Required minimum climb speed at 97\%MTOW, nominal initial cruise altitude } \\
\text { and MCL rating }\end{array}$ \\
\hline eff_vz_climb & $\mathrm{ft} / \mathrm{min}$ & 2 & $\begin{array}{l}\text { Effective climb speed at 97\%MTOW, nominal initial cruise altitude and MCL } \\
\text { rating }\end{array}$ \\
\hline req_vz_cruise & $\mathrm{ft} / \mathrm{min}$ & 2 & $\begin{array}{l}\text { Required minimum climb speed at 97\%MTOW, nominal initial cruise altitude } \\
\text { and MCR rating }\end{array}$ \\
\hline eff_vz_cruise & $\mathrm{ft} / \mathrm{min}$ & 2 & $\begin{array}{l}\text { Effective climb speed at 97\%MTOW, nominal initial cruise altitude and MCR } \\
\text { rating }\end{array}$ \\
\hline req_toc_altp & $\mathrm{ft}$ & 4 & Targeted Top Of Climb Altitude (TOC) for Time To Climb (TTC) computation \\
\hline cas1_ttc & $\mathrm{kt}$ & 2 & Calibrated Air Speed (CAS) below 10000ft for TTC computation \\
\hline cas2_ttc & $\mathrm{kt}$ & 2 & Calibrated Air Speed (CAS) above 10000ft for TTC computation \\
\hline req_ttc & $\mathrm{min}$ & 1 & Required maximum Time To Climb \\
\hline eff_ttc & $\mathrm{min}$ & 1 & Effective Time To Climb \\
\hline cruise_sfc & $\mathrm{kg} / \mathrm{daN} / \mathrm{h}$ & 0 & Specific fuel consumption in cruise \\
\hline cruise_lod & $\mathrm{no}$ nodim & 1 & Lift over drag ratio in cruise \\
\hline
\end{tabular}

\begin{tabular}{|l|l|l|l|}
\hline Name & Unit & $\begin{array}{l}\text { Order of } \\
\text { magni- } \\
\text { tude }\end{array}$ & Description \\
\hline \multicolumn{3}{|l|}{ max_payload_mission } \\
\hline range & $\mathrm{NM}$ & 3 & Range of the max payload mission \\
\hline payload & $\mathrm{kg}$ & 4 & Payload of the max payload mission \\
\hline tow & $\mathrm{kg}$ & 4 & Take off weight of the max payload mission \\
\hline total_fuel & $\mathrm{kg}$ & 4 & Total fuel of the max payload mission \\
\hline block_fuel & $\mathrm{kg}$ & 4 & Block fuel of the max payload mission \\
\hline block_time & $\mathrm{h}$ & 1 & Block time of the max payload mission \\
\hline
\end{tabular}

\begin{tabular}{|l|l|l|l|}
\hline Name & Unit & $\begin{array}{l}\text { Order of } \\
\text { magni- } \\
\text { tude }\end{array}$ & Description \\
\hline \multicolumn{2}{|l|}{} \\
\hline nominal_mission & $\mathrm{NM}$ & 3 & Range of the nominal mission \\
\hline range & $\mathrm{kg}$ & 4 & Payload of the nominal mission \\
\hline payload & $\mathrm{kg}$ & 4 & Take off weight of the nominal mission \\
\hline tow & $\mathrm{kg}$ & 4 & Total fuel of the nominal mission \\
\hline total_fuel & $\mathrm{kg}$ & 4 & Block fuel of the nominal mission \\
\hline block_fuel & $\mathrm{h}$ & 1 & Block time of the nominal mission \\
\hline block_time &
\end{tabular}




\begin{tabular}{|l|l|l|l|}
\hline Name & Unit & $\begin{array}{l}\text { Order of } \\
\text { magni- } \\
\text { tude }\end{array}$ & Description \\
\hline max_fuel_mission \\
\hline range & $\mathrm{NM}$ & 3 & Range of the max fuel mission \\
\hline payload & $\mathrm{kg}$ & 4 & Payload of the max fuel mission \\
\hline tow & $\mathrm{kg}$ & 4 & Take off weight of the max fuel mission \\
\hline total_fuel & $\mathrm{kg}$ & 4 & Total fuel of the max fuel mission \\
\hline block_fuel & $\mathrm{kg}$ & 4 & Block fuel of the max fuel mission \\
\hline block_time & $\mathrm{h}$ & 1 & Block time of the max fuel mission \\
\hline
\end{tabular}

\begin{tabular}{|l|l|l|l|}
\hline Name & Unit & $\begin{array}{l}\text { Order of } \\
\text { magni- } \\
\text { tude }\end{array}$ & Description \\
\hline \multicolumn{2}{|l|}{ zero_payload_mission } \\
\hline range & $\mathrm{NM}$ & 3 & Range of the zero payload mission \\
\hline tow & $\mathrm{kg}$ & 4 & Take off weight of the zero payload mission \\
\hline total_fuel & $\mathrm{kg}$ & 4 & Total fuel of the zero payload mission \\
\hline block_fuel & $\mathrm{kg}$ & 4 & Block fuel of the zero payload mission \\
\hline block_time & $\mathrm{h}$ & 1 & Block time of the zero payload mission \\
\hline
\end{tabular}

\begin{tabular}{|l|l|l|l|}
\hline Name & Unit & $\begin{array}{l}\text { Order of } \\
\text { magni- } \\
\text { tude }\end{array}$ & Description \\
\hline \multicolumn{4}{|l|}{ cost_mission } \\
\hline disa & degK & 1 & Temperature shift for cost evaluation mission computation \\
\hline range & $\mathrm{NM}$ & 3 & Range of cost evaluation mission \\
\hline payload & $\mathrm{kg}$ & 4 & Payload of the max cost mission \\
\hline tow & $\mathrm{kg}$ & 4 & Take off weight of the max cost mission \\
\hline total_fuel & $\mathrm{kg}$ & 4 & Total fuel of the max cost mission \\
\hline block_fuel & $\mathrm{kg}$ & 4 & Block fuel of the max cost mission \\
\hline block_time & $\mathrm{h}$ & 1 & Block time of the max cost mission \\
\hline block_CO2 & $\mathrm{kg}$ & 4 & Mass of carbon dioxide emitted during the mission \\
\hline
\end{tabular}




\begin{tabular}{|c|c|c|c|}
\hline Name & Unit & $\begin{array}{l}\text { Order of } \\
\text { magni- } \\
\text { tude }\end{array}$ & Description \\
\hline \multicolumn{4}{|l|}{ economics } \\
\hline gear_price & M\$ & 1 & Price of landing gears \\
\hline engine_price & M\$ & 1 & Price of one engine \\
\hline battery_price & $\$ / \mathrm{kg}$ & 1 & Mass price of battery (if any) \\
\hline airplane_price & M\$ & 1 & Price of the airplane \\
\hline fuel_price & \$/gal & 1 & Fuel price \\
\hline labor_cost & $\$ / \mathrm{h}$ & 1 & Labor cost \\
\hline irp & year & 1 & Interest recovery period \\
\hline period & year & 1 & Utilisation period \\
\hline interest_rate & $\%$ & 1 & Interest rate \\
\hline utilisation & int & 3 & Number of flights per year \\
\hline cockpit_crew_cost & $\$ /$ trip & 3 & Cockpit crew cost \\
\hline cabin_crew_cost & $\$ /$ trip & 3 & Cabin crew cost \\
\hline fuel_cost & $\$ /$ trip & 3 & Fuel cost \\
\hline landing_fees & $\$ /$ trip & 3 & Landing fees \\
\hline navigation_fees & $\$ /$ trip & 3 & Navigation fees \\
\hline catering_cost & $\$ /$ trip & 3 & Catering cost \\
\hline pax_handling_cost & $\$ /$ trip & 3 & Pax handling cost \\
\hline ramp_handling_cost & \$/trip & 3 & Ramp handling cost \\
\hline standard_operating_cost & $\$ /$ trip & 4 & Standard operating cost \\
\hline cash_operating_cast & $\$ /$ trip & 4 & Cash operating cost \\
\hline total_investment & $\$ /$ trip & 6 & Total investment \\
\hline insurance & $\$ /$ trip & 6 & Inssurance \\
\hline depreciation & $\$ /$ trip & 5 & Depreciation \\
\hline direct_operating_cost & $\$ /$ trip & 6 & Direct operating cost \\
\hline
\end{tabular}

\begin{tabular}{|l|l|l|l|}
\hline & Unit & $\begin{array}{l}\text { Order of } \\
\text { magni- } \\
\text { tude }\end{array}$ & Description \\
\hline environmental_impact & \multicolumn{3}{|l|}{} \\
\hline rgf & $\mathrm{m}^{2}$ & 2 & Reference Geometric Factor, close to the cabin floor pressurized area \\
\hline CO2_metric & $\mathrm{kg} / \mathrm{km} / \mathrm{m}^{0.48}$ & -4 & Fuel efficiency metric \\
\hline CO2_index & $\mathrm{g} / \mathrm{kg}$ & 3 & Mass of carbon dioxid emited per kilogram of fuel \\
\hline H2O_index & $\mathrm{g} / \mathrm{kg}$ & 3 & Mass of water emitted per kilogram of fuel \\
\hline SO2_index & $\mathrm{g} / \mathrm{kg}$ & 0 & Mass of sulfur dioxid emitted per kilogram of fuel \\
\hline NOx_index & $\mathrm{g} / \mathrm{kg}$ & 0 & Mass of nitrogen dioxid emitted per kilogram of fuel \\
\hline CO_index & $\mathrm{g} / \mathrm{kg}$ & 0 & Mass of carbon monoxid emitted per kilogram of fuel \\
\hline HC_index & $\mathrm{g} / \mathrm{kg}$ & 0 & Mass of unburnt hydrocarbon emitted per kilogram of fuel \\
\hline Sulfuric_acid_index & $\mathrm{g} / \mathrm{kg}$ & 0 & Mass of sulfuric acid emitted per kilogram of fuel \\
\hline nitrous_acid_index & $\mathrm{g} / \mathrm{kg}$ & 0 & Mass of nitrous acid emitted per kilogram of fuel \\
\hline nitric_acid_index & $\mathrm{g} / \mathrm{kg}$ & 0 & Mass of nitric acid emitted per kilogram of fuel \\
\hline soot_index & int & 12 & Number of soot particle emitted per kilogram of fuel \\
\hline
\end{tabular}




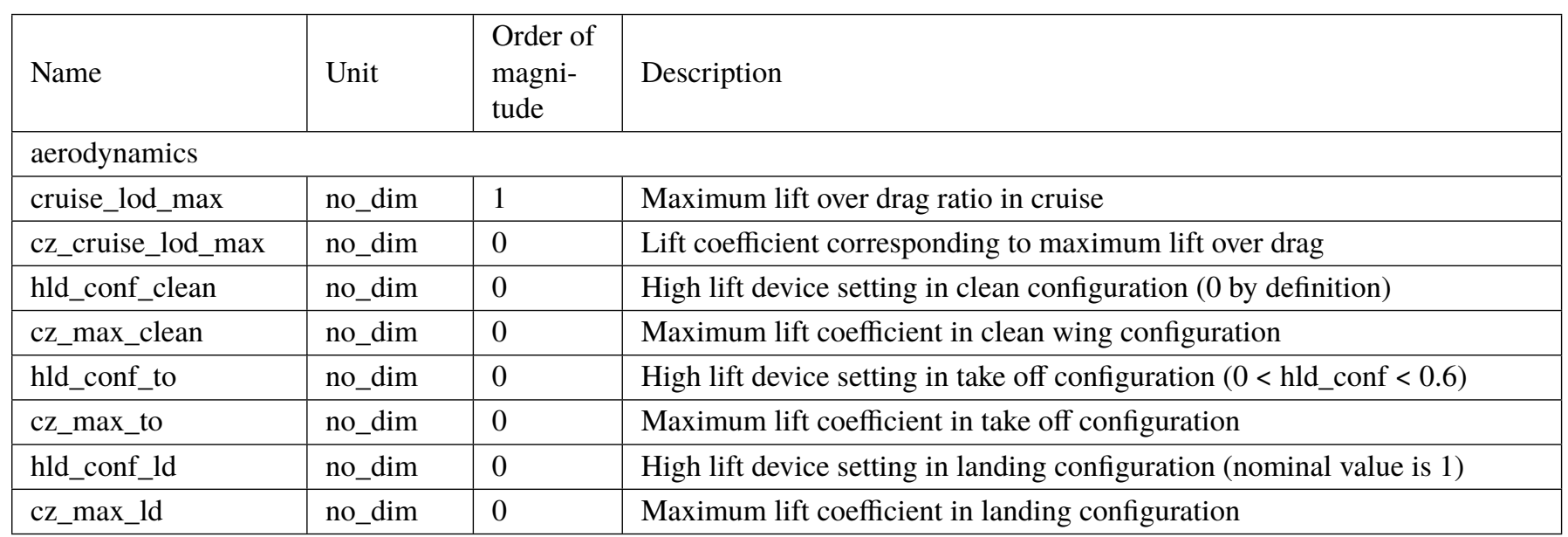

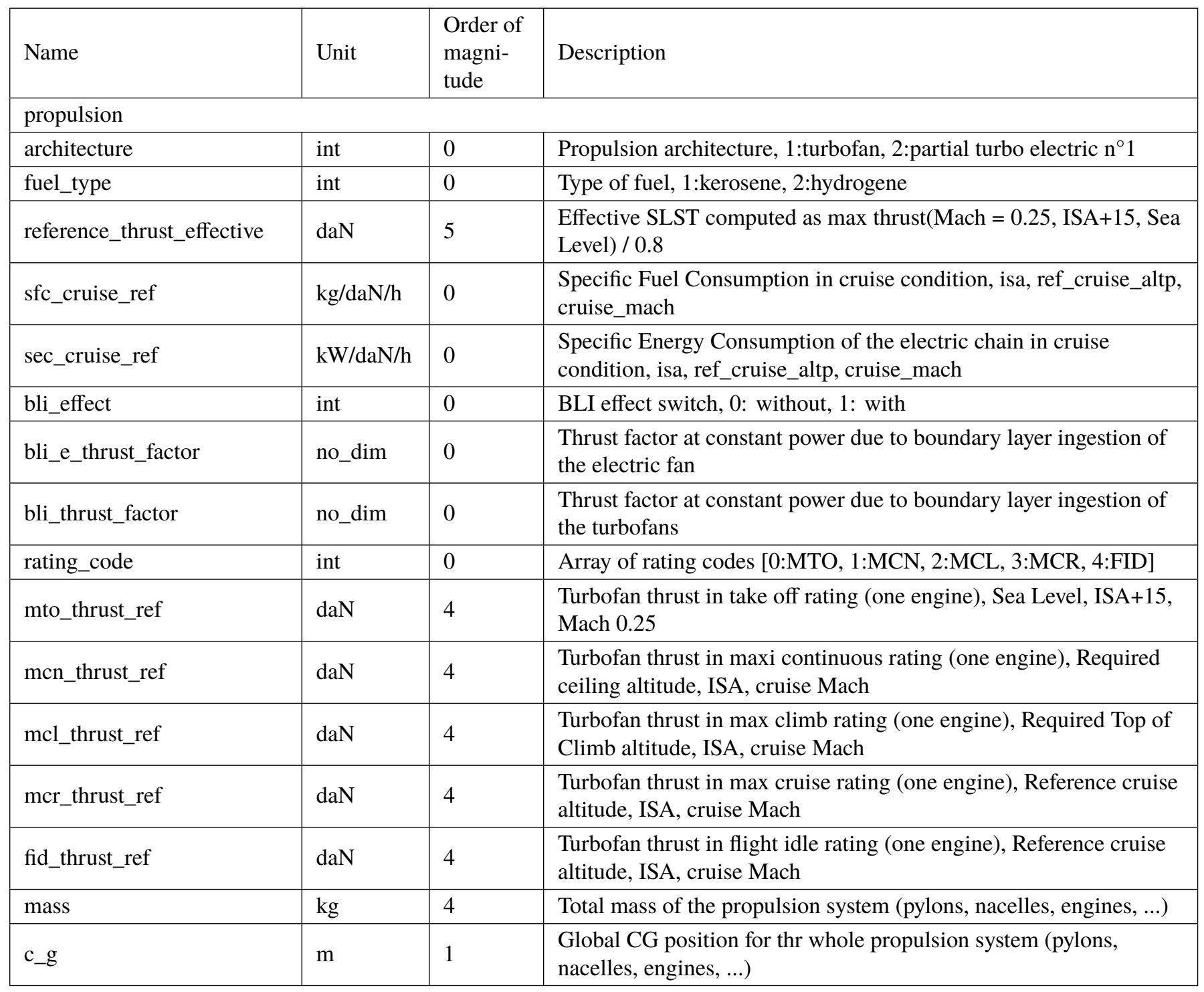




\begin{tabular}{|l|l|l|l|}
\hline Name & Unit & $\begin{array}{l}\text { Order of } \\
\text { magni- } \\
\text { tude }\end{array}$ & Description \\
\hline weights & $\mathrm{kg}$ & 4 & Manufacturer Weight Empty \\
\hline mwe & $\mathrm{kg}$ & 4 & Operating Weight Empty (= mwe + m_op_item + m_cont_pallet) \\
\hline owe & $\mathrm{kg}$ & 4 & Maximum Zero Fuel Weight (= owe + n_pax_ref.m_pax_max) \\
\hline mzfw & $\mathrm{kg}$ & 4 & $\begin{array}{l}\text { Maximum Landing Weight (close or equal to 1.07 mzfw except for small } \\
\text { aircraft where mlw = mtow) }\end{array}$ \\
\hline mlw & $\mathrm{kg}$ & 4 & Maximum Take Off Weight \\
\hline mtow & $\mathrm{kg}$ & 4 & Maximum Fuel Weight \\
\hline mfw & & &
\end{tabular}

\begin{tabular}{|l|l|l|l|}
\hline Name & Unit & $\begin{array}{l}\text { Order of } \\
\text { magni- } \\
\text { tude }\end{array}$ & Description \\
\hline \multicolumn{3}{|l|}{ center_of_gravity } \\
\hline mwe & $\mathrm{m}$ & 1 & Longitudinal position of MWE CG \\
\hline owe & $\mathrm{m}$ & 1 & Longitudinal position of OWE CG \\
\hline max_fwd_mass & $\mathrm{kg}$ & 2 & Aircraft mass at maximum forward CG \\
\hline max_fwd_req_cg & $\mathrm{m}$ & 1 & Required maximum forward CG \\
\hline max_fwd_trim_cg & $\mathrm{m}$ & 1 & Maximum trimmable forward CG \\
\hline max_bwd_mass & $\mathrm{kg}$ & 2 & Aircraft mass at maximum backward CG \\
\hline max_bwd_req_cg & $\mathrm{m}$ & 1 & Required maximum backward CG \\
\hline max_bwd_stab_cg & $\mathrm{m}$ & 1 & Maximum backward CG \\
\hline
\end{tabular}

\begin{tabular}{|l|l|l|l|}
\hline Name & Unit & $\begin{array}{l}\text { Order of } \\
\text { magni- } \\
\text { tude }\end{array}$ & Description \\
\hline cabin & int & 2 & Reference Number of passengers (most often 2 class layout) \\
\hline n_pax_ref & int & 0 & Number of aisle in economic section \\
\hline n_aisle & int & 0 & Number of seats in a row in economic section \\
\hline n_pax_front & $\mathrm{m}$ & 0 & Distance between aircraft nose and cabin forward limit \\
\hline fwd_limit & $\mathrm{m}$ & 0 & Maximum width of the cabin (not floor width) \\
\hline width & $\mathrm{m}$ & 1 & Total length of the cabin \\
\hline length & $\mathrm{m}^{2}$ & 2 & Area of the cabin taking into account its maximum width (not real floor area) \\
\hline floor_area & $\mathrm{kg}$ & 3 & Total mass of furnishing equipements \\
\hline m_furnishing & $\mathrm{kg}$ & 3 & Total mass of operator items \\
\hline m_op_item & $\mathrm{kg}$ & 3 & Center of gravity of furnishing equipements \\
\hline cg_furnishing & $\mathrm{kg}$ & 3 & Center of gravity of operator items \\
\hline cg_op_item & & &
\end{tabular}




\begin{tabular}{|l|l|l|l|}
\hline Name & Unit & $\begin{array}{l}\text { Order of } \\
\text { magni- } \\
\text { tude }\end{array}$ & Description \\
\hline payload \\
\hline m_pax_nominal & $\mathrm{kg}$ & 2 & Mass allowance per passenger to compute nominal payload \\
\hline m_pax_max & $\mathrm{kg}$ & 2 & Mass allowance per passenger to compute maximum payload \\
\hline m_container_pallet & $\mathrm{kg}$ & 3 & Mass of containers or pallets empty \\
\hline nominal & $\mathrm{kg}$ & 4 & Mass of nominal payload \\
\hline maximum & $\mathrm{kg}$ & 4 & Mass of maximum payload \\
\hline max_fwd_mass & $\mathrm{kg}$ & 2 & Payload mass at maximum forward payload CG \\
\hline max_fwd_req_cg & $\mathrm{m}$ & 1 & Required maximum forward CG \\
\hline max_bwd_mass & $\mathrm{kg}$ & 2 & Payload mass at maximum backward payload CG \\
\hline max_bwd_req_cg & $\mathrm{m}$ & 1 & Required maximum backward CG \\
\hline cg_container_palet & $\mathrm{m}$ & 1 & Center of gravity of containers or pallets empty \\
\hline
\end{tabular}

\begin{tabular}{|l|l|l|l|}
\hline Name & Unit & $\begin{array}{l}\text { Order of } \\
\text { magni- } \\
\text { tude }\end{array}$ & Description \\
\hline fuselage & \multicolumn{3}{|l|}{} \\
\hline width & $\mathrm{m}$ & 0 & Fuselage width of the cylindrical part \\
\hline height & $\mathrm{m}$ & 0 & Fuselage height of the cylindrical part \\
\hline length & $\mathrm{m}$ & 1 & Total fuselage length \\
\hline tail_cone_length & $\mathrm{m}$ & 0 & Length of rear evolutive part of the fuselage \\
\hline net_wetted_area & $\mathrm{m}^{2}$ & 2 & Fuselage total net wetted area \\
\hline mass & $\mathrm{kg}$ & 3 & Equiped fuselage mass (without systems) \\
\hline c_g & $\mathrm{m}$ & 1 & Longitudinal position of the fuselage CG \\
\hline
\end{tabular}




\begin{tabular}{|c|c|c|c|}
\hline Name & Unit & $\begin{array}{l}\text { Order of } \\
\text { magnitude }\end{array}$ & Description \\
\hline \multicolumn{4}{|l|}{ wing } \\
\hline attachment & int & 0 & Wing attachment, 1: low wing, 2: high wing \\
\hline morphing & int & 0 & Wing deformation driver, 1-> aspect ratio, 2-> span \\
\hline hld_type & int & 0 & Type of high lift devices \\
\hline t_o_c_r & $\%$ & 1 & Thickness over chord ratio of the wing at root \\
\hline t_o_c_k & $\%$ & 1 & Thickness over choerd ratio of the wing at main kink \\
\hline t_o_c_t & $\%$ & 1 & Thickness over chord ratio at wing tip \\
\hline sweep & deg & 0 & Wing sweep angle at $25 \%$ of the chord \\
\hline dihedral & deg & 0 & Mean dihedral of the wing \\
\hline setting & deg & 0 & Setting angle of the wing at root \\
\hline taper_ratio & no_dim & 0 & Wing taper ratio \\
\hline aspect_ratio & no_dim & 0 & Wing aspect ratio \\
\hline area & $m^{2}$ & 2 & Wing reference area (planform) \\
\hline span & $\mathrm{m}$ & 1 & Wing span \\
\hline mac & $\mathrm{m}$ & 0 & Mean aerodynamic chord of the wing \\
\hline net_wetted_area & $m^{2}$ & 2 & Wing total net wetted area \\
\hline mass & $\mathrm{kg}$ & 3 & Equiped wing mass (without systems) \\
\hline c_g & $\mathrm{m}$ & 1 & Longitudinal position of the wing CG \\
\hline X_root & $\mathrm{m}$ & 1 & Longitudinal position of $0 \%$ of wing root chord \\
\hline y_root & $\mathrm{m}$ & 0 & Span wise position of $0 \%$ of the wing root chord \\
\hline z_root & $\mathrm{m}$ & 0 & Vertical position of $0 \%$ of the wing root chord \\
\hline c_root & $\mathrm{m}$ & 0 & Wing root chord length \\
\hline x_kink & $\mathrm{m}$ & 1 & Longitudinal position of $0 \%$ of wing kink chord \\
\hline y_kink & $\mathrm{m}$ & 0 & Span wise position of $0 \%$ of the wing kink chord \\
\hline z_kink & $\mathrm{m}$ & 0 & Vertical position of $0 \%$ of the wing kink chord \\
\hline c_kink & $\mathrm{m}$ & 0 & Wing kink chord length \\
\hline x_tip & $\mathrm{m}$ & 1 & Longitudinal position of $0 \%$ of wing tip chord \\
\hline y_tip & $\mathrm{m}$ & 0 & Span wise position of $0 \%$ of the wing tip chord \\
\hline Z_tip & $\mathrm{m}$ & 0 & Vertical position of $0 \%$ of the wing tip chord \\
\hline c_tip & $\mathrm{m}$ & 0 & Wing tip chord length \\
\hline x_mac & $\mathrm{m}$ & 1 & Longitudinal position of wing mean aerodynamic chord \\
\hline y_mac & $\mathrm{m}$ & 0 & Span wise position of wing mean aerodynamic chord \\
\hline
\end{tabular}

\begin{tabular}{|l|l|l|l|}
\hline Name & Unit & $\begin{array}{l}\text { Order of } \\
\text { magni- } \\
\text { tude }\end{array}$ & Description \\
\hline landing_gears & $\mathrm{kg}$ & 3 & Mass of landing gears (nose and main) \\
\hline mass & $\mathrm{m}$ & 1 & Longitudinal position of the landing gears CG \\
\hline c_g
\end{tabular}




\begin{tabular}{|l|l|l|l|}
\hline Name & Unit & $\begin{array}{l}\text { Order of } \\
\text { magni- } \\
\text { tude }\end{array}$ & Description \\
\hline horizontal_tail & \multicolumn{3}{|l|}{} \\
\hline attachment & int & 0 & Type of horizontal tail, 1: classical, 2: T-tail \\
\hline sweep & deg & 0 & Horizontal tail sweep angle at 25\% of th echords \\
\hline taper_ratio & no_dim & 0 & Taper ratio of the horizontal tail \\
\hline aspect_ratio & no_dim & 0 & Aspect ratio of the horizontal tail \\
\hline dihedral & deg & 0 & Mean dihedral of the horizontal tail \\
\hline volume & no_dim & 0 & Volume coefficient of the horizontal tail \\
\hline lever_arm & $\mathrm{m}$ & 1 & Lever arm of the horizontal tail (from 25\% wing MAC to 25\% HTP MAC) \\
\hline area & $\mathrm{m}^{2}$ & 2 & Horizontal tail reference area \\
\hline span & $\mathrm{m}$ & 2 & Horizontal tail span \\
\hline mac & $\mathrm{m}$ & 0 & Mean aerodynamic part of the horizontal tail \\
\hline net_wetted_area & $\mathrm{m}^{2}$ & 2 & Total net wetted area of the horizontal tail \\
\hline mass & $\mathrm{kg}$ & 2 & Equiped mass of the horizontal tail \\
\hline c_g & $\mathrm{m}$ & 1 & Longitudinal position of the CG of the horizontal tail \\
\hline x_axe & $\mathrm{m}$ & 2 & Longituidinal position of the horizontal tail central chord \\
\hline z_axe & $\mathrm{m}$ & 1 & Vertical position of the horizontal tail central chord \\
\hline c_axe & $\mathrm{m}$ & 1 & Horizontal tail central chord \\
\hline x_tip & $\mathrm{m}$ & 2 & Longitudinal position of the horizontal tail tip chord \\
\hline y_tip & $\mathrm{m}$ & 1 & Lateral position of the horizontal tail tip chord \\
\hline z_tip & $\mathrm{m}$ & 1 & Vertical position of the horizontal tail tip chord \\
\hline c_tip & $\mathrm{m}$ & 1 & Horizontal tail tip chord \\
\hline x_mac & $\mathrm{m}$ & 2 & Longitudinal position of the horizontal tail mean aerodynamic chord \\
\hline y_mac & 1 & Lateral position of the horizontal tail mean chord \\
\hline
\end{tabular}




\begin{tabular}{|l|l|l|l|}
\hline Name & Unit & $\begin{array}{l}\text { Order of } \\
\text { magni- } \\
\text { tude }\end{array}$ & Description \\
\hline vertical_tail & \multicolumn{3}{|l|}{} \\
\hline sweep & deg & 0 & Vertical tail sweep angle at 25\% of th echords \\
\hline taper_ratio & no_dim & 0 & Taper ratio of the vertical tail \\
\hline aspect_ratio & no_dim & 0 & Aspect ratio of the vertical tail \\
\hline t_o_c & no_dim & 0 & Thickness to chord ratio of the vertical tail \\
\hline dihedral & deg & 0 & Mean dihedral of the vertical tail \\
\hline volume & $m^{2} / \mathrm{kN}$ & 0 & Volume coefficient of the vertical tail \\
\hline lever_arm & $\mathrm{m}$ & 1 & Lever arm of the vertical tail (from 25\% wing MAC to 25\% HTP MAC) \\
\hline area & $m^{2}$ & 2 & Vertical tail reference area \\
\hline height & $\mathrm{m}$ & 1 & Height of the vertical tail \\
\hline mac & $\mathrm{m}$ & 0 & Mean aerodynamic part of the vertical tail \\
\hline net_wetted_area & $\mathrm{m}^{2}$ & 2 & Total net wetted area of the vertical tail \\
\hline mass & $\mathrm{kg}$ & 2 & Equiped mass of the vertical tail \\
\hline c_g & $\mathrm{m}$ & 1 & Longitudinal position of the CG of the vertical tail \\
\hline x_root & $\mathrm{m}$ & 2 & Longituidinal position of the vertical tail root chord \\
\hline z_root & $\mathrm{m}$ & 1 & Vertical position of the vertical tail root chord \\
\hline c_root & $\mathrm{m}$ & 1 & Vertical tail root chord \\
\hline x_tip & $\mathrm{m}$ & 2 & Longitudinal position of the vertical tail tip chord \\
\hline z_tip & $\mathrm{m}$ & 1 & Vertical position of the vertical tail tip chord \\
\hline c_tip & $\mathrm{m}$ & 1 & Vertical tail tip chord \\
\hline x_mac & $\mathrm{m}$ & 2 & Longitudinal position of the vertical tail mean aerodynamic chord \\
\hline
\end{tabular}

\begin{tabular}{|l|l|l|l|}
\hline Name & Unit & $\begin{array}{l}\text { Order of } \\
\text { magni- } \\
\text { tude }\end{array}$ & Description \\
\hline tanks & \multicolumn{3}{|l|}{} \\
\hline cantilever_volume & $m^{3}$ & 1 & Volume of tanks in the cantilever wing \\
\hline central_volume & $m^{3}$ & 1 & Volume of tanks in the central part of the wing (inside the fuselage) \\
\hline mfw_volume_limited & $m^{3}$ & 1 & Maximum geometrical fuel volume \\
\hline fuel_density & $\mathrm{kg} / \mathrm{m}^{3}$ & 2 & Fuel density \\
\hline fuel_cantilever_cg & $\mathrm{m}$ & 1 & Center of gravity of tanks in the cantilever wing \\
\hline fuel_central_cg & $\mathrm{m}$ & 1 & Center of gravity of tanks in the central part of the wing (inside the fuselage) \\
\hline fuel_body_cg & $\mathrm{m}$ & 1 & Center of gravity of tanks in the nacelle bodies \\
\hline fuel_max_fwd_mass & $\mathrm{kg}$ & 3 & Fuel mass of max forward fuel cg \\
\hline fuel_max_fwd_cg & $\mathrm{m}$ & 1 & Max forward fuel cg \\
\hline fuel_max_bwd_mass & $\mathrm{kg}$ & 3 & Fuel mass of max backward fuel cg \\
\hline fuel_max_bwd_cg & $\mathrm{m}$ & 1 & Max backward fuel cg \\
\hline
\end{tabular}




\begin{tabular}{|l|l|l|l|}
\hline Name & Unit & $\begin{array}{l}\text { Order of } \\
\text { magni- } \\
\text { tude }\end{array}$ & Description \\
\hline systems & $\mathrm{kg}$ & 3 & Mass of all airplane systems \\
\hline mass & $\mathrm{m}$ & 1 & Longitudinal position of the system CG \\
\hline c_g
\end{tabular}

\begin{tabular}{|l|l|l|l|}
\hline Name & Unit & $\begin{array}{l}\text { Order of } \\
\text { magni- } \\
\text { tude }\end{array}$ & Description \\
\hline turbofan_pylon & $\mathrm{kg}$ & 3 & Equiped mass of the pylons \\
\hline mass & $\mathrm{m}$ & 1 & Longitudinal position of the CG of the pylons \\
\hline c_g
\end{tabular}

\begin{tabular}{|l|l|l|l|}
\hline Name & Unit & $\begin{array}{l}\text { Order of } \\
\text { magni- } \\
\text { tude }\end{array}$ & Description \\
\hline turbofan_nacelle & \multicolumn{3}{|l|}{} \\
\hline attachment & int & 0 & Nacelle attachment (1= under wing, 2= rear fuselage) \\
\hline width & m & 0 & Maximum width of the nacelles \\
\hline length & m & 0 & Length of the fan cowl \\
\hline x_ext & m & 1 & Longitudinal position of the center of the air inlet of the external engine \\
\hline y_ext & m & 1 & Span wise position of the center of the air inlet of the external engine \\
\hline z_ext & m & 0 & Vertical position of the center of the air inlet of the external engine \\
\hline x_int & $\mathrm{m}$ & 1 & Longitudinal position of the center of the air inlet of the internal engine \\
\hline y_int & $\mathrm{m}$ & 1 & Span wise position of the center of the air inlet of the internal engine \\
\hline z_int & $\mathrm{m}$ & 0 & Vertical position of the center of the air inlet of the internal engine \\
\hline net_wetted_area & $\mathrm{m}^{2}$ & 1 & Total net wetted area of the nacelles (fan cowls) \\
\hline efficiency_fan & no_dim & 0 & Fan efficiency for turbofan (capability to turn shaft power into kinetic energy) \\
\hline efficiency_prop & no_dim & 0 & "Propeller like" Fan+Cowl efficiency for turbofan \\
\hline hub_width & $\mathrm{m}$ & 0 & Diameter of the hub of the fan (for pusher fan only) \\
\hline fan_width & $\mathrm{m}$ & 0 & Diameter of the fan of the turbofan nacelle \\
\hline nozzle_width & $\mathrm{m}$ & 0 & Diameter of the nozzle of the turbofan nacelle \\
\hline nozzle_area & $m^{2}$ & 0 & Exhaust nozzle area of the turbofan nacelle \\
\hline body_length & $\mathrm{m}$ & 0 & Length of the body in front of the turbofan nacelle \\
\hline bnd_layer & $\mathrm{m}$ & 0 & Boundary layer thickness law in front of the fan \\
\hline mass & $\mathrm{kg}$ & 3 & Equiped mass of the nacelles (including engine masses) \\
\hline c_g & $\mathrm{m}$ & 1 & Longitudinal position of the CG of the nacelles \\
\hline
\end{tabular}




\begin{tabular}{|l|l|l|l|}
\hline Name & Unit & $\begin{array}{l}\text { Order of } \\
\text { magni- } \\
\text { tude }\end{array}$ & Description \\
\hline turbofan_engine & int & 0 & Number of turbofans \\
\hline n_engine & no_dim & 0 & By Pass Ratio of the turbofans \\
\hline bpr & daN & 4 & Design Reference thrust of the turbofan \\
\hline reference_thrust & no_dim & 0 & Array of rating factors versus maximum thrust \\
\hline rating_factor & no_dim & 0 & $\begin{array}{l}\text { Fraction of the total thrust of a turbofan which is due to the core (typically } \\
\text { between } 10 \% \text { and } 16 \% \text { for BPR }>5 \text { ) }\end{array}$ \\
\hline core_thrust_ratio & no_dim & 0 & Fraction of the total nacelle diameter which is taken by the core \\
\hline core_width_ratio & no_dim & 0 & Fraction of the total nacelle mass which is taken by the core \\
\hline core_weight_ratio & no_dim & 0 & SLST thrust factor due to power off take (if any) \\
\hline kfn_off_take &
\end{tabular}

\begin{tabular}{|l|l|l|l|}
\hline Name & Unit & $\begin{array}{l}\text { Order of } \\
\text { magni- } \\
\text { tude }\end{array}$ & Description \\
\hline turboprop_pylon \\
\hline mass & $\mathrm{kg}$ & 3 & Equiped mass of the pylons \\
\hline c_g & $\mathrm{m}$ & 1 & Longitudinal position of the CG of the pylons \\
\hline
\end{tabular}

\begin{tabular}{|l|l|l|l|}
\hline Name & Unit & $\begin{array}{l}\text { Order of } \\
\text { magni- } \\
\text { tude }\end{array}$ & Description \\
\hline turboprop_nacelle \\
\hline width & $\mathrm{m}$ & 0 & Maximum width of the nacelle \\
\hline length & $\mathrm{m}$ & 0 & Length of the nacelle \\
\hline x_ext & $\mathrm{m}$ & 1 & Longitudinal position of the center of the propeller \\
\hline y_ext & $\mathrm{m}$ & 1 & Span wise position of the center of the propeller \\
\hline z_ext & $\mathrm{m}$ & 0 & Vertical position of the center of the propeller \\
\hline net_wetted_area & $m^{2}$ & 1 & Total net wetted area of the nacelles \\
\hline mass & $\mathrm{kg}$ & 3 & Equiped mass of the nacelles (including engine masses) \\
\hline c_g & $\mathrm{m}$ & 1 & Longitudinal position of the CG of the nacelles \\
\hline
\end{tabular}

\begin{tabular}{|l|l|l|l|}
\hline Name & Unit & $\begin{array}{l}\text { Order of } \\
\text { magni- } \\
\text { tude }\end{array}$ & Description \\
\hline turboprop_engine \\
\hline n_engine & int & 0 & Number of turbofans \\
\hline reference_thrust & daN & 4 & Design Reference thrust of the turboprop \\
\hline reference_power & shp & 4 & Reference power of the turboprop \\
\hline rating_factor & no_dim & 0 & Array of rating factors versus maximum thrust \\
\hline propeller_diameter & no_dim & 0 & Diameter of the propeller \\
\hline propeller_efficiency & no_dim & 0 & Efficiency of the propeller in cruise condition \\
\hline
\end{tabular}




\begin{tabular}{|l|l|l|l|}
\hline Name & Unit & $\begin{array}{l}\text { Order of } \\
\text { magni- } \\
\text { tude }\end{array}$ & Description \\
\hline body_nacelle & $\mathrm{m}$ & 0 & Maximum width of the nacelle body \\
\hline width & $\mathrm{m}$ & 0 & Length of the nacelle body \\
\hline length & $\mathrm{m}$ & 1 & Longitudinal position of the center of the nacelle body nose \\
\hline x_axe & $\mathrm{m}$ & 1 & Span wise position of the center of the nacelle body nose \\
\hline y_axe & $\mathrm{m}$ & 0 & Vertical position of the center of the nacelle body nose \\
\hline z_axe & $m^{2}$ & 1 & Total net wetted area of the nacelle bodies \\
\hline net_wetted_area & $\mathrm{kg}$ & 3 & Equiped mass of the nacelle bodies without engines \\
\hline mass & $\mathrm{m}$ & 1 & Longitudinal position of the CG of the nacelle body \\
\hline c_g & &
\end{tabular}

\begin{tabular}{|c|c|c|c|}
\hline Name & Unit & $\begin{array}{l}\text { Order of } \\
\text { magni- } \\
\text { tude }\end{array}$ & Description \\
\hline \multicolumn{4}{|l|}{ power_elec_chain } \\
\hline mto & uc & 0 & $\begin{array}{l}\text { Tale off power, mto }<1 \text { : turbofan shat power ratio off take, mto }>1 \text { : e-fan } \\
\text { motor power }\end{array}$ \\
\hline men & uc & 0 & $\begin{array}{l}\text { Maxi continuous power, } m c n<1 \text { : turbofan shat power ratio off take, } \\
\text { mcn>1: e-fan motor power }\end{array}$ \\
\hline $\mathrm{mcl}$ & uc & 0 & $\begin{array}{l}\text { Max climb power, mcl<1: turbofan shat power ratio off take, mcl }>1 \text { : } \\
\text { e-fan motor power }\end{array}$ \\
\hline mcr & uc & 0 & $\begin{array}{l}\text { Max cruise power, } m c r<1 \text { : turbofan shat power ratio off take, mcr }>1 \text { : } \\
\text { e-fan motor power }\end{array}$ \\
\hline fid & uc & 0 & $\begin{array}{l}\text { Flight idle power, fid <1: turbofan shat power ratio off take, fid }>1 \text { : e-fan } \\
\text { motor power }\end{array}$ \\
\hline max_power & $\mathrm{kW}$ & 4 & E-fan motor maximum power \\
\hline max_power_rating & int & 0 & Engine rating of e-fan motor maximum power \\
\hline overall_efficiency & no_dim & 0 & Power efficiency of the electric chain \\
\hline generator_pw_density & $\mathrm{kW} / \mathrm{kg}$ & 0 & Power density of electric generation \\
\hline rectifier_pw_density & $\mathrm{kW} / \mathrm{kg}$ & 0 & Power density of rectifiers \\
\hline wiring_pw_density & $\mathrm{kW} / \mathrm{kg}$ & 0 & Power density of wiring \\
\hline cooling_pw_density & $\mathrm{kW} / \mathrm{kg}$ & 0 & Power density of cooling system \\
\hline mass & $\mathrm{kg}$ & 2 & Mass of the electric chain (generator, rectifier, wires, cooling) \\
\hline c_g & $\mathrm{m}$ & 1 & Longitudinal position of the $\mathrm{CG}$ of the electric chain \\
\hline
\end{tabular}




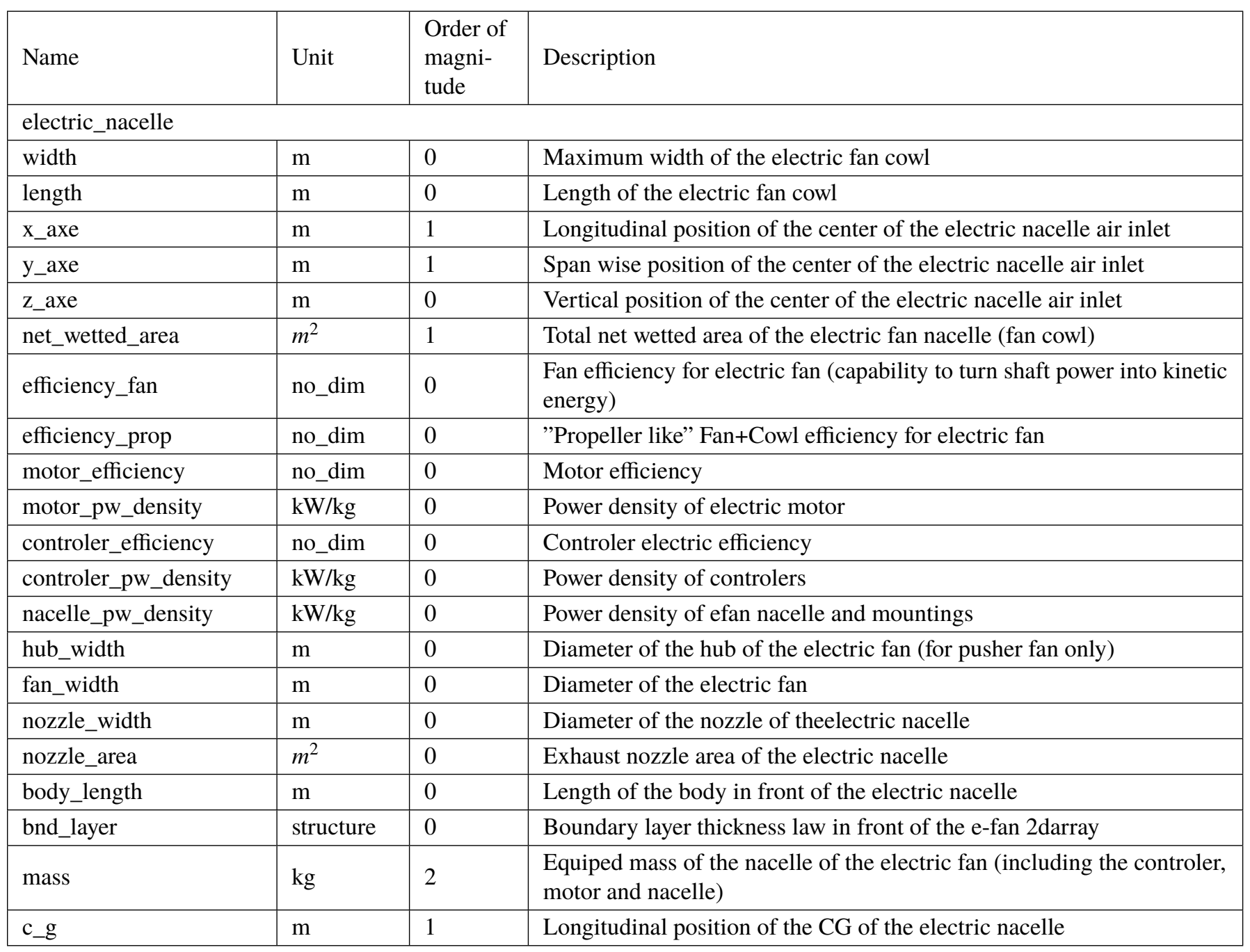




\begin{tabular}{|c|c|c|c|}
\hline Name & Unit & $\begin{array}{l}\text { Order of } \\
\text { magnitude }\end{array}$ & Description \\
\hline \multicolumn{4}{|l|}{ electric_engine } \\
\hline mto_e_power_ratio & no_dim & 0 & $\begin{array}{l}\text { Turbofan off take power ratio in take off rating (one engine), Sea } \\
\text { Level, ISA }+15 \text {, Mach } 0.25\end{array}$ \\
\hline mto_e_shaft_power & $\mathrm{kW}$ & 3 & $\begin{array}{l}\text { E-fan shaft power in take off rating (one engine), Sea Level, } \\
\text { ISA }+15 \text {, Mach } 0.25\end{array}$ \\
\hline mto_e_fan_thrust & $\mathrm{daN}$ & 3 & $\begin{array}{l}\text { E-fan thrust in take off rating (one engine), Sea Level, ISA+15, } \\
\text { Mach } 0.25\end{array}$ \\
\hline mcn_e_power_ratio & no_dim & 0 & $\begin{array}{l}\text { Turbofan off take power ratio maxi continuous rating (one engine), } \\
\text { Required ceiling altitude, ISA, cruise Mach }\end{array}$ \\
\hline mcn_e_shaft_power & $\mathrm{kW}$ & 3 & $\begin{array}{l}\text { E-fan shaft power in maxi continuous rating (one engine), Required } \\
\text { ceiling altitude, ISA, cruise Mach }\end{array}$ \\
\hline mcn_e_fan_thrust & daN & 3 & $\begin{array}{l}\text { E-fan thrust in maxi continuous rating (one engine), Required } \\
\text { ceiling altitude, ISA, cruise Mach }\end{array}$ \\
\hline mcl_e_power_ratio & no_dim & 0 & $\begin{array}{l}\text { Turbofan off take power ratio in max climb rating (one engine), } \\
\text { Required Top of Climb altitude, ISA, cruise Mach }\end{array}$ \\
\hline mcl_e_shaft_power & $\mathrm{kW}$ & 3 & $\begin{array}{l}\text { E-fan shaft power in max climb rating (one engine), Required Top } \\
\text { of Climb altitude, ISA, cruise Mach }\end{array}$ \\
\hline mcl_e_fan_thrust & $\mathrm{daN}$ & 3 & $\begin{array}{l}\text { E-fan thrust in max climb rating (one engine), Required Top of } \\
\text { Climb altitude, ISA, cruise Mach }\end{array}$ \\
\hline mcr_e_power_ratio & no_dim & 0 & $\begin{array}{l}\text { Turbofan off take power ratio in max cruise rating (one engine), } \\
\text { Reference cruise altitude, ISA, cruise Mach }\end{array}$ \\
\hline mcr_e_shaft_power & $\mathrm{kW}$ & 3 & $\begin{array}{l}\text { E-fan shaft power in max cruise rating (one engine), Reference } \\
\text { cruise altitude, ISA, cruise Mach }\end{array}$ \\
\hline mcr_e_fan_thrust & $\mathrm{daN}$ & 3 & $\begin{array}{l}\text { E-fan thrust in max cruise rating (one engine), Reference cruise } \\
\text { altitude, ISA, cruise Mach }\end{array}$ \\
\hline fid_e_power_ratio & no_dim & 0 & $\begin{array}{l}\text { Turbofan off take power ratio in flight idle rating (one engine), } \\
\text { Reference cruise altitude, ISA, cruise Mach }\end{array}$ \\
\hline fid_e_shaft_power & $\mathrm{kW}$ & 3 & $\begin{array}{l}\text { E-fan shaft power in flight idle rating (one engine), Reference } \\
\text { cruise altitude, ISA, cruise Mach }\end{array}$ \\
\hline fid_e_fan_thrust & $\mathrm{daN}$ & 3 & $\begin{array}{l}\text { E-fan thrust in flight idle rating (one engine), Reference cruise } \\
\text { altitude, ISA, cruise Mach }\end{array}$ \\
\hline flight_data & structure & dict & $\begin{array}{l}\text { Dictionary of flying conditions for each rating "disa":array, } \\
\text { "altp":array, "mach":array, "nei":array }\end{array}$ \\
\hline
\end{tabular}




\begin{tabular}{|l|l|l|l|}
\hline Name & Unit & $\begin{array}{l}\text { Order of } \\
\text { magni- } \\
\text { tude }\end{array}$ & Description \\
\hline battery & int & 0 & $\begin{array}{l}\text { Battery sizing strategy, 1: power_feed and energy_cruise driven, 2: battery } \\
\text { mass driven }\end{array}$ \\
\hline strategy & $\mathrm{kW}$ & 4 & Power delivered to e-fan(s) at take off and(or) climb during a total of time_feed \\
\hline power_feed & $\mathrm{min}$ & 1 & Maximum duration of the power_feed delivered to e-fan(s) \\
\hline time_feed & $\mathrm{kWh}$ & 1 & Total battery energy dedicated to cruise \\
\hline energy_cruise & $\mathrm{kWh} / \mathrm{kg}$ & 0 & Battery energy density \\
\hline energy_density & $\mathrm{kW} / \mathrm{kg}$ & 0 & Battery power density (capability to release power per mass unit \\
\hline power_density & $\mathrm{kg}$ & 3 & Total battery mass \\
\hline mass & $\mathrm{m}$ & 1 & Global CG of batteries \\
\hline c_g & &
\end{tabular}




\section{Acknowledgments}

The authors wish to thank Serge Bonnet, Airbus Senior Expert in Overall Aircraft Design for his review and advise as weel as the Institute of Technology IRT Saint-Exupéry researchers for their valuable support.

\section{References}

[1] Gould, N. I., Orban, D., and Toint, P. L., "CUTEr and SifDec: A constrained and unconstrained testing environment, revisited," ACM Transactions on Mathematical Software (TOMS), Vol. 29, No. 4, 2003, pp. 373-394.

[2] Gould, N. I., Orban, D., and Toint, P. L., "CUTEst: a constrained and unconstrained testing environment with safe threads for mathematical optimization,” Computational Optimization and Applications, Vol. 60, No. 3, 2015, pp. 545-557.

[3] Martins, J. R. R. A., and Lambe, A. B., "Multidisciplinary Design Optimization: A Survey of Architectures," AIAA Journal, Vol. 51, No. 9, 2013, pp. 2049-2075. doi:10.2514/1.J051895.

[4] Agte, J. S., Sobieszczanski-Sobieski, J., and Sandusky, R. R., "Supersonic business jet design through bi-level integrated system synthesis," Tech. rep., SAE Technical Paper, 1999.

[5] MacDonald, T., Clarke, M., Botero, E. M., Vegh, J. M., and Alonso, J. J., "SUAVE: an open-source environment enabling multi-fidelity vehicle optimization," 18th AIAA/ISSMO Multidisciplinary Analysis and Optimization Conference, 2017, p. 4437.

[6] Kao, J., Hwang, J., Martins, J., Gray, J. S., and Moore, K. T., "A modular adjoint approach to aircraft mission analysis and optimization,” 56th AIAA/ASCE/AHS/ASC Structures, Structural Dynamics, and Materials Conference, 2015, p. 0136.

[7] Gallard, F., Vanaret, C., Guénot, D., Gachelin, V., Lafage, R., Pauwels, B., Barjhoux, P.-J., and Gazaix, A., "GEMS: A Python Library for Automation of Multidisciplinary Design Optimization Process Generation," 2018 AIAA/ASCE/AHS/ASC Structures, Structural Dynamics, and Materials Conference, 2018, p. 0657.

[8] Gallard, F., Barjhoux, P., Olivanti, R., and A., G., "GEMS, a Generic Engine for MDO Scenarios : Key Features In Application," 2019 AIAA AVIATION Forum, 2019.

[9] Raymer, D., Aircraft Design: A Conceptual Approach 5e and RDSWin STUDENT, American Institute of Aeronautics and Astronautics, Inc., 2012.

[10] Torenbeek, E., Synthesis of subsonic airplane design: an introduction to the preliminary design of subsonic general aviation and transport aircraft, with emphasis on layout, aerodynamic design, propulsion and performance, Springer Science \& Business Media, 2013.

[11] Roskam, J., “Airplane Design Parts I to VIII,” nalysis Research Corporation, 2002.

[12] Sforza, P. M., Commercial airplane design principles, Elsevier, 2014.

[13] Anderson, J. D., Aircraft performance and design, Vol. 1, WCB/McGraw-Hill Boston, MA, 1999.

[14] Shevell, R. S., and Shevell, R. S., Fundamentals of flight, Vol. 2, Prentice Hall Englewood Cliffs, NJ, 1989.

[15] Roux, E., "Pour une approche analytique de la dynamique du vol," These, SUPAERO-ONERA, 2005.

[16] Birman, J., "Uncertainty quantification and propagation in Conceptual Aircraft Design: from deterministic optimization to chance constrained optimization," Ph.D. thesis, Ph. D. thesis. University of Toulouse III-Paul Sabatier, 2013.

[17] Welstead, J., and Felder, J. L., "Conceptual design of a single-aisle turboelectric commercial transport with fuselage boundary layer ingestion,” 54th AIAA Aerospace Sciences Meeting, 2016, p. 1027. 